\title{
DIVERSIDADE DE ÁCAROS (ARTHROPODA: ACARI) EM EUFORBIÁCEAS (EUPHORBIACEAE) DE TRÊS LOCALIDADES \\ DO ESTADO DE SÃO PAULO
}

MAURICIO SERgIO ZACARIAS

Engenheiro Agrônomo

Orientador: Prof. Dr. GILBERTO JOSÉ DE MORAES

Tese apresentada à Escola Superior de Agricultura "Luiz de Queiroz", Universidade de São Paulo, para obtenção do título de Doutor em Ciências, Área de Concentração: Entomologia.

P I R A C I C A B A

Estado de São Paulo - Brasil

Fevereiro - 2001 
ZACARIAS, Mauricio S. Diversidade de ácaros (Arthropoda: Acari) em euforbiáceas (Euphorbiaceae) de três localidades do Estado de São Paulo. Piracicaba, 2001. 154 p. Tese (Doutorado) - Escola Superior de Agricultura "Luiz de Queiroz", Universidade de São Paulo.

ERRATA \& CORRIGENDA

$\begin{array}{cccc}p . & \text { item } & \text { linha } & \text { onde se le } \\ 05 & 2.1 & \text { quarta } & \ldots \text { (Flechtmann, 1977; Krantz, 1978;... } \\ 09 & 2.2 & \text { sexta } & \ldots \text { (parasitos ou parasitóides, ... } \\ 14 & \text { RESUMO } & \text { primeira } & \text { Vinte e nove espécies já descritas ... } \\ & & & \\ 15 & \text { SUMMARY } & \text { primeira } & \text { Twenty nine known species... } \\ 75 & 5.4 & \text { segunda } & \text { Palpo mais curto que femurogenu. }\end{array}$

110

7.2 décima quinta e décima sexta

110

117

Legenda

118

118

120

7.4

8

120 sétima

décima quarta

décima quinta e

décima sexta

décima nona ...tomaram-se vários pontos na a $24^{\circ}$

$36^{\prime} 50^{\prime \prime}$ de latitude sul e $47^{\circ} 53^{\prime} 00^{\prime \prime}$ de

longitude oeste, onde foram procuradas

$$
\text { plantas... }
$$

...já no interior da ilha. Em Piracicaba

(24 $55^{\prime} 00^{\prime \prime}$ de latitude sul, $47^{\circ} 50^{\prime} 00^{\prime \prime}$ de longitude oeste), as plantas foram...

Classificaçāo dos grupos de espécies ...

Os grupos "Pariquera-Açu" e "Pera glabrata" apresentam ... ou fitófagas, enquanto o Grupo "Piracicaba" apresenta maior proporçāo de espécies fitófagas.

...que de fitófagas.

Os grupos "Pariquera-Açu" e "Pera glabrata" apresentam ... de predadoras ou fitófagas, enquanto ... fïtófagas.

...de predadoras,... leia-se ...(Krantz, 1978;... ... (parasitóides, ...

Vinte e quatro espécies já descritas e 5 espécies novas...

Twenty four known and 5 new species...

Tarso do palpo mais curto que femurogenu.

...tomaram-se vários pontos na "Estaçāo Experimental J. Cione" (24 $36^{\prime} 50^{\prime \prime}$ de latitude sul e $47^{\circ} 53^{\prime} 00^{\prime \prime}$ de longitude oeste), onde foram procuradas plantas...

...já no interior da ilha $\left(24^{\circ} 55^{\prime} 00^{\prime \prime}\right.$ de latitude sul, $47^{\circ} 50^{\prime} 00^{\prime \prime}$ de longitude oeste). Em Piracicaba, as plantas foram...

Agrupamento de espécies ...

As plantas do grupo "Pera glabrata" apresentam ... ou fitófagas.

As plantas do Grupo "Piracicaba" apresentam maior proporção de espécies fitófagas que de generalistas ou predadoras.

...que de generalistas ou fitófagas. As plantas do grupo "Pera glabrata" apresentam ... de predadoras ou fitófagas.

As plantas do Grupo "Piracicaba" apresentam maior proporção de espécies fitófagas que de generalistas ou predadoras.

...de generalistas ou predadoras,... 


\title{
Dados Internacionais de Catalogação na Publicação (CIP) DIVISĀO DE BIBLIOTECA E DOCUMENTAÇĀO - Campus "Luiz de Queiroz"/USP
}

\author{
Zacarias, Mauricio Sergio \\ Diversidade de ácaros (Arthropoda : Acari) em euforbiáceas (Euphorbiaceae) de três \\ localidades do Estado de São Paulo / Mauricio Sergio Zacarias. - - Piracicaba, 2001. \\ $154 \mathrm{p}$. \\ Tese (doutorado) - Escola Superior de Agricultura Luiz de Queiroz, 2001. \\ Bibliografia. \\ 1. Ácaro-fitófago 2. Ácaro-predador 3. Classificaçāo (Biologia) 4. Controle biológico \\ 5. Diversidade 6. Euforbiácea 7. Planta nativa I. Título
}

CDD 583.95

Temitida a copia total ou narcial deste documento. desie que citada a fonte 0 autor?

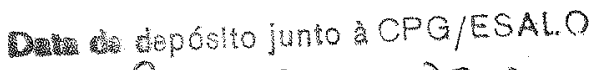

$02,02,200$ 


\section{AgRADECIMENTOS}

Ao Prof. Gilberto J. de Moraes, pela amizade, orientação, apoio, confiança e respeito demonstrado durante nosso convívio.

Ao Prof. Carlos H. W. Flechtmann, pela identificação dos eriofideos e principalmente pela amizade, atenção, paciência e valiosos ensinamentos.

Aos colegas Lásaro V. F. Silva e Renata A. P. Freire, que colaboraram diretamente no desenvolvimento deste trabalho.

Aos Professores dos Setores de Zoologia Agrícola e de Entomologia (LEF - ESALQ/USP), pela ajuda e colaboração no desenvolvimento deste trabalho e no decorrer do curso de Doutorado.

A todos os colegas dos Setores de Zoologia Agrícola e de Entomologia (LEF - ESALQ/USP), do "Xerox do CALQ" e da seção de COMMUT da Biblioteca, que fizeram com que nosso convívio fosse mais do que simples companheirismo, mas uma relação de amizade.

Aos Professores e colegas dos Laboratórios de Fisiologia da Lactação e de Fisiologia Animal do Departamento de Produção Animal (ESALQ/USP), pela amizade e apoio no desenvolvimento deste trabalho.

Aos Profs. Ricardo R. Rodrigues e Vinícius V. Souza, e a Técnica Tereza, do Departamento de Botânica (ESALQ/USP), pelo apoio na identificação das espécies de euforbiáceas coletadas.

Ao Dr. André L. Lourenção e ao Instituto Agronômico de Campinas (IAC), pela colaboração e apoio logístico para o desenvolvimento deste trabalho.

Ả CAPES - Fundação Coordenação de Aperfeiçoamento de Pessoal de Ensino Superior, ao PRONEX e ao BIOTA-FAPESP, pelo suporte financeiro. 
Este trabalho é dedicado a Deus e a toda minha família, especialmente minha esposa Cidinha e minha filha Gabriela, pela paciência, atenção e principalmente pelo amor que me dedicam. 


\section{SUMÁRIO}

Página

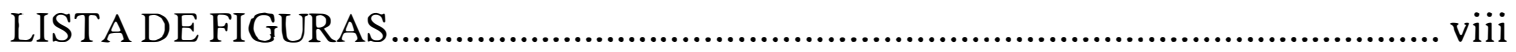

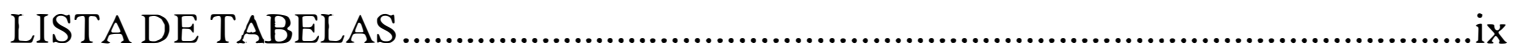

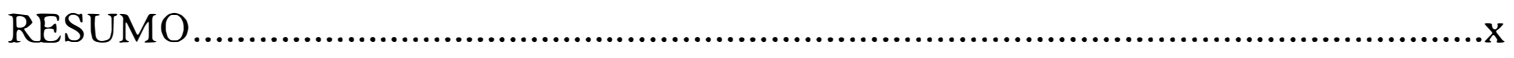

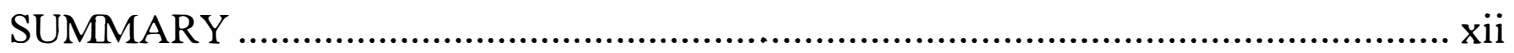

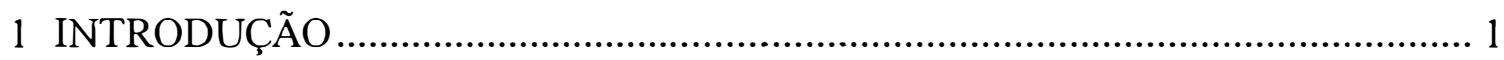

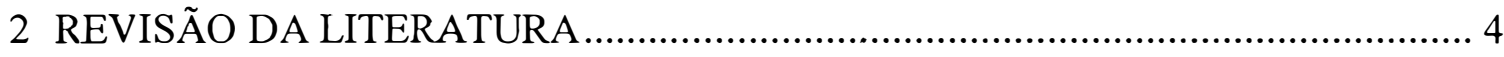

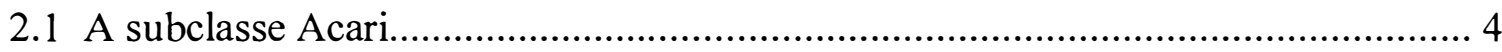

2.2 Agricultura e o Controle Biológico ……............................................................. 7

2.3 Importância da vegetação natural próxima aos cultivos ............................................11

2.4 Ácaros em seringueira no Estado de São Paulo .................................................13

3 FITOSEÍDEOS (ACARI: PHYTOSEIIDAE) ASSOCIADOS A

EUFORBIÁCEAS (EUPHORBIACEAE) EM TRÊS LOCALIDADES DO

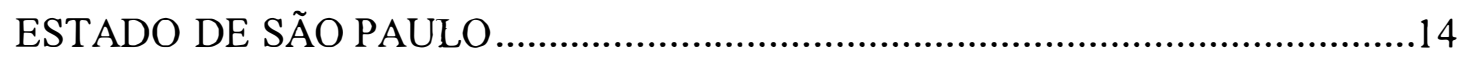

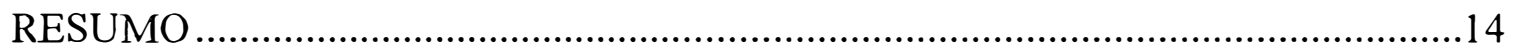

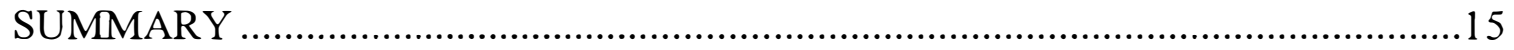

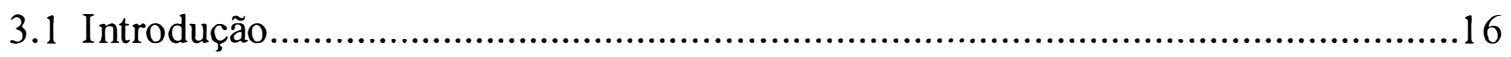

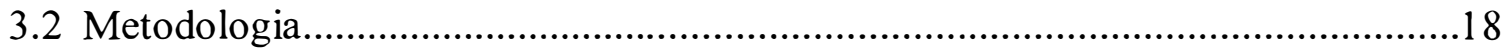

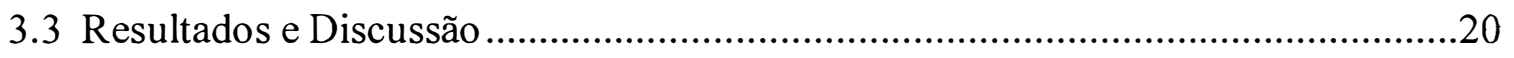

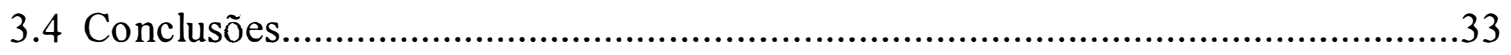

4 DESCRIÇÃO DE QUATRO ESPÉCIES NOVAS DE FITOSEÍDEOS (ACARI: PHYTOSEIIDAE) DO ESTADO DE SÃO PAULO ................................................34

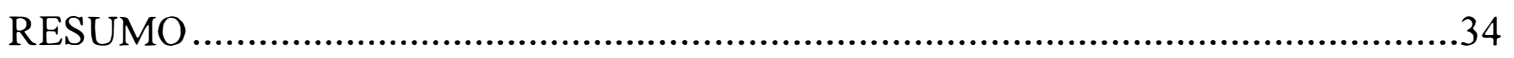

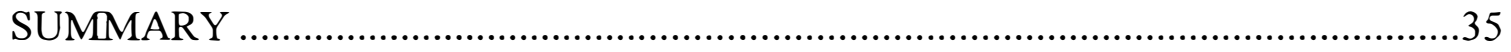

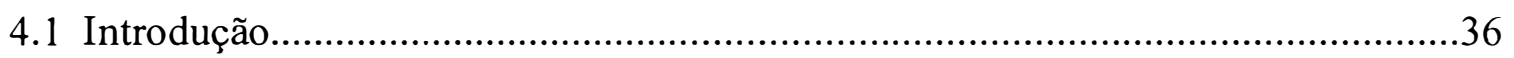

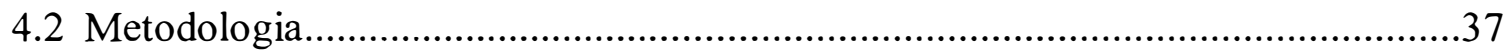

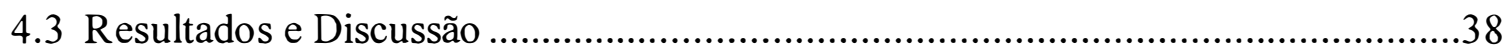


5 ÁCAROS DA FAMÍLIA TYDEIDAE (ACARI: ACTINEDIDA) ASSOCIADOS A EUFORBIÁCEAS (EUPHORBIACEAE) EM TRÊS LOCALIDADES DO ESTADO DE SÃO PAULO ...........................................................................50

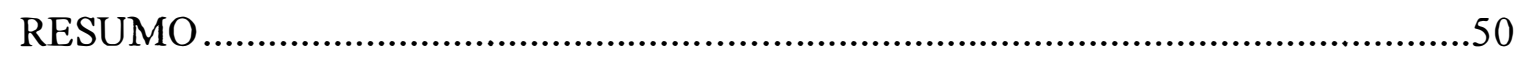

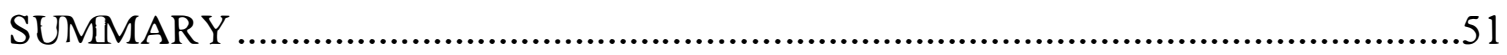

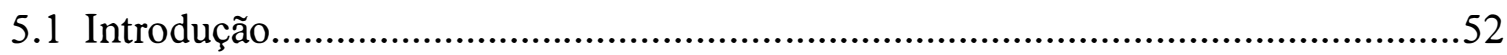

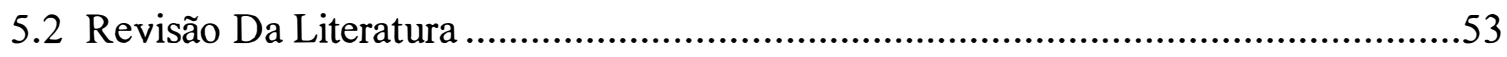

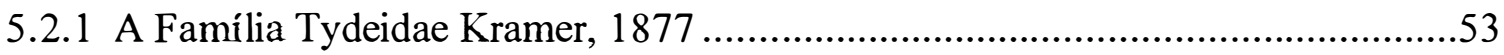

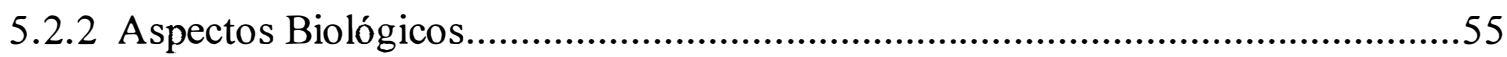

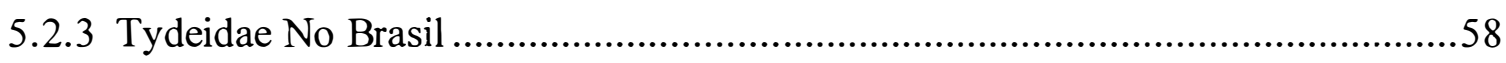

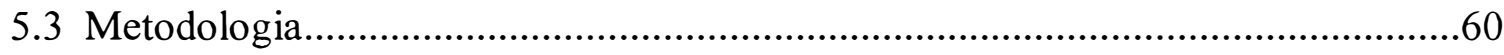

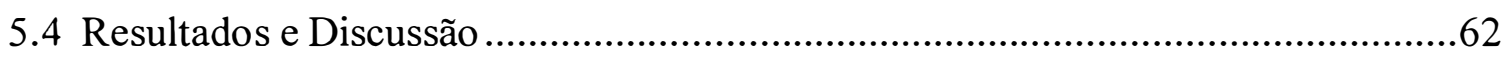

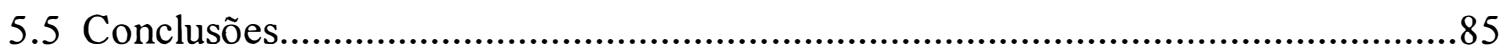

6 OUTROS ÁCAROS (ARTHROPODA: ACARI) ASSOCIADOS A EUFORBIÁCEAS (EUPHORBIACEAE) EM TRÊS LOCALIDADES DO

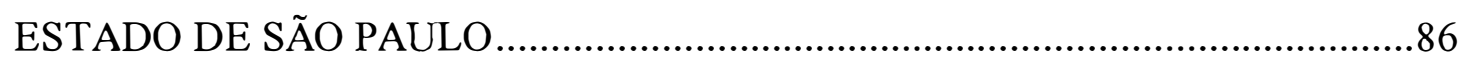

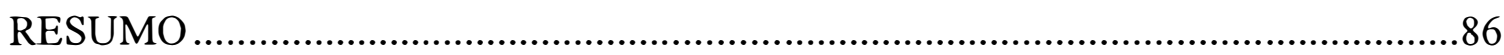

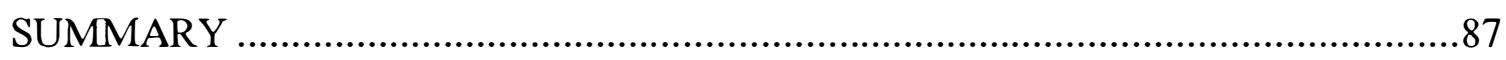

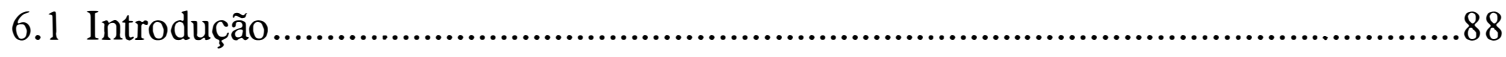

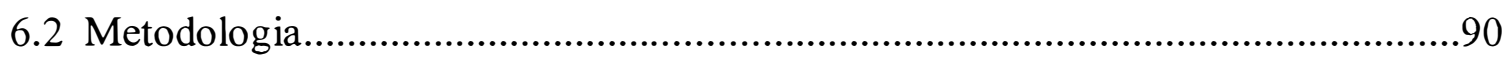

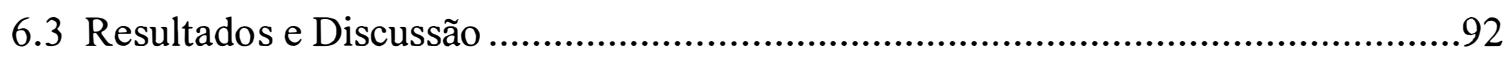

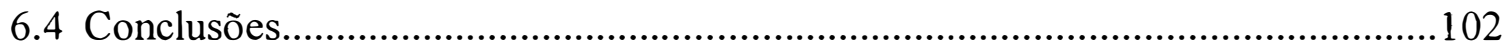

7 DIVERSIDADE DE ÁCAROS (ARTHROPODA: ACARI) EM

EUFORBIÁCEAS DE TRÊS LOCALIDADES DO ESTADO DE

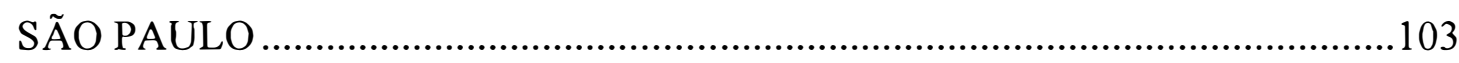

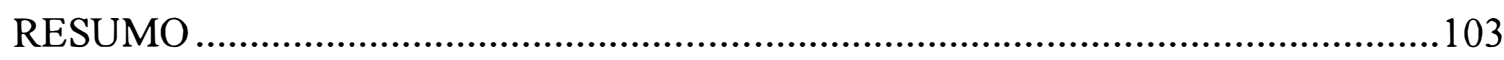

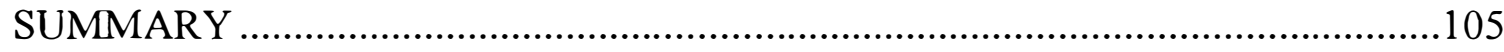

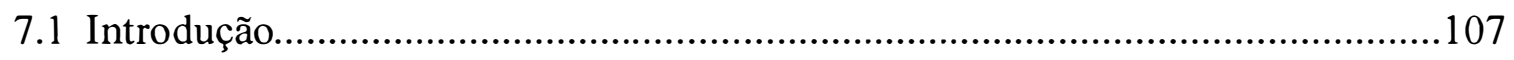

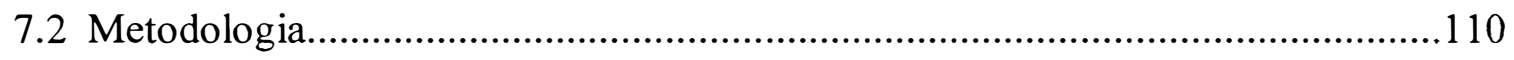




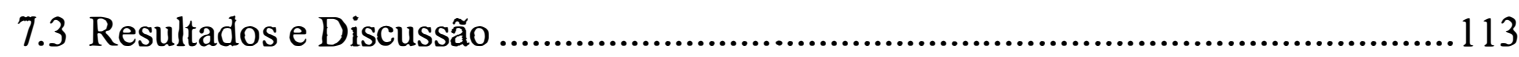

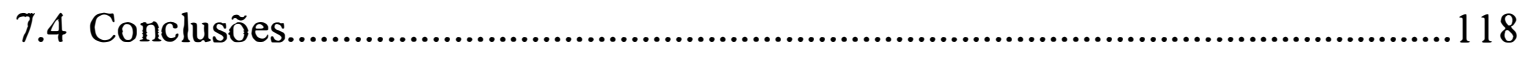

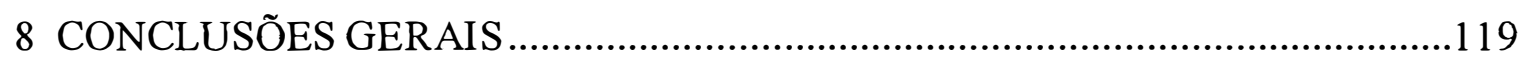

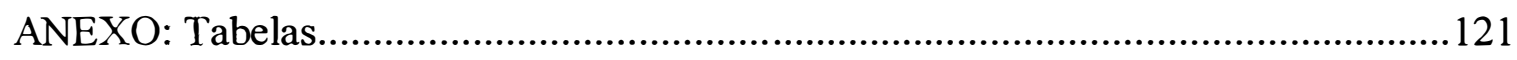

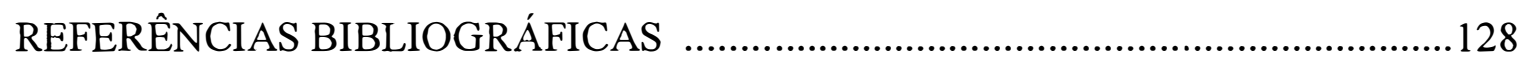

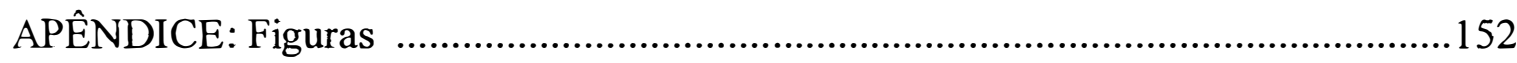




\section{LISTA DE FIGURAS}

Página

1 Proprioseius retroacuminatus sp.n.: A - Placa dorsal da fềmea; B - Placas; ventrais da fềmea; C - Placa ventrianal do macho; D - Quelícera da fềmea; E - Espermadáctilo; F - Espermateca

2 Phytoseius globuliformis sp.n.: A - Placa dorsal; B - Placas ventrais;

C - Placa ventrianal do macho; D - Quelícera; E - Espermadáctilo:

F - Espermateca; G - Genu, tíbia e tarso da perna IV

3 Kampimodromus multicupuli sp.n.: A - Placa dorsal da fềmea; B - Placas ventrais da fềmea; $\mathrm{C}$ - Placa ventrianal do macho; D - Quelícera da fềmea; E - Espermadáctilo; F - Espermateca

4 Galendromimus paulista sp.n.: A - Placa dorsal da fềmea; B - Placas ventrais da fềmea; C - Placa ventrianal do macho; D - Quelícera da fềmea; E - Espermadáctilo; F - Espermateca

5 Vista dorsal (A) e ventral (B) de um ácaro da família Phytoseiidae, com indicações da quetotaxia de acordo com Rowell et al. (1978) e Chant \& Yoshida-Shaul (1991) respectivamente 
6 Superfície dorsal e ventral do idiossoma (baseado em Kazmierski, 1989a) e quetotaxia do palpo e pernas (baseada em André, 1981b) de um ácaro da família Tydeidae: A - quetotaxia ventral e dorsal com prodorso procurvado; $\mathrm{B}$ - quetotaxia dorsal com prodorso recurvado, presença da seta $d_{2}$ e do poro ip; $\mathrm{C}$ - principais divisões do corpo; $\mathrm{D}$ - perna I; $\mathrm{E}$ - tarso e tíbia da perna II e solenídio $\varphi_{\mathrm{II}}$ em destaque; $\mathrm{F}$ - palpo; $\mathrm{G}$ - vista lateral da apotele do tarso; $\mathrm{H}$ - vista dorsal da apotele do tarso

7 Classificação dos grupos de espécies de euforbiáceas (Euphorbiaceae) de três localidades do Estado de São Paulo (Cananéia $=\mathrm{CA}$, Pariquera-Açu = PA e Piracicaba = PI) pela ocorrência em comum de espécies de ácaros, obtida com o índice de Mountford (Silveira Neto et al., 1976) 


\section{LISTA DE TABELAS}

Página

1 Relação de outras espécies de ácaros da família Tydeidae (Acari: Actinedida) com ocorrência relatada no Brasil, os substratos e regiões onde foram relatadas e citação

2 Espécies e número de espécimens de ácaros (Arthropoda: Acari) coletados em euforbiáceas (Euphorbiaceae) de três localidades do Estado de São Paulo (Cananéia, Pariquera-Açu e Piracicaba)

3 Número total de espécimens $(N)$, número total de espécies $(S)$, índice de diversidade de espécies de Shanonn-Weiner $(H)$ e índices de uniformidade de espécies $(e)$ e de riqueza de espécies de Pielou $(d)$ para os ácaros (Arthropoda: Acari) coletados em euforbiáceas (Euphorbiaceae) de três localidades do Estado de São Paulo (Cananéia, Pariquera-Açu e Piracicaba) 


\title{
DIVERSIDADE DE ÁCAROS EM EUFORBIÁCEAS (EUPHORBIACEAE) DE TRÊS LOCALIDADES DO ESTADO DE SÃO PAULO
}

\author{
Autor: MAURICIO SERGIO ZACARIAS \\ Orientador: PROF. DR. GILBERTO JOSÉ DE MORAES
}

\section{RESUMO}

Pouco se sabe sobre a diversidade de ácaros em plantas nativas no Brasil. No contexto do controle biológico de pragas agrícolas, a preservação de estações de refúgio tem função fundamental na conservação da diversidade de inimigos naturais.

Plantas da família Euphorbiaceae são bastante comuns e freqüentes em ecossistemas naturais e mesmo em sistemas regenerados no Estado de São Paulo. Estas plantas podem atuar como reservatórios dos ácaros fitófagos e seus inimigos naturais que ocorrem ou possam vir a ocorrer em plantas cultivadas. Isto se reveste de importância se for considerada a tendência ao monocultivo de seringueiras (Hevea brasiliensis (H.B.K.) M. Arg.) em larga escala e a destruição de áreas remanescentes de ecossistemas naturais, com a diminuição da biodiversidade dos inimigos naturais das pragas.

Este trabalho foi conduzido nos municípios de Pariquera-Açu, Cananéia e Piracicaba, para se determinar as espécies de ácaros encontradas em plantas da família Euphorbiaceae. No total, foram amostradas folhas de 49 plantas pertencentes a 12 espécies de 9 gêneros diferentes. Nestas, foram coletados 31.603 ácaros de 105 espécies pertencentes a 74 gêneros e 16 famílias.

Do total de espécies de ácaros coletados, 21 pertencem a famílias essencialmente fitófagas (Tenuipalpidae, Tetranychidae, Diptilomiopidae e Eriophyidae) e 43 a espécies essencialmente predadoras (Ameroseiidae, Ascidae, Cunaxidae, Stigmaeidae, Cheyletidae, Eupalopsellidae e Phytoseiidae). As demais (41 espécies) são compostas principalmente por ácaros que se alimentam sobre o filoplano, sendo principalmente detritívoros, algívoros, fungívoros, bacteriófagos ou polenófagos. 
A análise da similaridade entre as espécies de plantas, de acordo com as espécies de ácaros que apresentavam em comum, possibilitou a delimitação de 3 grupos de espécies vegetais distintos: Grupo "Pariquera-Açu" - todas espécies vegetais de Pariquera-Açu mais Alchornea triplinervea M. Arg. de Cananéia; Grupo "Piracicaba" todas espécies vegetais de Piracicaba e Grupo "Pera glabrata (Schott) Baill." de Cananéia, composta por apenas uma espécie de planta de Cananéia.

De maneira geral, pode-se dizer que o Grupo "Pariquera-Açu" apresentou aproximadamente a mesma diversidade que o Grupo " $P$. glabrata", e ambos consideravelmente maior que aquela do Grupo "Piracicaba". A riqueza de espécies do Grupo "Pariquera-Açu" foi consideravelmente maior que a dos demais grupos.

Entre os ácaros da família Phytoseiidae coletados, 24 pertencem a espécies já descritas e 5 a espécies novas para a ciência. As espécies de fitoseídeos encontradas em seringueira de Pariquera-Açu são distintas daquelas encontradas na mesma planta em Piracicaba. As espécies vegetais $P$. glabrata e $A$. triplinervea de Cananéia e Alchornea glandulosa Poepp. \& Endl., A. triplinervea e Sebastiania sp. de Pariquera-Açu também abrigam a espécie de fitoseídeo mais abundante em seringueiras em Pariquera-Açu (Typhlodromips sp.). As espécies vegetais Hura crepitans Linn., Joanesia princeps Vell. e Pachistromma longifolium M. Arg. de Piracicaba abrigam a espécie de fitoseídeo mais abundante em seringueiras daquela localidade (Typhlodromina camelliae (Chant \& Yoshida-Shaul)).

São descritas 4 espécies novas de fitoseídeos coletados em plantas da Mata Atlântica: Proprioseius retroacuminatus sp. n., Phytoseius globuliformis sp. n., Kampimodromus multicupuli sp. n. e Galendromimus paulista sp. n.

Os ácaros da família Tydeidae coletados neste estudo pertencem a 29 espécies em 18 gêneros. Destas, 22 espécies e 8 gêneros são novos para a ciência. Lorryia sp. n. 1 se apresentou como o ácaro mais abundante em seringueiras de Piracicaba.

O estudo indicou que espécies de euforbiáceas encontradas na vegetação natural dos locais estudados podem desempenhar papel importante de reservatório de inimigos naturais de ácaros praga da seringueira. 


\title{
DIVERSITY OF MITES (ACARI: ARTHROPODA) ON EUPHORBIACEOUS PLANTS (EUPHORBIACEAE) IN THREE LOCALITIES OF THE STATE OF SÃO PAULO, BRAZIL
}

\author{
Author: MAURICIO SERGIO ZACARIAS \\ Adviser: PROF. DR. GILBER TO JOSÉ DE MORAES
}

\section{SUMMARY}

Little is known about the diversity of mites on native plants in Brazil. In relation to the biological control of agricultural pests, the preservation of natural reserves plays a fundamental role in the conservation of the diversity of natural enemies.

Plants of the family Euphorbiaceae are very common and frequent in natural ecosystems and even in regenerated systems of the State of São Paulo. Those plants may function as reservoirs of phytophagous mites and their natural enemies that occur now or may occur in the future on cultivated plants. This aspect is important, considering the present trend towards large scale monocultures of rubber tree, Hevea brasiliensis (H.B.K.) M. Arg., in Brazil and the concurrent destruction of remnants of natural vegetation and reduction of biodiversity of natural enemies of pest species.

The present study was conducted in the municipalities of Pariquera-Açu, Cananéia and Piracicaba, to determine the mite species found on selected species of plants of the family Euphorbiaceae. Leaves from 49 plants belonging to 12 species within 9 different genera were examined. A total of 31,603 mites belonging to 105 species within 74 genera of 16 families were collected.

Twenty one of the species collected belonged to families composed of essentially phytophagous species (Tenuipalpidae, Tetranychidae, Diptilomiopidae and Eriophyidae) and 43 belonged to families composed of essentially predaceous species (Ameroseiidae, Ascidae, Cunaxidae, Cheyletidae, Stigmaeidae, Eupalopsellidae and Phytoseiidae). The remaining 41 species contain mainly plant mites that are mostly detritivorous, algivorous, fungivorous, bacteriophagous and pollenophagous. 
A similarity analysis between plant species, based on the mite species they harbored in common, indicated the occurrence of 3 distinct groups of plants: "Pariquera-Açu" Group, containing all plant species from Pariquera-Açu and Alchornea triplinervea M. Arg. from Cananéia; "Piracicaba" Group, containing all plant species from Piracicaba; and "Pera glabrata (Schott) Baill." Group, composed of a single plant species from Cananéia.

As a whole, the "Pariquera-Açu" Group had about the same average level of diversity as the "P. glabrata" Group, which was however considerably higher than the average level of the "Piracicaba" Group. The index of species richness of "Pariquera-Açu" Group was considerably higher than those of other groups.

Twenty four of the phytoseiid species collected were already known, but 5 were new to science. The plant species $P$. glabrata and A. triplinervea from Cananéia, and A. glandulosa Poepp. \& Endl., A. triplinervea and Sebastiania sp. from PariqueraAçu harbored the most common phytoseiid mite found on rubber tree in Pariquera-Açu (Typhlodromips sp.). The plant species Hura crepitans Linn., Joanesia princeps Vell. and Pachistromma longifolium M. Arg. from Piracicaba harbored the most common phytoseiid mite found on rubber tree of the latter locality (Typhlodromina camelliae (Chant \& Yoshida-Shaul)). The phytoseiid mites found on rubber tree in Pariquera-Açu are not the same found on the same plant in Piracicaba.

Four new species of phytoseid mites collected from trees in woody areas are described as new to the science. The species are: Proprioseius retroacuminatus sp. n., Phytoseius globuliformis sp. n., Kampimodromus multicupuli sp. $\mathrm{n}$. and Galendromimus paulista sp. n..

Tydeids of 29 species belonging to 18 genera were collected. Twenty two of those species and 8 of those genera are new to science. Lorryia sp. n. 1 was the most abundant tydeid mite found in rubber tree plants from Piracicaba in this study.

This study shows that the euphorbiacean plants found in natural vegetation could play a important role as natural enemies reservoir of rubber tree mite pests. 


\section{INTRODUÇÃO}

Pouco se sabe sobre a diversidade de ácaros em plantas nativas no Brasil.

Em sua maioria, os apelos pela conservação, veiculados nos meios de comunicação, são emocionais e alertam para o perigo que sofrem principalmente grandes mamíferos, répteis, peixes e certos vegetais. Ecologistas estimulam os estudos dos recursos de emprego imediato (frutos diversos, borracha, etc.) presentes e importantes para as comunidades humanas nas florestas. Também tem se discutido a pesquisa de potencial dos fármacos de origem vegetal. Todos estes recursos de nossa vegetação natural tem forte apelo visual no dia a dia.

Já, os inimigos naturais de organismos indesejáveis, especialmente os artrópodes, tem pouco destaque, seja pelo seu reduzido tamanho, ou por serem seus efeitos não diretamente visíveis ao público leigo. No entanto. estes se apresentam como muito sensíveis ao menor distúrbio nos ambientes naturais.

No contexto do controle biológico de pragas agrícolas, a manutenção de estações de refúgio tem função fundamental na preservação da diversidade de inimigos naturais. Pesquisas têm demonstrado que tanto o tamanho quanto a proximidade das estações entre si são importantíssimos na manutenção a longo prazo da diversidade dos organismos aí presentes.

Plantas da família Euphorbiaceae são bastante comuns e freqüentes em ecossistemas naturais e mesmo em sistemas regenerados no Estado de São Paulo (Nogueira, 1976; Cesar \& Leitão Filho, 1990; Salis et al., 1994).

Estas plantas podem atuar como reservatórios naturais dos ácaros fitófagos e seus inimigos naturais que ocorrem ou possam vir a ocorrer em plantas cultivadas. Isto se reveste de importância se levarmos em consideração a tendência ao 
monocultivo em larga escala e a destruição de áreas remanescentes de ecossistemas naturais, com a diminuição da biodiversidade dos inimigos naturais das pragas.

As constantes e rápidas alterações por que passam nossos sistemas de cultivo bem como a introdução de novas espécies cultivadas demandam espécies de inimigos naturais com diversidade genética que permita o estabelecimento de populações adaptadas a diferentes condições ambientais e diferentes pragas (Lasalle \& Gauld, 1991).

Dentre os inimigos naturais de ácaros fitófagos, destacam-se os ácaros predadores da família Phytoseiidae (Moraes et al., 1986). Sobre outras famílias de ácaros predadores, como Stigmaeidae, Bdellidae, Cheyletidae e Cunaxidae, muito pouco se conhece no Brasil (Flechtmann, 1986; Lorenzato, 1987; Pallini Filho et al.., 1992).

Muitos conceitos têm sido formulados para se definir biodiversidade (uma contração de diversidade biológica), alguns com uma forte visão conservacionista. Segundo Gaston (1996), podemos dividir biodiversidade em três níveis, a saber, diversidade genética, diversidade taxonômica ou de espécies e diversidade de ecossistemas. O último é referido por Harper \& Hawksworth (1996) como diversidade ecológica ou de comunidades.

Walter \& O’Dowd (1995) citam muitos estudos conduzidos para se determinar a biodiversidade de invertebrados em ambientes florestais, a maioria relacionados aos insetos e poucos relacionados aos ácaros. Aqueles autores citam três fătores principais responsáveis pela quase ausência de dados sobre ácaros. Em primeiro lugar, os ácaros são diminutos, de coloração translúcida a marrom pálida, e podem passar desapercebidos nas amostragens; em segundo lugar, alguns autores excluíram propositadamente artrópodos diminutos de suas análises, enquanto outros devem ter seguido subjetivamente este critério; e em terceiro lugar está a utilização de métodos químicos de "knockdown" nem sempre eficientes para amostragem de pequenos artrópodos como os ácaros.

Apesar dos poucos estudos realizados com ácaros, estes têm revelado que as copas nas matas apresentam altas densidades destes organismos, que embora podendo não ser tão diversos como os insetos, são sem dúvida mais abundantes (Walter \& 
O’Dowd, 1995).

Considera-se como diversidade taxonomica a variedade de taxa presentes em uma determinada unidade de biota (Gaston, 1996; Harper \& Hawksworth, 1996). Esta variedade pode ser qualitativa (número de taxa), quantitativa (freqüência relativa) ou do papel desempenhado por estes nos níveis tróficos. Estudam-se os mais variados níveis taxonômicos, desde grandes grupos, como família, até grupos subespecíficos. Para os ecologistas, outras dimensões da biodiversidade são representadas pelo número de níveis tróficos presentes, número de guildas, variedade de ciclos de vida e a diversidade de recursos biológicos.

Como não é possível se determinar a diversidade real, esta é estimada através da análise de amostras. Existem muitos métodos de análise que podem fornecer índices para isso. Os indices mais comumente considerados são os de dominância, diversidade de espécies, uniformidade de comunidades, riqueza relativa de espécies, abundância de espécies. coexistência de espécies e estrutura de populações.

O presente trabalho teve como objetivo a capacitação para o estudo da diversidade de ácaros em plantas nativas da família Euphorbiaceae e em plantas de seringueira, Hevea brasiliensis (H.B.K.) M. Arg., em três localidades do estado de São Paulo, de forma a subsidiar estudos para o controle biológico de pragas nesta cultura. Também teve como objetivo a capacitação em taxonomia de ácaros das famílias Phytoseiidae e Tydeidae. 


\section{REVISÃO DA LITERATURA}

A presente revisão fundamenta a razão de se estudar a diversidade de ácaros em euforbiáceas. Inicialmente, apresenta-se a posição sistemática da subclasse Acari, bem como particularidades morfológicas e biológicas de uma forma geral. Informações básicas sobre grupos importantes para a agricultura, em especial as famílias Phytoseiidae e Tydeidae, são também apresentadas.

Versa sobre o papel que reservas de vegetação natural apresentam em relação ao controle biológico de pragas das culturas. Destaque é dado à sua importância como reservatórios de inimigos naturais, fundamental no emprego do controle biológico como estratégia de redução populacional de pragas.

\subsection{A subclasse Acari}

Os organismos do filo Arthropoda (artrópodes) se caracterizam por apresentar exoesqueleto quitinoso e patas articuladas. Neste filo existe o subfilo Chelicerata (cujos representantes diferem dos miriápodos e insetos pela ausência de antenas e mandíbulas), que contém como principal componente a classe Arachnida. Os aracnídeos são quelicerados principalmente terrestres, dentre os quais se inclui a subclasse Acari (Krantz, 1978). Dentre os aracnídeos, apenas os representantes desta subclasse e da subclasse Opiliones podem apresentar comportamento não predador. $\mathrm{Na}$ realidade, diversas espécies de Acari são pragas importantes de plantas cultivadas (Jeppson et al., 1975).

A subclasse Acari compreende os ácaros e carrapatos, que diferem da 
maioria dos demais aracnídeos pela ausência de segmentação aparente. Somente membros da subclasse Araneae também apresentam esta conformação (com exceção de um pequeno grupo desta subclasse), diferindo entretanto dos Acari pela divisão do corpo em cefalotórax (que contém as peças bucais e patas) e abdome (Flechtmann, 1977; Krantz, 1978; Evans, 1992).

Apesar de pequenos em sua maioria, estes animais são muito bem sucedidos na natureza e ocorrem em qualquer lugar onde seja possível a existência de vida. São encontrados sobre plantas (de habitats nativos ou cultivadas), em depósitos de alimento, no solo, sobre animais (parasitando ou não), em ambientes aquáticos e nas residências humanas. Já foram encontrados nas profundezas oceânicas $( \pm 6000 \mathrm{~m}$ de profundidade), nas margens de vulcões, fontes termais, em montanhas de grande altitude (até $5000 \mathrm{~m}$ ), nas regiões polares, nos desertos, em cavernas e a grandes profundidades no solo (em lençóis freáticos) rivalizando, com vantagem, os insetos em distribuição geográfica e ocupação de nichos. Isto se deve à sua grande variedade de hábitos alimentares (predação, fitofagia, micofagia, saprofagia, coprofagia e necrofagia) e à ocorrência da forésia (Flechtmann, 1977; Krantz, 1978; Evans, 1992).

Os ácaros apresentam uma grande diversidade em sua morfologia, que se associa às suas variações comportamentais, ou seja, à especialização em hábitos e habitats. No corpo de um ácaro típico pode-se reconhecer basicamente um gnatossoma (anterior) e um idiossoma (que compreende a maior parte do corpo do ácaro). O gnatossoma é formado pelos palpos e pelas quelíceras, que se fundem na região basal ou se modificam em proporções variáveis, de acordo com o grupo considerado.

Em sua forma mais primitiva, a quelícera apresenta-se em forma de tesoura. Geralmente, o terceiro segmento da quelícera é modificado em um dígito móvel que se opõe à parte fixa distal do segundo segmento. Esses dígitos opostos, ou quelas, podem ser denteados para auxiliar a preensão e dilaceração. Nos ácaros fitófagos, é comum a redução do dígito fixo e o desenvolvimento do dígito móvel em uma estrutura estiletiforme, penetrante (Flechtmann, 1977).

O ciclo evolutivo inclui um ou mais estádios imaturos ativos. A larva, que emerge do ovo, é hexápoda (exceto nos eriofióideos em que todos os estágios ativos 
apresentam apenas dois pares de pernas; alguns Podapolipidae também podem ter menos de 4 pares, assim como alguns gêneros de Tenuipalpidae). Em seguida, ocorrem até três estádios ninfais octópodes antes de chegarem ao estádio adulto, todos geralmente octópodes (Flechtmann, 1977; Evans, 1992).

A subclasse Acari é dividida nas ordens Parasitiformes e Acariformes. A primeira é subdividida nas subordens Ixodida, Gamasida, Holothyrida e Opilioacarida, enquanto que a segunda é subdividida nas subordens Actinedida, Oribatida e Acaridida (Krantz, 1978).

Os ácaros plantícolas de maior importância pertencem às subordens Actinedida (contendo a maioria das espécies fitófagas) e Gamasida (principalmente parasitos de animais domésticos e predadores de pragas agrícolas).

$\mathrm{Na}$ subordem Actinedida, devem-se destacar as famílias Tetranychidae, Tarsonemidae, Tenuipalpidae e Eriophyidae, que contém as espécies fitófagas mais importantes (Jeppson et al., 1975). Devem-se destacar também as famílias Stigmaeidae, Bdellidae, Cheyletidae e Cunaxidae, constituídas de espécies predadoras (Flechtmann, 1986; Lorenzato, 1987; Pallini Filho et al., 1992).

Na subordem Gamasida, deve-se destacar a família Phytoseiidae, como os predadores de ácaros fitófagos mais estudados e importantes do ponto de vista aplicado (Moraes et al., 1986). Fitoseídeos foram os ácaros predadores mais abundantes encontrados por Walter \& O'Dowd (1992b) em folhas de plantas lenhosas de mata nativa da Austrália.

Estes ácaros podem ser classificados em 4 grupos, de acordo com McMurtry \& Croft (1997). Segundo aquela classificação, os fitoseídeos dos tipos III e IV são generalistas e se utilizam de alimentos alternativos para sua manutenção no campo, tais como outros ácaros fitófagos (para os de tipo III) e pólen (especialmente para os do tipo IV). De acordo com aqueles autores, fitoseídeos destes dois grupos devem ser responsáveis pela manutenção de populações de tetraniquídeos em baixos níveis, principalmente em plantas perenes, sendo importantes em estratégias de conservação (Walter \& O’Dowd, 1992b; Walter, 1996).

Acaros da família Tydeidae estão entre os alimentos alternativos mais 
importantes para ácaros fitoseídeos. A despeito disto, pouco é conhecido a respeito da biologia destes (Baker, 1970; Knop \& Hoy, 1983b; Calis et al., 1988). Pallini Filho et al. (1992) observaram, através da dilaceração de tecidos periféricos de domáceas em folhas de cafeeiro, que ninfas de fitoseídeos se alimentavam dos ácaros tideídeos ali presentes.

Homeopronematus anconai (Baker) exemplifica a importância desta família por ser uma presa alternativa do mundialmente famoso fitoseídeo Typhlodromus occidentalis Nesbitt e, ao mesmo tempo, um predador generalista, predando ácaros eriofideos e ovos de Brevipalpus lewisi McGregor (Acari, Tenuipalpidae) em videira (Knop \& Hoy, 1983a e b; Hessein \& Perring, 1988).

Tideídeos têm sido encontrados predando eriofídeos, especialmente em pomares e hortaliças (Knop \& Hoy, 1983b; Laing \& Knop, 1983; Perring \& McMurtry, 1996). Hessein \& Perring (1986) concluíram que, em condições de plantio em estufa, $H$. anconai causa um impacto significativo nas populações do eriofideo do bronzeamento do tomateiro, Aculops lycopercisi (Massee). Perring \& McMurtry (1996) consideram bastante promissor o uso de $H$. anconai para o controle de eriofídeos.

Tideídeos podem ser os ácaros mais abundantes dentre os que ocorrem nas folhas em mata ou em cultivo. A predominância deste grupo foi constatada por Walter \& O’Dowd (1992b) em folhas de plantas lenhosas de mata nativa na Austrália (31\% do total) e também por Pallini Filho et al. (1992) em folhas de cafeeiro, especialmente dentro de domáceas.

\subsection{Agricultura e o Controle Biológico}

Para sobreviver, a crescente população humana tem que explorar o seu ambiente, transformando os ecossistemas naturais estáveis em ecossistemas artificiais, como os cultivos. Os sistemas modificados são instáveis, e para se manter a produção de alimentos nestas condições é necessário se impor fluxos de energia e nutrientes em direção aos campos de cultivo (por exemplo: adubação, uso de defensivos, etc.) (Altieri, 1987; Gallo et al., 1988; Altieri, 1994). 
A distribuição de certos organismos é afetada por sua especificidade a um determinado recurso alimentar de distribuição variável. Outros inespecíficos, têm maiores possibilidades de expansão geográfica, podendo sobreviver em organismos hospedeiros alternativos/intermediários. A abundância dos organismos está na dependência do maior ou menor suprimento de alimentos (Gallo et al., 1988). Com a implantação da agricultura, o homem tem proporcionado alimento abundante para uma variedade de organismos, dentre os quais as pragas, permitido com isto o aumento vultoso de suas populações (Gallo et al., 1988).

Sob o sistema de produção agrícola atualmente convencional, o homem simplificou a estrutura do ambiente sobre vastas áreas, trocando a diversidade natural por um número reduzido de plantas cultivadas. Este processo de simplificação encontra sua forma extrema na monocultura. O objetivo desta simplificação é aumentar a proporção de energia solar fixada pelas comunidades de plantas de interesse ao agricultor, que, se relativamente eficiente em realidades de reduzida diversidade biológica, tem elevado exponencialmente os problemas fitossanitários (Altieri, 1987; Costa, 1993; Paschoal, 1979 citado por Costa, 1993).

Desta forma, pode ser arriscado depender exclusivamente de poucas variedades de uma cultura agrícola, que no momento dão maior retorno econômico. Poderá haver uma alteração súbita no meio ou nos próprios organismos, favorecendo o aparecimento de certas doenças ou pragas, que poderão exterminar a cultura considerada (Silveira Neto et al., 1976).

Controlar a sucessão (invasão de plantas e competição) e a proteção contra pragas e doenças são o maior problema na manutenção da continuidade de produção em agroecossistemas. Estratégias ecológicas de manejo de pragas usam uma combinação de técnicas, visando tornar o ambiente inadequado às pragas mas favorável aos inimigos naturais (Altieri, 1987).

O controle natural inclui as forças coletivas do ambiente que servem para manter uma determinada população em cheque contra sua própria capacidade de crescimento numérico. Desta forma o controle natural inclui os fatores climáticos, desaparecimento ou deterioração dos recursos alimentares e a ação de espécies 
competidoras e inimigos naturais (Van den Bosch et al., 1982).

No manejo integrado de pragas, os métodos biológicos constituem o componente básico. Assim, as populações dos inimigos naturais (parasitóides, predadores e patógenos) devem ser preservadas no ambiente e, se possível, aumentadas com a interferência do homem(Parra, 1993).

Todas as espécies de plantas e animais têm inimigos naturais (parasitos ou parasitóides, predadores e patógenos) atacando seus vários estágios de vida, constituindo-se em agentes bióticos de mortalidade (Gallo et al., 1988). DeBach (1964) considerou o controle biológico de uma perspectiva aplicada e ecológica. Ele o definiu como "a ação de parasitos, predadores ou patógenos na manutenção da densidade de populações de outros organismos a uma média abaixo da que ocorreria em sua ausência". Esta definição ecológica inclui as interações naturais (controle biológico natural), implicando que na natureza a interação é contínua e auto-sustentável em relação ao tempo e ao lugar. Este conceito ecológico fundamental admite muitas atividades geralmente classificadas como controle biológico no manejo de pragas. Do ponto de vista aplicado, tal como o aumento de inimigos naturais, o controle biológico pode não ser auto-sustentável em um sistema não natural, restringindo-se a surtos momentâneos de ação dos agentes de controle biológico introduzidos ou de ocorrência natural (Gallo et al., 1988; Van den Bosch et al., 1982; Garcia et al., 1988).

Devido ao controle biológico ser uma manifestação da associação natural de diferentes tipos de organismos, é um fenômeno dinâmico, sujeito a perturbações causadas por oscilações dos fatores abióticos, e adaptações, propriedades e limitações dos organismos envolvidos em cada caso (Huffaker \& Messenger, 1964 citados por Van den Bosch et al., 1982). Quando bem sucedido, o controle biológico aplicado, pode fornecer uma solução permanente, harmoniosa e econômica.

No controle biológico aplicado, as estratégias empregadas incluem a conservação e aumento dos inimigos naturais já disponíveis, através da manipulação do ambiente ou do próprio organismo. O procedimento de conservação e aumento dos inimigos naturais visa proteger, manter ou, se possível, aumentar o que já existe naturalmente. Neste procedimento estão incluídos as práticas de época de plantio 
adequada (medidas culturais), manutenção de habitat ou fontes de alimentação para inimigos naturais, escolha de pesticidas seletivos, etc. (Parra, 1993).

O controle biológico aplicado pode envolver também a importação e colonização de inimigos naturais de pragas exóticas ou nativas. Esta última é uma prática usual, que depende da aclimatação do inimigo natural às novas condições, resultando em casos de maior ou menor sucesso (Gallo et al., 1988; Higley et al., 1989 citados por Parra, 1993).

Os projetos de controle biológico aplicado de espécies nativas são tecnicamente mais complicados do que os de pragas invasoras. Uma espécie nativa já tem associações com uma variedade de inimigos naturais presentes no local considerado, que deveriam mantê-la sob controle efetivo. Entretanto, as práticas de cultivo de uma cultura tendem, muitas vezes, a favorecer o aumento populacional de organismos fitófagos nativos e, paralelamente, reduzir a eficácia dos inimigos naturais responsáveis pelo controle natural daqueles. Uma das formas de fomentar o controle biológico das pragas nativas é a modificação de práticas agriculturais visando favorecer as atividades dos inimigos naturais (Van den Bosch et al., 1982).

Em locais onde os fatores limitantes atuam intensamente a diversidade tende a diminuir, com o aumento concomitante do número de indivíduos das espécies mais comuns e a diminuição do número de indivíduos das espécies mais raras (Silveira Neto et al., 1976). Em geral, nossas culturas anuais, e muitas perenes com utilização intensiva de insumos, são locais com atuação intensa dos fatores limitantes, consequentemente, são lugares com diversidade mais baixa.

Mas qual é a vantagem da diversidade? Ou, qual a ação das espécies raras? Acredita-se que a vantagem da diversidade esteja na maior estabilidade proporcionada ao sistema. Sob estas condições, admite-se que espécies raras e aparentemente sem importância podem desempenhar funções indiretas importantes (Silveira Neto et al., 1976). Diversidade na agricultura é essencial não somente para a supressão de pragas, mas também para garantir a base biológica para a sustentabilidade da produção (Altieri, 1994).

Os habitats naturais e seminaturais detém o estoque mundial de agentes 
de controle biológico potenciais. Sua erosão compromete a habilidade das futuras gerações em colher os benefícios de novas oportunidades de controle biológico, e é claramente incompatível com desenvolvimento sustentável (Kunin \& Lawton, 1996).

\subsection{Importância da vegetação natural próxima aos cultivos}

Como parte da estratégia de conservação e aumento de inimigos naturais, a prática de manutenção de áreas de vegetação natural próxima aos cultivos visa a manter habitats apropriados para a preservação de inimigos naturais. Esta cria condições favoráveis à manutenção, proliferação e diversificação dos inimigos naturais. Estas áreas de vegetação são comumente referidas como "estações de refúgio".

Muitos estudos documentam a importância das "estações de refúgio" na perpetuação de inimigos naturais de pragas que se movem para os cultivos próximos (Altieri, 1994). Vegetações naturais ao redor dos cultivos fornecem alimento alternativo e habitat para inimigos naturais de pragas agrícolas, assim provendo recursos sazonais para que estes atravessem períodos desfavoráveis à sua manutenção nas culturas de interesse em certas épocas do ano (Altieri, 1994).

A vegetação natural pode servir também de local de hibernação de inimigos naturais durante períodos de condições climáticas adversas ou na ausência das presas na cultura atacada.

Vários estudos indicam que a abundância e diversidade de insetos entomófagos em um campo determinado estão intimamente relacionadas à natureza da vegetação circundante. Esta pode determinar as taxas de colonização de inimigos naturais em uma cultura particular (Altieri \& Todd, 1981, citados por Altieri, 1994).

Outra função importante destas estações é a manutenção de inimigos naturais ainda pouco ou não estudados. Novas pragas podem vir a surgir no futuro e mesmo pragas atuais podem vir a desenvolver alguma forma de resistência aos inimigos naturais atualmente conhecidos e, então, torna-se necessário retornar aos habitats naturais à procura de novas opções para uso prático. Como exemplo, Pristiphora 
erichsonii (Hartig) (Insecta: Tenthredinidae) raramente atinge na Europa, em seu habitat natural, o status de praga devido à ação de inimigos naturais. Esta espécie se tornou uma praga séria nos Estados Unidos da América do Norte, chegando a causar perdas de $40 \%$ no volume de madeira no Estado de Minnesota. A condução de um trabalho de pesquisa bem sucedido resultou no controle parcial deste inseto por uma espécie de parasitóide introduzido, Mesoleius tenthredinis Morley (Insecta: Ichneumonidae). O controle posteriormente falhou quando a praga desenvolveu resistência ao parasitóide e se tornou capaz de encapsular e matar seus ovos. Estudos posteriores, no habitat natural da praga, levaram à descoberta de uma linhagem do parasitóide que conseguia superar a reação de encapsulação. A introdução desta nova linhagem e de um segundo parasitóide, Olesicampe benefactor Hinz (Insecta: Ichneumonidae), aumentou as perspectivas do controle biológico da praga (Lasalle \& Gauld, 1991).

A degradação ambiental em larga escala causada pela atividade humana não somente pode eliminar um grande número de espécies, mas pode deixar as espécies sobreviventes em amplas áreas biológicamente empobrecidas (Myers, 1996), tais como áreas com diversidade simplificada por desmatamento ou os monocultivos em grande escala.

Biotas homogêneos conterão um número desproporcional de espécies agressivas ( $\mathrm{r}$-selecionadas). Estas se caracterizam por vários traços em comum: exploração rápida de novos nichos; ciclo de vida curto, com breves espaços entre gerações; altas taxas de crescimento populacional; e adaptação a uma ampla gama de ambientes. Todas estas características as capacitam a explorar novos ambientes, precisamente os atributos que habilitam estas espécies a se tornarem oportunistas e prosperar em um mundo perturbado pelo homem (Myers, 1996). Hoje menos de $5 \%$ de todos insetos merecem ser chamados de pragas (Pimentel, 1991 citado por Myers, 1996), mas se o padrão de extinção continuar a favorecer as espécies generalistas, o resultado pode ser uma situação onde espécies oportunistas cresçam, aumentando continuamente o número de espécies praga (Lasalle \& Gauld, 1991).

Espécies especialistas, principalmente os inimigos naturais, podem sofrer perdas desproporcionalmente maiores. Isto é causado porque suas populações são 
normalmente muito menores. Desde que estes especialistas são as criaturas que servem como controladores naturais de populações de generalistas, há pouco para segurar estes últimos a níveis populacionais baixos.

\section{4 Ácaros em seringueira no Estado de São Paulo}

Poucos trabalhos enfocam o estudo da acarofauna associada a seringueira, Hevea brasiliensis (H.B.K.) M. Arg. (Euphorbiaceae). Feres (2000) relatou 28 espécies de ácaros pertencentes a 24 gêneros em 11 famílias em plantas do gênero Hevea.

No Estado de São Paulo, a seringueira é atacada por três espécies de ácaros da família Eriophyidae, a saber, Calacarus heveae Feres, 1992, Shevtchenkella petiolula Feres, 1998 e Phyllocoptruta seringueirae Feres, 1998 (Feres, 2000).

Severa desfolha da seringueira devido ao ataque de $C$. heveae foi relatada no Estado de São Paulo pela primeira vez entre 1990 e 1991 (Feres, 1992). Esta espécie pode ter atingido o status de praga devido à modificação em seu habitat, visto que a seringueira é nativa da Região Amazônica onde ocorre dispersa na vegetação nativa (Feres, 1992). O monocultivo desta planta pode representar um habitat desfavorável aos seus inimigos naturais, que poderiam estar mantendo $C$. heveae a baixos níveis populacionais em um possível hospedeiro original representado por outra espécie de planta da vegetação nativa do Estado de São Paulo. É possível ainda que $C$. heveae tenha sido introduzido da Região Norte do Brasil, através do transporte de mudas de seringueira, sem que tivesse sido acompanhado de seus inimigos naturais.

O estudo da acarofauna em Euphorbiaceae, família à qual a seringueira pertence, em vegetações naturais do Estado de São Paulo poderá auxiliar na identificação da provável origem dos ácaros fitófagos encontrados em seringueiras, especialmente $C$. heveae. Estes estudos poderão também auxiliar a identificação de inimigos naturais que poderão futuramente serem usados no controle biológico daquelas espécies e de outros ácaros praga de euforbiáceas cultivadas. 


\title{
3 FITOSEÍDEOS (ACARI: PHYTOSEIIDAE) ASSOCIADOS A EUFORBIÁCEAS (EUPHORBIACEAE) EM TRÊS LOCALIDADES DO ESTADO DE SÃO PAULO
}

\author{
Autor: MAURICIO SERGIO ZACARIAS \\ Orientador: PROF. DR. GILBERTO JosÉ DE MORAES
}

\section{RESUMO}

Vinte e nove espécies já descritas de ácaros da família Phytoseiidae foram encontradas em espécies arbóreas da família Euphorbiaceae, incluindo plantas nativas e a seringueira, em um levantamento conduzido em três regiões do Estado de São Paulo. Vários dos ácaros coletados eram conhecidos até o momento apenas pela descrição original. Descrições complementares de várias das espécies coletadas são apresentadas. 


\section{PHYTOSEIID MITES (ACARI: PHYTOSEIIDAE) ASSOCIATED WITH \\ EUPHORBIACEOUS TREES (EUPHORBIACEAE) IN THE \\ SOUTHEASTERN BRAZIL}

Author: MAURICIO SER GIO ZACARIAS

Adviser: Prof. DR. GILBERTo José DE MORAES

\section{SUMMARY}

Twenty nine known species of mites of the family Phytoseiidae were found on trees of the family Euphorbiaceae, including native plant species and rubber tree, in a survey conducted in 3 regions of the State of São Paulo. Several of the species collected were known until now only from the original description. Complementary descriptions of several of the species collected are provided. 


\subsection{Introdução}

Ácaros da família Phytoseiidae são os mais estudados para o controle biológico de ácaros fitófagos. Moraes et al. (1986) relacionaram 93 espécies de fitoseídeos em plantas da família Euphorbiaceae, sendo 8 em seringueiras, Hevea brasiliensis (H.B.K.) M. Arg. ou outras plantas do gênero Hevea: Amblyseiullela heveae (Oudemans, 1930), A hevearum (Oudemans, 1930), Euseius similiovalis (Liang \& Ke, 1983), E. ovalis (Evans, 1953), E. vivax (Chant \& Baker, 1965), E. longicervix (Liang \& Ke, 1983), Okiseius chinensis Wu, 1983 e Typhlodromips newsami (Evans, 1953). As demais foram relatadas principalmente em Ricinus communis L. e Manihot spp..

Feres (2000) relatou a ocorrência de 28 espécies de ácaros pertencentes a 24 gêneros em 11 famílias em plantas do gênero Hevea nos Estados de Minas Gerais, São Paulo, Mato Grosso e Mato Grosso do Sul. Dentre estas somente três espécies de fitoseídeos (Euseius citrifolius Denmark \& Muma, 1970, E. concordis (Chant, 1959) e Typhlodromus annectens DeLeon, 1958) foram relatadas. Este é o único relato de fitoseídeos em seringueira no Brasil.

A seringueira é uma das principais culturas em diferentes regiões brasileiras. Poucas espécies de ácaros são consideradas danosas à seringueira, mas pelo menos duas têm sido consideradas por produtores como de importância significativa, são as espécies Calacarus heveae Feres (Feres, 2000) e, apesar da ausência de suporte em dados publicados, Tenuipalpus heveae Baker. Em um estudo para se determinar a possibilidade de se controlar estes ácaros biologicamente, o primeiro passo consiste em se conhecer os inimigos naturais a eles associados, em seringueira e em outras plantas da mesma família com características relativamente semelhantes.

O presente trabalho teve como objetivo o estudo da variedade de espécies 
de fitoseídeos em plantas nativas da família Euphorbiaceae e em plantas de seringueira cultivada no Estado de São Paulo, de forma a subsidiar estudos para o controle biológico de pragas nesta cultura. São relatadas neste trabalho todas as espécies coletadas, mas as descrições de algumas das espécies novas são feitas no capítulo subsequente. 


\subsection{Metodologia}

Foram escolhidas 3 localidades para amostragem, nos municípios de Pariquera-Açu, Cananéia e Piracicaba. Em Pariquera-Açu a amostragem foi realizada em uma região de Mata Atlântica dentro da "Estação Experimental J. Cione" (24 36' 50" de latitude sul, $47^{\circ} 53^{\prime} 00^{\prime \prime}$ de longitude oeste) pertencente ao Instituto Agronômico de Campinas. Em Cananéia, a coleta foi realizada em pontos à margem da rodovia SP-226, já no interior da ilha ( $24^{\circ} 55^{\prime} 00^{\prime}$ " de latitude sul, $47^{\circ} 50^{\prime} 00^{\prime \prime}$ de longitude oeste). Em Piracicaba, as plantas foram amostradas em caminhamento pelo "Parque Phillipe Westin Cabral de Vasconcellos" no Campus Universitário da Escola Superior de Agricultura "Luiz de Queiroz" (22 $22^{\circ}$ ' 30" de latitude sul, 47 37' 40" de longitude oeste), Universidade de São Paulo.

As espécies vegetais amostradas foram: Alchornea glandulosa Poepp. \& Endl., A. sidifolia M. Arg., A. triplinervea M. Arg., Aparisthmium cordatum (A. Juss.) Baill., Croton floribundus Spreng., C. urucurana Baill., Hevea brasiliensis (H.B.K.) M. Arg. clones C7 e 527-A, Hura crepitans Linn., Joannesia princeps Vell. e Pachystroma longifolium M. Arg., Pera glabrata (Schott) Baill., Sebastiania sp..

O material vegetal coletado de cada planta foi acondicionado em um saco de papel devidamente identificado, que por sua vez foi colocado em um saco plástico e guardado em caixa de isopor com gelo até o retorno ao laboratório, onde foi mantido em refrigerador a aproximadamente $10^{\circ} \mathrm{C}$ para posterior coleta dos ácaros em um período de no máximo uma semana. A montagem dos ácaros foi realizada em lâminas com meio de Hoyer (Flechtmann, 1977).

As espécies de ácaros encontrados no presente trabalho são relacionadas com suas respectivas plantas hospedeiras, localidade e observações pertinentes. As 
plantas de Cananéia e Pariquera-Açu foram amostradas em abril de 1998 e as de Piracicaba, em junho do mesmo ano.

A nomenclatura das setas utilizada neste trabalho é aquela proposta por Rowell et al. (1978) para a superfície dorsal e Chant \& Yoshida-Shaul (1991) para a superfỉcie ventral do idiossoma (Figura 5). A citação da distribuição geográfica das espécies é baseada em Moraes et al. (1986); informações adicionais são indicadas no texto acompanhadas das respectivas referências. Apresentam-se novas medições para espécies pouco conhecidas ou conhecidas somente pela descrição original, bem como para as que apresentaram diferenças morfológicas em relação ao verificado na literatura. As medições são sempre apresentadas em micrômetros.

Espécimens representativos de cada espécie foram depositados no Setor de Zoologia Agrícola do Departamento de Entomologia, Fitopatologia e Zoologia Agrícola da Escola Superior de Agricultura "Luiz de Queiroz" da Universidade de São Paulo (Piracicaba - São Paulo - Brasil). 


\subsection{Resultados e Discussão}

As coletas resultaram na constatação de 24 espécies já descritas e 5 espécies novas de fitoseídeos, relacionadas a seguir:

\section{Subfamília Amblyseinae Muma}

Amblyseiulella sooretama (El-Banhawy) n. comb.

Amblyseius sooretamus El-Banhawy 1984: 128.

Distribuição: Brasil.

Material examinado: Pariquera-Açu: A. glandulosa.

Observações: As medições de 4 espécimens de Pariquera-Açu mostraram os seguintes valores: comprimento do escudo dorsal 297 (292-303), largura do escudo dorsal 167 (165-171), jl 31 (30-32), j3 70 (68-73), j4 4, j5 3 (3-4), j6 5 (4-7), J2 5, J5 5, z2 8 (8-9), z4 11, z5 5 (4-5), Zl 6 (5-7), Z4 106 (103-111), Z5 127, s4 130 (127-132), S2 11 (1112), S5 12 (11-14), r3 36 (35-38), Rl 10 (9-11), Sge I 18 (16-19), Sge II 16 (15-16), Sge III 15 (15-16), Sti III 15 (14-16), Sge IV 69 (65-73), Sti IV 94 (89-97), St IV 67 (65-70), Stl-St3 67 (65-68), St2-St2 72 (70-73), St5-St5 68 (65-70), largura do escudo ventrianal ao nível de ZV2 73 (70-76), largura do escudo ventrianal ao nível do ânus 61 (59-62), comprimento do escudo ventrianal 102 (97-105), cálice da espermateca 5, dígito fixo 29 (27-30), dígito móvel 36 (35-38). Estas medições são próximas da descrição original mas apresentam as setas jl, z2, z4 e S5 20\% menores e a macroseta Sge IV 20\% maior. Os espécimens coletados apresentam também os escudos metapodais mais alongados e reentrâncias no escudo dorsal ao nível de s4 menos conspícuas. Além disso, os exemplares coletados apresentam entre 11 e 13 dentes no dígito fixo enquanto o desenho apresentado na descrição original da espécie mostra apenas 7 dentes neste dígito. Tendo 
em vista que os dentes mais distais são muito pequenos, acredita-se que estes tenham passado desapercebidos pelo autor da espécie no ato da descrição, que parece ter sido baseada em um reduzido número de indivíduos.

\section{Amblyseius herbicolus (Chant)}

Typhlodromus (Amblyseius) herbicolus Chant 1959: 84.

Amblvseius herbicolus. Daneshvar \& Denmark 1982: 5: McMurtry \& Moraes 1984: 34: Denmark \& Muma 1989: 59.

Amblyseius deleoni, Muma \& Denmark 1970: 68 (sinonímia, de acordo com Daneshvar \& Denmark 1982: 5).

Amblyseius impactus, Chaudhri 1968: 553 (sinonímia, de acordo com Daneshvar \& Denmark 1982: 5).

Distribuição: Africa do Sul, Angola, Austrália, Brasil, China, Colômbia, EUA, Guatemala, India, Indonésia, Irã, Japão, Madagascar, Nova Caledônia, Papua Nova Guine, Porto Rico, Tailândia e Taiwan; Costa Rica, Honduras, El Salvador (Denmark et al., 1999); Guadalupe, Martinica, Les Saintes (Moraes et al., 2000).

Material examinado: Piracicaba: P. longifolium.

Amblyseius impeltatus Denmark \& Muma

Amblyseius impeltatus Denmark \& Muma 1973: 241; 1989: 91.

Distribuição: Brasil

Material examinado: Pariquera-Açu: A. triplinervea, A. glandulosa, H. brasiliensis.

Observações: As medições de 4 espécimens de Pariquera-Açu mostraram os seguintes valores: comprimento do escudo dorsal 365 (339-377), largura do escudo dorsal 267 (247-286), j1 18 (15-20), j3 22 (21-23), j4 6 (4-8), j5 5 (3-7), j6 7 (5-8), J2 8 (5-11), J5 7 (6-8), z2 13 (11-13), z4 10 (8-12), z5 7 (6-9), Z1 9 (5-11), Z4 34 (32-39), Z5 128 (126131), s4 37 (35-39), S2 10 (9-11), S4 10 (10-11), S5 9 (8-10), r3 11 (10-12), R1 9(8-9), Sge I 30 (27-31), Sge II 30 (29-31), Sge III 37 (35-39), Sti III 26 (25-26), Sge IV 60 (5665), Sti IV 45 (43-48), St IV 49 (48-51), St 1-St3 53 (51-55), St2-St2 72 (69-74), St5-St5 79 (77-80), largura do escudo ventrianal ao nível de ZV2 85 (84-85), largura do escudo 
ventrianal ao nível do ânus 76 (75-79), comprimento do escudo ventrianal 98 (89-102), cálice da espermateca 11 (10-12), dígito fixo 28 (26-29), dígito móvel 31 (30-32). As medições correspondem à descrição original e à de Lofego (1998) mas o formato da espermateca não corresponde à da descrição original, parecendo mais com a descrita por Lofego (1998) que também é ligeiramente diferente da descrição original.

Amblyseius neochiapensis Lofego, Moraes \& McMurtry

Amblyseius neochiapensis Lofego, Moraes \& McMurtry 2000: 462.

Distribuição: Brasil (Lofego et al., 2000).

Material examinado: Piracicaba: A. glandulosa, A. sidifolia, C. floribundus, $C$. urucurana.

\section{Amblyseius operculatus DeLeon}

Amblyseius operculatus DeLeon 1967:26; Denmark \& Muma 1989: 47.

Distribuição: Brasil e Trinidad-Tobago.

Material examinado: Pariquera-Açu: A. glandulosa, A. sidifolia, A. triplinervea, $H$. brasiliensis, Sebastiania sp..

Observações: As medições de 3 espécimens correspondem às obtidas por Denmark \& Muma (1989) e Gondim Jr. (2000) que também obtiveram medições em torno de $15 \%$ inferiores àquelas da descrição original. $\mathrm{O}$ formato do cálice da espermateca também corresponde ao que foi apresentado por Denmark \& Muma (1989), diferindo um pouco da descrição original.

Amblyseius saopaulus Denmark \& Muma

Amblyseius saopaulus Denmark \& Muma 1973: 243; 1989: 32.

Distribuição: Brasil.

Material examinado: Cananéia: $P$. glabrata. Pariquera-Açu: $A$. sidifolia, $A$. triplinervea, H. brasiliensis. 


\section{Euseius alatus DeLeon}

Euseius alatus DeLeon 1966: 87; Denmark \& Muma 1973: 262; Moraes \& McMurtry 1983: 137; Feres \& Moraes 1998: 127.

Euseius paraguayensis, Denmark \& Muma 1970: 224 (sinonímia, de acordo com Moraes \& McMurtry 1983:137).

Distribuição: Brasil, Colômbia, Guiana e Paraguai; Peru (McMurtry \& Moraes, 1989); Martinica (Moraes et al., 2000).

Material examinado: Pariquera-Açu: A triplinervea. Piracicaba: A. glandulosa, $H$. brasiliensis, J. princeps, P. longifolium.

\section{Euseius citrifolius Denmark \& Muma}

Euseius citrifolius Denmark \& Muma 1970: 222; Moraes \& McMurtry 1983: 138; Moraes et al. 1991: 131; Feres \& Moraes 1998: 127.

Distribuição: Brasil e Paraguai; Peru (McMurtry \& Moraes, 1989); Colômbia e Nicaragua (Moraes et al., 1991).

Material examinado: Piracicaba: $H$. brasiliensis, $H$. crepitans, $J$. princeps, $P$. longifolium.

Euseius ho (DeLeon)

Amblyseius (Euseius) ho DeLeon 1965a: 125.

Euseius ho. Denmark \& Muma 1973: 262: Moraes \& McMurtry 1983: 139: Moraes et al.. 1991: 132.

Distribuição: Brasil, Jamaica e Porto Rico; Colômbia, Equador, Mexico e Peru (Moraes et al.., 1991).

Material examinado: Pariquera-Açu: A. glandulosa, A. sidifilia. Piracicaba: $A$. glandulosa, A. sidifolia, C. floribundus.

Iphiseiodes zuluagai Denmark \& Muma Iphiseiodes zuluagai Denmark \& Muma 1972: 23; Aponte \& McMurtry 1995: 165; Kreiter \& Moraes 1997: 377; Feres \& Moraes 1998: 127. 
Amblyseius zuluagai, Moraes \& Mesa 1988: 79; Moraes et al.. 1991: 125.

Distribuição: Brasil, Colômbia e Porto Rico; Cuba e Panamá (Moraes et al.., 1991); Guadalupe (Kreiter \& Moraes, 1997); Maria Galante, Martinica (Moraes et al.., 2000).

Material examinado: Piracicaba: A. glandulosa, A. sidifolia, C. floribundus, C. urucurana, $H$. brasiliensis, $H$. crepitans, J. princeps, P. longifolium.

\section{Paraphytoseius multidentatus Swirski \& Shechter}

Paraphytoseius multidentatus Swirski \& Shechter 1961: 114; McMurtry \& Moraes 1984:27.

Paraphytoseius bhadrakaliensis (Gupta, 1969); Paraphytoseius horrifer (Pritchard \& Baker, 1962); Paraphytoseius hyalinus (Tseng, 1973); Paraphytoseius narayanani (Ehara \& Ghain, 1967); Paraphytoseius nicobarensis (Gupta, 1977); Paraphytoseius orientalis (Narayanan, Kaur \& Ghain, 1960); Paraphytoseius parabilis (Chaudhiri, 1967); Paraphytoseius santurcensis DeLeon, 1965; Paraphytoseius subtropicus (Tseng, 1972) e Paraphytoseius urumanus (Ehara, 1967) (sinonímia, de acordo Matthysse \& Denmark, 1981).

Distribuição: Cosmopolita, tendo já sido constatada no Brasil (Lofego, 1998).

Material examinado: Pariquera-Açu: A. glandulosa, A. cordatum. Piracicaba: $A$. glandulosa, C. floribundus, C. urucurana.

\section{Phytoscutus sexpilis Muma}

Phytoscutus sexpilis Muma 1961: 275; DeLeon 1967:17; Muma \& Denmark 1970: 24; Yoshida-Shaul \& Chant 1997: 234.

Typhlodromus sexpilis, Hirschmann 1962: 17.

Amblyseius sexpilis, Van der Merwe 1968: 161.

Distribuição: Cuba, EUA e Trinidad-Tobago; Brasil (Gondim Jr., 2000); Guadalupe (Moraes et al.., 2000).

Material examinado: Cananéia: $P$. glabrata. Pariquera-Açu: $H$. brasiliensis. Piracicaba: A. glandulosa, A. sidifolia. 


\section{Proprioseiopsis cannaensis (Muma)}

Amblyseiulus cannaensis Muma 1962:4.

Amblvseius cannaensis, Moraes \& McMurtry 1983:132: Moraes \& Mesa 1988: 77:

Moraes et al.. 1991: 126.

Proprioseiopsis cannaensis, Muma et al.. 1970:38; Kreiter \& Moraes 1997: 379.

Distribuição: Guiana, Nova Caledônia, Paraguai e EUA; Brasil, Colômbia, Cuba, Equador (Moraes et al.., 1991); El-Salvador, Guadalupe (Kreiter \& Moraes, 1997); Maria Galante, Martinica (Moraes et al.., 2000).

Material examinado: Piracicaba: P. longifolium.

Observações: Apesar de sua difícil diferenciação de P. ovatus, os exemplares observados apresentam medições comparáveis às obtidas por Moraes \& McMurtry (1983) para exemplares coletados no Brasil e identificados como P. cannaensis; a forma do cálice da espermateca também é mais próximo à de $P$. cannaensis.

\section{Proprioseiopsis dominigos (El-Banhawy)}

Amblyseius dominigos El-Banhawy 1984: 130; McMurtry \& Moraes 1989: 185; Moraes et al.. 1991: 126; Feres \& Moraes 1998: 126.

Proprioseiopsis dominigos, Gondim Jr. 2000: 91.

Distribuição: Brasil; Peru (Mcmurtry \& Moraes, 1989); Colômbia (Moraes et al.., 1991). Material examinado: Pariquera-Açu: A. glandulosa, A. sidifolia, A. cordatum, $H$. brasiliensis. Piracicaba: A. glandulosa, P. longifolium.

Observações: Os espécimens observados apresentaram medições que correspondem às obtidas por Gondim Jr. (2000), que são até 30\% maiores que as da descrição original.

\section{Proprioseiopsis neotropicus (Ehara)}

Amblyseius neotropicus Ehara 1966: 133; Moraes \& Mesa 1988: 79; Moraes et al.. 1991: 127.

Proprioseiopsis neotropicus (Ehara), Gondim Jr. 2000: 92.

Distribuição: Brasil; Colômbia (Moraes \& Mesa, 1988); Equador (Moraes et al.., 1991). Material examinado: Pariquera-Açu: A. glandulosa, A. sidifolia, A. triplinervea, A. 
cordatum. Piracicaba: C. floribundus.

Observações: Os espécimens observados apresentam medições com valores comparáveis àquelas obtidas por Moraes \& Mesa (1988) e Gondim Jr. (2000), que são próximos aos da descrição original, exceto por j3 e r3 que são $50 \%$ maiores.

Proprioseius sp. n.

Material examinado: Pariquera-Açu: A. cordatum.

Typhlodromalus aripo DeLeon

Typhlodromalus aripo DeLeon 1967: 21; Denmark \& Muma 1973: 257

Amblyseius aripo, Moraes \& McMurtry 1983: 132; Moraes \& Mesa 1988: 73

Distribuição: Brasil, Colômbia, El-Salvador, Guiana, Jamaica, Trinidad-Tobago; Guadalupe (Moraes et al., 2000)

Material examinado: Piracicaba: A. glandulosa.

Observações: Somente 1 espécimen foi coletado neste estudo. As medições das setas em geral e de forma particular a proporção entre os comprimentos das setas z2 e z4 correspondem ao que foi citado por Moraes \& Mesa (1988).

\section{Typhlodromalus manihoti (Moraes et al.)}

Amblyseius manihoti Moraes et al.. 1994: 211.

Typhlodromalus manihoti,Lofego 1998: 64; Gondim Jr. 2000: 93.

Distribuição: Bolívia, Brasil, Colômbia, Cuba, Equador, Nicaragua, Paraguai, Peru, Suriname, Trinidad-Tobago, Venezuela (Moraes et al.., 1994).

Material examinado: Pariquera-Açu: $A$. sidifolia, A. triplinervea. Piracicaba: $C$. urucurana.

Observações: As medições dos exemplares coletados estão de acordo com a descrição original. Foram coletados espécimens de vários estágios, sugerindo que o ácaro se desenvolve e multiplica nas plantas citadas acima. Um único exemplar foi coletado em Piracicaba, estando as medições deste de acordo com a descrição da espécie. O cálice da espermateca deste exemplar apresenta-se esclerotizado em toda sua extensão diferindo 
levemente do que se verifica no material tipo. Novas coletas na mesma planta poderão indicar se trata-se de uma outra espécie próxima.

Typhlodromalus sp. $\mathrm{n}$.

Material examinado: Pariquera-Açu: A. cordatum.

Typhlodromalus villacarmelensis Moraes

Typhlodromalus villacarmelensis Moraes et al, 1994: 214.

Distribuição: Colômbia, Peru (Moraes et al., 1994).

Material examinado: Pariquera-Açu: A. glandulosa.

Observações: As medições de 2 espécimens correspondem bem à descrição original, exceto pela seta $\mathrm{Z} 4$ que é cerca de $20 \%$ menor.

Typhlodromalus peregrinus (Muma)

Typhlodromus peregrinus Muma 1955:270.

Typhlodromus (Amblyseius) peregrinus, Chant 1959: 97.

Amblyseius peregrinus, McMurtry 1983: 255.

Typhlodromalus peregrinus, Muma et al.. 1970: 88.

Typhlodromus (Amblyseius) robineae, Chant 1959: 98; Typhlodromus (Amblyseius) evansi, Chant 1959: 99; Typhlodromus (Amblyseius) primulae, Chant 1959: 99 (sinonímia de acordo com Muma, 1964)

Distribuição: Brasil, Colômbia, Costa Rica, Equador, Guatemala, Guiana, Havaí, Honduras, México, Nicarágua, Porto Rico, Suriname.

Material examinado: Pariquera-Açu: A triplinervea.

Observações: As medições dos espécimens observados correspondem àquelas apresentadas por Moraes \& Mesa (1988); entretanto, a macroseta StIV não é afilada e SgeI não é maior que as demais, mas é distintamente mais grossa que outras setas do mesmo segmento. 
Typhlodromips sp.

Material examinado: Cananéia: $A$. triplinervea, $P$. glabrata. Pariquera-Açu: $A$. glandulosa, A. triplinervea, H. brasiliensis, Sebastiania sp..

Observações: Trata-se de uma espécie nova que está sendo descrita por M.G.C. Gondin Jr. e G.J. de Moraes, coletada previamente em Cananéia sobre palmáceas nativas.

\section{Typhlodromips linharis El-Banhawy}

Typhlodromips linharis El-Banhawy 1984: 136

Neoseiulus linharis, Lofego 1998: 51.

Distribuição: Brasil.

Material examinado: Pariquera-Açu: Sebastiania sp..

Observações: As medições obtidas de 4 fềmeas são: comprimento do escudo dorsal 311 (286-330), largura do escudo dorsal 204 (193-215), j1 19 (19-20), j3 26 (24-27), j4 8, j5 8, j6 12 (9-14), J2 13 (11-14), J5 8, z2 12 (11-12), z4 18 (16-19), z5 8, Z1 16 (14-18), Z4 53 (51-54), Z5 59 (57-59), s4 27, S2 20 (19-22), S4 13 (11-14), S5 10 (8-11), r3 11 (1112), R1 11, Sge I 15 (14-16), Sge II 15 (12-16), Sge III 16 (15-16), Sti III 15 (14-16), Sge IV 29 (27-30), Sti IV 18 (16-19), St IV 29 (27-30), St1-St3 58 (57-59), St2-St2 66 (58-68), ST5-ST5 69 (58-76), largura do escudo ventrianal ao nível de ZV2 94 (92-95), largura do escudo ventrianal ao nível do ânus 77 (76-81), comprimento do escudo ventrianal 88 (81-92), cálice da espermateca 11, dígito fixo 29 (27-30), dígito móvel 39 (38-41). Estes valores são muito próximos, mas ligeiramente inferiores aos da descrição original e correspondem aos obtidos por Gondim Jr. (2000). Observando-se a gravura da espermateca na descrição original (que não foi mensurada), esta parece ser pouco mais longa nos exemplares estudados.

Typhlodromips sp. $\mathrm{n}$.

Material examinado: Pariquera-Açu: A. glandulosa. Sebastiania sp.. 


\section{Subfamília Phytoseinnae Berlese}

Phytoseius sp. n.

Material examinado: Pariquera-Açu: A. sidifolia.

\section{SubFAmília TyPhLODROMINAE WAINSTEIN}

Galendromimus alveolaris (DeLeon)

Typhlodromus alveolaris DeLeon 1957: 141.

Typhlodromus (Typhlodromus) alveolaris, Chant 1959: 52.

Galendromimus alveolaris, Muma 1961:297, DeLeon 1962: 175, 1967: 13, Wainstein 1962: 19, Muma et al. 1970: 58.

Cydnodromella alveolaris, Chant \& Yoshida-Shaul 1986: 482, Moraes \& Mesa 1988:80. Galendromimus (Galendromimus) alveolaris, Chant \& McMurtry 1994: 242.

Distribuição: Costa Rica, Jamaica, México, Trinidad-Tobago; Brasil (Feres \& Moraes, 1998); Martinica (Moraes et al., 2000).

Material examinado: Piracicaba: A. glandulosa, C. floribundus.

Observações: Dentre as 3 fềmeas medidas, uma apresentou Z4 e Z5 cerca de 20\% menor e o escudo dorsal visivelmente menos esclerotizado que as demais.

\section{Galendromimus sp. n.}

Material examinado: Piracicaba: $C$. floribundus.

\section{Typhlodromus annectens DeLeon}

Typhlødromus annectens DeLeon 1958: 75; Chant \& Yoshida-Shaul 1984: 1868; Moraes \& McMurtrv 1983: 142: Moraes \& Mesa 1988: 82: Moraes et al.. 1991: 134: Feres \& Moraes 1998: 128.

Galendromus annectens, Muma 1961: 298; 1963: 30; Muma \& Denmark 1970: 135; Denmark \& Muma 1973: 274; Denmark 1982: 142; Moraes et al.. 1982: 21.

Distribuição: Brasil, Canadá, Colômbia, EUA, Galápagos, Honduras, México e Porto Rico; Costa Rica e El Salvador (Denmark et al.., 1999).

Material examinado: Pariquera-Açu: A. sidifolia. Piracicaba: A. glandulosa, $C$. 


\section{floribundus.}

Observações: As medições obtidas de 3 fềmeas de Piracicaba são: comprimento do escudo dorsal 274 (264-282), largura do escudo dorsal 138 (134-141), j1 19 (18-21), j3 39 (36-41), j4 33 (32-34), j5 40 (38-42), j6 47 (46-47), J2 50 (48-51), J5 6 (5-6), z2 43 (41-45), z3 40 (38-41), z4 43 (41-45), z5 42 (41-43), Z4 51 (47-55), Z5 48 (46-49), s4 46 (45-47), s6 53 (51-55), S2 54 (53-55), S5 45 (44-47), r3 33 (32-35), St1-St3 59 (5861), St2-St2 53 (50-55), ST5-ST5 46 (45-46), Largura do escudo ventrianal ao nível de ZV2 56 (55-58), largura do escudo ventrianal ao nível do ânus 61 (60-63), comprimento do escudo ventrianal 94 (86-103), cálice da espermateca 35 (34-35). As medições obtidas de 3 fềmeas de Pariquera-Açu são: comprimento do escudo dorsal 309 (301319), largura do escudo dorsal 155 (148-162), j1 25 (23-26), j3 50 (48-53), j4 37 (3638), j5 48 (47-50), j6 59 (57-61), J2 60 (58-63), J5 6(4-8), z2 54 (52-56), z3 43 (39-46), z4 54 (52-55), z5 48 (46-51), Z4 54 (51-56), Z5 57 (54-60), s4 57 (57-58), s6 61 (59-64), S2 64 (62-67), S5 56 (55-59), r3 42 (37-47), R1 16 (15-16), St1-St3 64 (62-65), St2-St2 55 (54-56), ST5-ST5 51 (49-53), largura do escudo ventrianal ao nível de ZV2 58 (5660), largura do escudo ventrianal ao nível do ânus 63 (59-65), comprimento do escudo ventrianal 101 (100-102), cálice da espermateca 33 (32-34). As medições dos exemplares de Piracicaba estão de acordo com as de Moraes \& Mesa (1988), que são maiores que as do material tipo. Os espécimens de Pariquera-Açu são ainda maiores que os de Piracicaba, mas os limites inferiores de suas medições se sobrepõem aos limites superiores apresentados por Moraes \& Mesa (1988). Os espécimens de ambas localidades apresentaram a distância entre os poros pré-anais semelhante à distância entre as setas JV2, como verificado por Moraes \& Mesa (1988).

Typhlodromina camelliae (Chant \& Yoshida-Shaul), n. comb.

Typhlodromus camelliae Chant \& Yoshida-Shaul 1983b: 1053; Feres \& Moraes 1998: 130.

Distribuição: Uruguai; Brasil (Feres \& Moraes, 1998).

Material examinado: Piracicaba: H. brasiliensis, $H$. crepitans, J. princeps, $P$. longifolium. 
O presente estudo acrescenta 9 outras espécies àquelas conhecidas até o momento em euforbiáceas no Brasil (Moraes et al.,1986; Feres, 2000). Estas novas constatações são: Amblyseius impeltatus Denmark \& Muma, 1973; Amblyseius operculatus DeLeon, 1967; Amblyseius saopaulus Denmark \& Muma, 1973; Euseius alatus DeLeon, 1966; Iphiseiodes zuluagai Denmark \& Muma, 1972; Phytoscutus sexpilis Muma, 1961; Proprioseiopsis dominigos (El-Banhawy, 1984); Typhlodromips sp. e Typhlodromina camelliae (Chant \& Yoshida-Shaul, 1983b).

$A$. operculatus foi a espécie de fitoseídeo com maior amplitude de hospedeiros em Pariquera-Açu (5 espécies vegetais, incluindo a seringueira). Em Cananéia a espécie de maior amplitude de hospedeiros foi Typhlodromips sp., esta também foi a espécie mais abundante. Em Piracicaba I. zuluagai foi a que apresentou maior amplitude (8 espécies vegetais incluindo a seringueira; embora apenas 1 espécimen tenha sido encontrada nesta última).

Seis espécies foram encontradas em seringueira em Pariquera-Açu ( $A$. saopaulus, A. operculatus, A. impeltatus, P. sexpilis, P. dominigos e Typhlodromips.sp.). Em Piracicaba, 4 espécies foram encontradas, sendo estas totalmente distintas daquelas de Pariquera-Açu (E. alatus, E. citrifolius, I. zuluagai e T. camelliae).

Em Pariquera-Açu, 4 plantas apresentaram pelo menos duas espécies de fitoseídeos comuns às encontradas em seringueira: A. glandulosa, A. sidifolia, $A$. triplinervea e Sebastiania sp. A espécie de fitoseídeo mais abundante encontrada em Pariquera-Açu foi Typhlodromips sp.

Em Piracicaba, também 4 plantas apresentaram pelo menos duas espécies de fitoseídeos comuns às encontradas em: A. glandulosa, H. crepitans, J. princeps e $P$. longifolium. A espécie de fitoseídeo mais abundante encontrada em seringueira de Piracicaba foi $T$. camelliae e outras 3 plantas apresentaram este ácaro (as 3 últimas da lista acima). Feres \& Moraes (1998) já haviam relatado a ocorrência desta espécie em outra euforbiácea (Mabea fistulifera na Região Noroeste do Estado de São Paulo).

Portanto, isto tudo indica que os fitoseídeos mais abundantemente encontrados nas seringueiras se mantém também em plantas comuns de cada região estudada. Destas plantas "alternativas", estes predadores poderiam talvez se dispersar à 
seringueira quando presas favoráveis ao seu desenvolvimento atingissem níveis relativamente altos.

Como não foram encontradas espécies comuns às seringueiras das duas regiões, podemos dizer que para a seringueira é mais importante a preservação das comunidades locais de plantas nativas e seus fitoseídeos associados, onde se deseja implantar ou está implantado um seringal, com o objetivo de manejar estes ácaros. 


\subsection{Conclusões}

- As espécies vegetais Pera glabrata e Alchornea triplinervea em Cananéia e A. glandulosa, A. triplinervea e Sebastiania sp. em Pariquera-Açu abrigam o fitoseídeo mais abundante em seringueiras de Pariquera-Açu (Typhlodromips sp.).

- As espécies vegetais Hura crepitans, Joanesia princeps e Pachistromma longifolium em Piracicaba abrigam o fitoseídeo mais abundante em seringueiras daquela localidade (Typhlodromina camelliae (Chant \& Yoshida-Shaul, 1983b)).

- As espécies de fitoseídeos encontradas em seringueira de Pariquera-Açu são distintas daquelas encontradas na mesma planta em Piracicaba. 


\title{
4 DESCRIÇÃO DE QUATRO ESPÉCIES NOVAS DE FITOSEÍDEOS (ACARI: PHYTOSEIIDAE) DO ESTADO DE SÃO PAULO (ACARI: PHYTOSEIIDAE)
}

\author{
Autor: MAURICIO SERgIO ZACARIAS \\ Orientador: Prof. Dr. GILBERTo José DE MORAES
}

\section{RESUMO}

Quatro novas espécies de fitoseídeos coletados em plantas da Mata Atlântica do Estado de São Paulo são descritas como novas para a ciência. As espécies são: Proprioseius retroacuminatus sp. n., Phytoseius globuliformis sp. n., Kampimodromus multicupuli sp. n. e Galendromimus paulista sp. n. 


\section{FOUR NEW SPECIES OF PHYTOSEIID MITES (ACARI: PHYTOSEIIDAE) FROM THE STATE OF SĀO PAULO, BRAZIL}

Author: MAURICIO SERGIO ZaCARIAS

Adviser: Prof. Dr. GILBERTo JosÉ DE MORAES

\section{SUMMARY}

Four new species of phytoseid mites collected from trees in woody areas are described as new to the science. The species are: Proprioseius retroacuminatus sp. n., Phytoseius globuliformis sp. n., Kampimodromus multicupuli sp. $\mathrm{n}$. and Galendromimus paulista sp. n.. 


\subsection{Introdução}

A família Phytoseiidae contém os predadores de ácaros fitófagos mais estudados e importantes (Moraes et al., 1986). Estes podem predar principalmente pequenos artrópodos mas muitas espécies também se alimentam de uma grande variedade de diferentes substâncias, como pólen, exsudatos, etc.

Estes ácaros podem ser classificados em 4 grupos, de acordo com McMurtry \& Croft (1997). Segundo aquela classificação, os fitoseídeos dos tipos III e IV são generalistas e se utilizam de uma gama mais ampla de alimentos alternativos para sua manutenção no campo. De acordo com aqueles autores, fitoseídeos destes dois grupos devem ser responsáveis pela manutenção de populações de tetraniquídeos em baixos níveis, principalmente em plantas perenes, sendo importantes em estratégias de conservação (Walter \& O’Dowd, 1992b; Walter, 1996).

Fitoseídeos foram os ácaros predadores mais abundantes encontrados por Walter \& O'Dowd (1992b) em folhas de plantas lenhosas de mata nativa da Austrália. No entanto, no Brasil, pouco se conhece a respeito destes ácaros em ambientes de floresta nativa, exceto pelos trabalhos conduzidos por Feres (1993), Feres \& Moraes (1998) e Gondim Jr. (2000).

O presente trabalho relata quatro novas espécies de fitoseídeos coletados em plantas da Mata Atlântica no Estado de São Paulo. 


\subsection{Metodologia}

Ácaros foram coletados em 3 localidades nos municípios de PariqueraAçu, Iguape e Piracicaba. Na região de Pariquera-Açu os ácaros foram coletados em áreas de Mata Atlântica dentro na "Estação Experimental J. Cione", do Instituto Agronômico de Campinas. Em Iguape, a coleta foi realizada à margem do Rio Ribeira do Iguape. Em Piracicaba, a coleta foi realizada no Campus Universitário da Escola Superior de Agricultura "Luiz de Queiroz" em uma área de vegetação secundária sob influência de um remanescente de Mata Atlântica chamado de Mata da Pedreira (Ivanauskas \& Rodrigues, 1995).

O material vegetal coletado de cada planta foi acondicionado em um saco de papel devidamente identificado, que por sua vez foi colocado em um saco plástico e guardado em caixa de isopor com gelo até o retorno ao laboratório, onde foi mantido em refrigerador a aproximadamente $10^{\circ} \mathrm{C}$ para posterior coleta dos ácaros em um período de no máximo uma semana. A montagem dos ácaros foi realizada em lâminas com meio de Hoyer (Flechtmann, 1977).

A nomenclatura das setas utilizada neste trabalho é aquela proposta por Rowell et al.. (1978) para a superficie dorsal e Chant \& Yoshida-Shaul (1991) para a superfície ventral do idiossoma (Figura 5). As medições são sempre apresentadas em micrômetros.

Espécimens tipo foram depositados no Setor de Zoologia Agrícola do Departamento de Entomologia, Fitopatologia e Zoologia Agrícola da Escola Superior de Agricultura "Luiz de Queiroz" da Universidade de São Paulo, Piracicaba -SP, Brasil (ESALQ-USP) e na Ohio State University Acarology Collection, Ohio State University, Museum of Biological Diversity, Columbus, OH, USA (OSAL). 


\subsection{Resultados e discussão}

\section{Proprioseius Chant}

Proprioseius Chant 1957: 357; Chant, 1959:111; Moraes \& Denmark, 1999: 97. Amblyseius (Proprioseius), Pritchard \& Baker 1962: 294.

Phytoseiulus (Proprioseius), Wainstein 1962: 9.

Amblyseius Berlese (part), Chant 1965: 372.

1. Proprioseius retroacuminatus Zacarias \& Moraes, espécie nova (Figura 01)

Diagnose: Esta espécie é similar a $P$. gibbus Moraes \& Denmark (1999) e $P$. aculeatus Moraes \& Denmark (1999) por apresentar uma elevação dorso-central imediatamente posterior às setas $\mathrm{j} 6$; difere entretanto daquelas por apresentar as setas $\mathrm{j} 3$, J5, z4 e S5 maiores, j1 menor e elevação dorso-central posterior a j6 menos conspícua. Além disso, difere de $P$. aculeatus por não apresentar macrosetas nas pernas.

FÊMEA: Escudo dorsal rugoso, com uma elevação dorso-central imediatamente posterior às setas $\mathrm{j} 6$; no topo desta protuberância ocorrem normalmente 3 estruturas longitudinais, paralelas, em forma de dente e levemente voltadas para trás; em alguns espécimens uma quarta estrutura é visível posteriormente às demais e em linha com a de posição central; as medições médias de 8 espécimens, seguidas (entre parênteses) pelas respectivas amplitudes são: comprimento do escudo dorsal 287 (277298), largura do escudo dorsal 160 (152-166), j1 29 (27-31), j3 17 (15-24), j4 7 (7-9), j5 7 (6-8), j6 9 (8-11), J5 7 (6-7), z2 15 (13-18), z4 18 (16-20), z5 7 (6-9), Z4 100 (95-104), Z5 117 (112-123), s4 108 (102-117), S2 13 (12-15), S5 14 (12-17), r3 31 (24-36), R1 11 
(9-12). Escudos ventrais lisos. Escudo esternal com três pares de setas e dois pares de solenóstomos; distâncias entre St1-St3 58 (55-60), St2-St2 62 (60-65) e St5-St5 62 (5663). Com dois pares de escudos metapodais. Escudo ventrianal com três pares de setas preanais e um par de solenóstomos pouco discerníveis; comprimento do escudo 106 (90113), largura ao nível de Zv2 61 (58-65); largura ao nível do ânus 61 (57-68). Setas Zv1, Zv3 e Jv5 localizadas no tegumento em torno do escudo ventrianal. Peritrema se estendendo anteriormente a j1. Dígito móvel com comprimento de 25 (24-26), com 2 dentes; dígito fixo com comprimento de 23 (21-24), com 7 dentes. Nenhuma macroseta discernivel em nenhuma das pernas. Cálice da espermateca em forma de "prato" com profundidade de $3(2-4)$.

MACHO: Semelhante à fềmea, exceto pela ausência da elevação dorsocentral posterior às setas $\mathrm{j} 6$; as medições médias de 4 espécimens, seguidas (entre parênteses) pelas respectivas amplitudes são: comprimento do escudo dorsal 233 (227239), largura do escudo dorsal 145 (137-150), j1 23 (23-24), j3 18 (17-19), j4 9 (8-9), j5 9 (8-9), j6 11 (10-11), J5 5 (4-6), z2 15 (13-16), z4 17 (15-21), z5 9 (8-9), Z4 43 (4246), Z5 53 (51-54), s4 57 (56-58), S2 14 (13-16),S5 9 (8-10), r3 22 (20-23), R1 9 (7-10). Escudos ventrais lisos. Distâncias entre St1-St3 56 (53-58), St2-St2 55 (55-56) e St5St5 40 (38-43). Escudo ventrianal com um par de solenóstomos pouco discerníveis: comprimento do escudo 100 (93-109), largura ao nível dos ângulos anteriores 139 (128151). Peritrema se estendendo anteriormente a j1. Dígito móvel com comprimento de 19 (18-19), com 1 dente; dígito fixo com comprimento de 17 (16-18), com 7 dentes. Nenhuma macroseta discernível nas pernas. Espermadáctilo com comprimento de 14.

LOCALIDADE E MATERIAL TIPO: Holótipo fềmea, alótipo macho mais 4 parátipos fềmeas e 2 parátipos machos (ESALQ/USP) coletados em Pariquera-Açu, São Paulo, Brasil, IV-98, M.S. Zacarias, em Aparisthmium cordatum (A. Juss.) Baill.

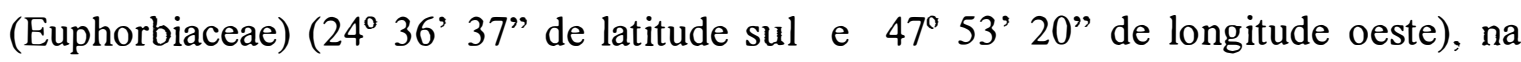
"Estação Experimental J. Cione" do Instituto Agronômico de Campinas. 3 parátipos fềmeas mais 1 parátipo macho (OSAL), idem.

ETIMOLOGIA: retroacuminatus, refere-se à elevação dorsal apresentada pelas fềmeas da espécie, posteriormente às setas j6. 


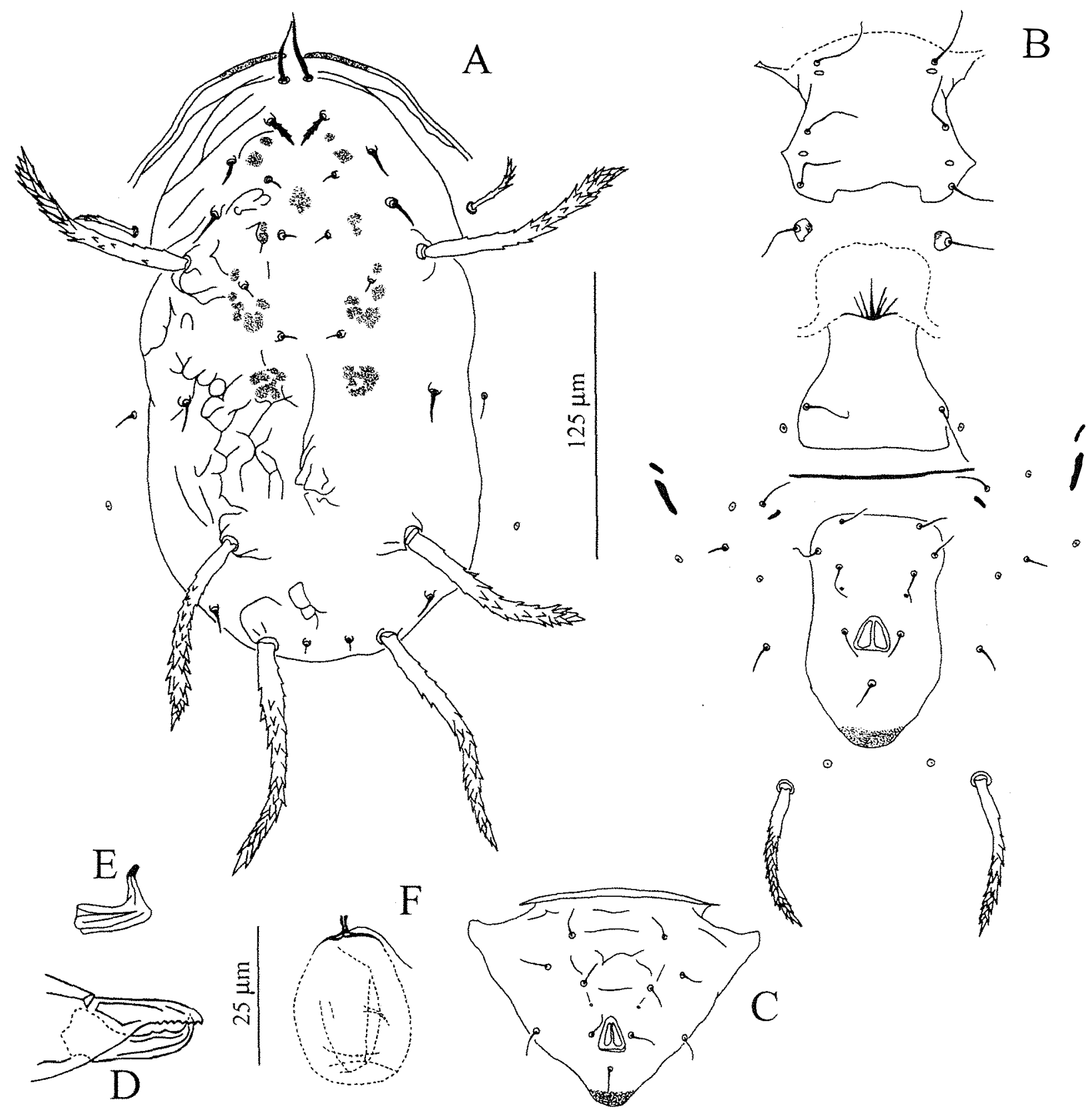

Figura 1: Proprioseius retroacuminatus sp. n.: A - Placa dorsal da fềmea; B - Placas ventrais da fềmea; C - Placa ventrianal do macho; D - Quelícera da fềmea; E-Espermadáctilo; F-Espermateca. 


\section{Phytoseius Ribaga}

Phytoseius Ribaga, 1904: 177; Chant \& Yoshida-Shaul, 1992: 11-12; Chant \& McMurtry, 1994: 232

Phytoseius (Phytoseius) Wainstein, 1959: 1361.

Phytoseius (Dubininellus) Wainstein, 1959: 1361.

Dubininellus, Muma 1961: 293.

Phytoseius (Pennaseius), Pritchard \& Baker 1962: 223-224.

Pennaseius, Schuster \& Pritchard 1963: 279.

Typhlodromus (Phytoseius) Van der Merwe, 1968: 100-101.

\section{Phytoseius globuliformis Zacarias \& Moraes, espécie nova (Figura 2)}

DiAGNOSE: Difere de todas as espécies do grupo de espécies plumifer, como caracterizado por Chant \& McMurtry (1994), por apresentar o cálice da espermateca globular e a quarta macrosseta no telotarso IV.

FÊMEA: Escudo dorsal rugoso; as medições médias de 8 espécimens, seguidas (entre parênteses) pelas respectivas amplitudes são: comprimento do escudo dorsal 274 (263-281), largura do escudo dorsal 137 (133-141), jl 18 (16-19), j3 30 (2934), j4 6 (5-7), j5 6 (4-7), j6 7 (6-7), J2 5 (5-6), J5 6 (6-7), z2 7 (6-8), z3 36 (33-37), z4 8 (6-9), z5 5 (4-5), Z4 48 (47-51), Z5 53 (50-55), s4 48 (45-50), s6 56 (53-58), r3 34 (3135), R1 11 (9-13). Escudos ventrais lisos. Escudo esternal com três pares de setas e dois pares de solenóstomos; distâncias entre St1-St3 61 (60-62), St2-St2 67 (65-70) e St5St5 55 (52-58). Com dois pares de escudos metapodais. Escudo ventrianal com três pares de setas pré-anais e um par de solenóstomos; comprimento do escudo 90 (85-94), largura ao nível de Zv2 50 (46-54), largura ao nível do ânus 49 (47-50). Setas Zvl, Zv3, e Jv5 localizadas no tegumento em torno do escudo ventrianal. Peritrema se estendendo anteriormente a j1. Dígito móvel com comprimento de 28 (26-29), com 1 dente; dígito fixo com comprimento de 25 (23-30), com 3 dentes. Comprimento das macrosetas da perna IV: Sge 27 (26-28), Sti 26 (25-28), St (basitarso) 28 (26-32) e St (telotarso) 31 
(29-33). Cálice da espermateca em forma globular com profundidade de 12 (10-13).

MACHO: Semelhante à fềmea; as medições médias de 4 espécimens, seguidas (entre parênteses) pelas respectivas amplitudes são: comprimento do escudo dorsal 224 (216-232), largura do escudo dorsal 142 (135-148), j1 17 (15-19), j3 26 (2428), j4 6, j5 5 (4-6), j6 6 (5-6), J2 5, J5 4 (3-5), z2 7 (6-8), z3 29 (25-30), z4 7 (6-8), z5 4, Z4 32 (31-33), Z5 25 (23-25), s4 37 (35-38), s6 41 (38-43), r3 27 (26-29), R1 7 (6-9). Escudos ventrais lisos. Distâncias entre St1-St3 60 (58-62), St2-St2 57 (57-58) e St5St5 35 (34-35). Escudo ventrianal rugoso com um par de solenóstomos; comprimento do escudo 87 (83-89), largura ao nível dos ângulos anteriores 123 (116-133). Peritrema se estendendo anteriormente a j1. Dígito móvel com comprimento de 19 (18-19), com 1 dente; dígito fixo com comprimento de 16 (14-17), com 7 dentes. Comprimento das macrosetas da perna IV: Sge 18 (17-18), Sti 14 (13-15), St (basitarso) 24 (21-25) e St (telotarso) 26 (25-27). Espermadáctilo com comprimento de 13 (12-13).

LOCALIDADE E MATERIAL TIPO: Holótipo fêmea e alótipo macho mais 7 parátipos fềmeas e 3 parátipos machos (ESALQ/USP) coletados em Pariquera-Açu, São Paulo, Brasil, IV-98, M.S. Zacarias, em Crescentia cujete L. (Bignoniaceae) (24 $36^{\prime}$ 40" de latitude sul e $47^{\circ} 53^{\prime}$ 05" de longitude oeste); 3 parátipos fềmeas (OSAL) coletados em Pariquera-Açu, São Paulo, Brasil, IV-98, M.S. Zacarias, em Alchornea sidifolia M. Arg. (Euphorbiaceae) (24 36' 46" de latitude sul e $47^{\circ} 53^{\prime} 11^{\prime \prime}$ de longitude oeste), ambas na Estação Experimental J. Cione do Instituto Agronômico de Campinas.

ETIMOLOGIA: globuliformis, referente à forma do cálica da espermateca.

Observações: Não é possível se posicionar esta espécie dentro de nenhum dos grupos de espécies reconhecidos por Chant \& Mcmurtry (1994). A presença das setas J2 e R1 a colocaria no grupo de espécies plumifer. Já o formato do cálice da espermateca e a presença da macrosseta no telotarso da perna IV a colocaria no grupo de espécies horridus, não fosse a presença da seta $\mathrm{R} 1$, que é encontrada nas espécies do grupo purseglovei, às quais, entretanto, apresentam cálice da espermateca tubular na maior parte de sua extensão. 


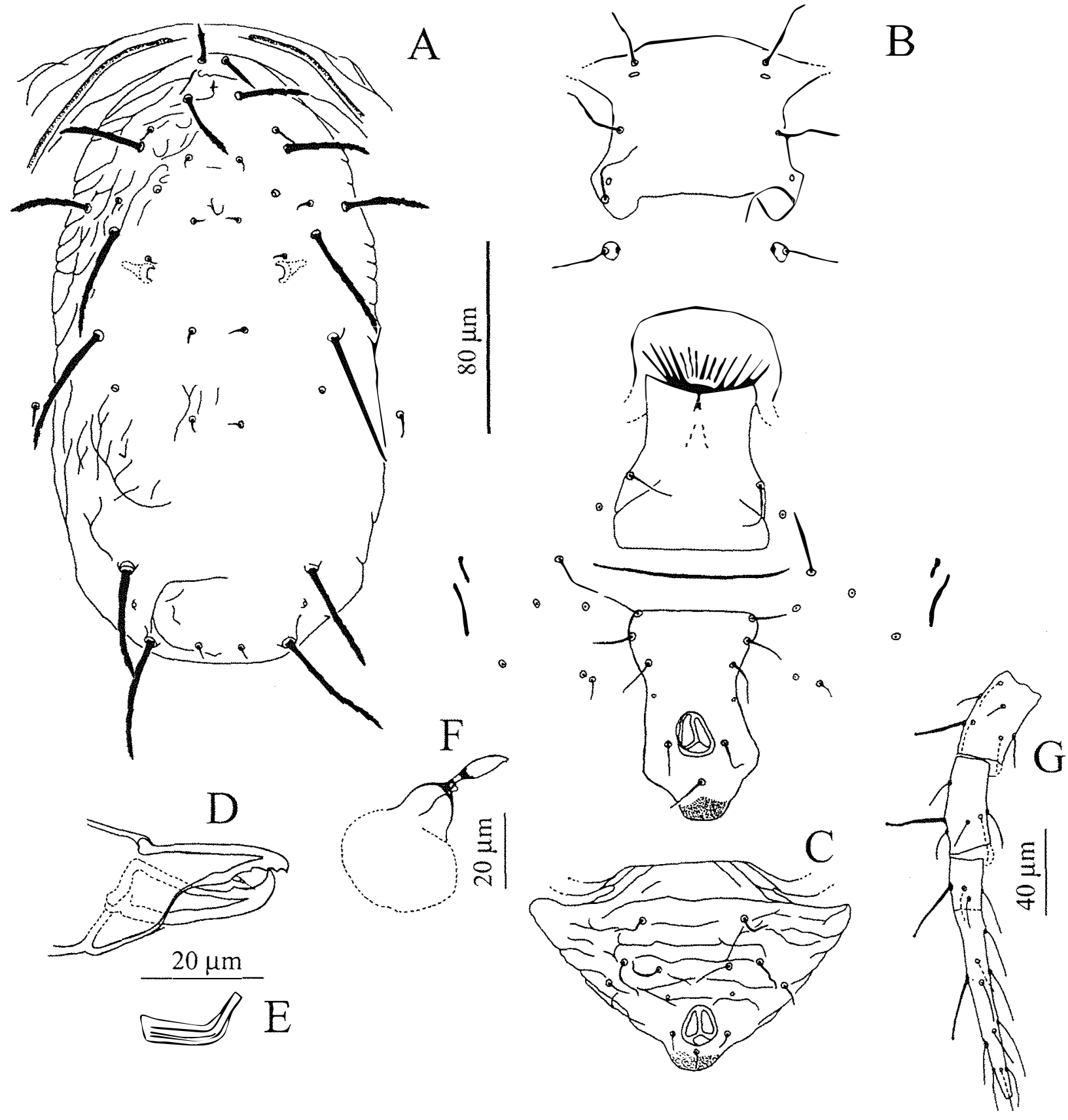

Figura 2: Phytoseius globuliformis sp. n.: A - Placa dorsal da fềmea; B - Placas ventrais da fềmea; C - Placa ventrianal do macho; D - Quelícera da fềmea; E - Espermadáctilo; F - Espermateca; G - Genu, tíbia e tarso da perna IV. 


\section{Kampimodromus Nesbitt}

Kampimodromus Nesbitt 1951: 52; Schuster \& Pritchard 1963: 225; Muma 1963: 12; Muma \& Denmark 1968: 234.

Amblyseius (Kampimodromus), Pritchard \& Baker 1962: 294.

Amblyseius (Kampimodromus), Wainstein 1962: 14 (em parte); Muma 1963: 12.

Paradromus Muma 1961: 286; Muma 1963: 12.

\section{Kampimodromus multicupuli Zacarias \& Moraes, espécie nova (Figura 3)}

DiAGNOSE: Esta espécie difere das demais espécies do gênero pela presença de um grande número de depressões no escudo dorsal.

FÊMEA: Escudo dorsal rugoso; com 53 depressões distribuídas pela placa dorsal; as medições médias de 8 espécimens, seguidas (entre parênteses) pelas respectivas amplitudes são: comprimento do escudo dorsal 292 (278-306), largura do escudo dorsal 172 (164-180), j1 17 (15-19), j3 18 (17-19), j4 10 (8-12), j5 9 (9-10), j6 11 (9-13), J2 12 (11-15), J5 10 (7-12), z2 21 (20-22), z4 33 (30-37), z5 12 (10-13), Z1 33 (27-44), Z4 51 (46-57), Z5 50 (46-52), s4 31 (27-36), S2 37 (34-42), S5 17 (16-21), r3 16 (16-18). Escudos ventrais lisos. Escudo esternal pouco esclerotizado com três pares de setas e dois pares de solenóstomos pouco discerníveis; distâncias entre Stl-St3 61 (59-66), St2-St2 51 (48-53) e St5-St5 46 (44-48). Com dois pares de escudos metapodais. Escudo ventrianal com três pares de setas pré-anais e um par de solenóstomos; comprimento do escudo 86 (79-92), largura ao nível de Zv2 48 (39-51), largura ao nível do ânus 53 (49-56). Setas Zvl, Zv3, e Jv5 localizadas no tegumento em torno do escudo ventrianal. Peritrema se estendendo anteriormente a j1. Dígito móvel com comprimento de 21 (21-22), com 1 dente; dígito fixo com comprimento de 19 (1821), com 2 dentes. Macrosetas ausentes. Cálice da espermateca tubular, 20 (18-22) de comprimento, normalmente esclerotizado em alguns espécimens ou levemente esclerotizado em outros; alguns espécimens com cálice normalmente esclerotizado em um lado e pouco esclerotizado em outro lado. 
MACHO: Semelhante à fềmea, também apresentando depressões no escudo dorsal; as medições médias de 4 espécimens, seguidas (entre parênteses) pelas respectivas amplitudes são: comprimento do escudo dorsal 231 (216-239), largura do escudo dorsal 139 (126-147), j1 13 (10-15), j3 15 (14-16), j4 10 (9-12), j5 10 (9-10), j6 11 (9-12), J2 10 (9-10), J5 8 (6-9), z2 16 (14-19), z4 20 (18-23), z5 11 (9-13), Z1 19 (15-21), Z4 28 (26-30), Z5 30 (28-31), s4 20 (18-22), S2 23 (21-24), S5 13 (11-15), r3 14 (13-14). Escudos ventrais lisos. Distâncias entre St1-St3 57 (54-59), St2-St2 44 (4345) e St5-St5 27 (25-28). Escudo ventrianal rugoso com um par de solenóstomos; comprimento do escudo 91 (79-114), largura ao nível dos ângulos anteriores 91 (71112). Peritrema se estendendo anteriormente a j1. Dígito móvel com comprimento de 17 , com 1 dente; dígito fixo com comprimento de 15 (14-15), com 2 dentes. Macrosetas ausentes. Espermadáctilo com comprimento de 17 (16-19).

LOCALIDADE E MATERIAL TIPO: Holótipo fềmea, alótipo macho, 4 parátipos fêmeas e 2 parátipos machos (ESALQ/USP) coletados em Iguape, São Paulo, Brasil, VII-99, M.S. Zacarias, em Inga uruguensis Hook \& Am. (Mimosaceae), margem do Rio Ribeira do Iguape. 3 parátipos fềmeas e 1 parátipo macho (OSAL), idem.

ETTMOLOGIA: multicupuli, referente ao grande número de depressões no escudo dorsal. 


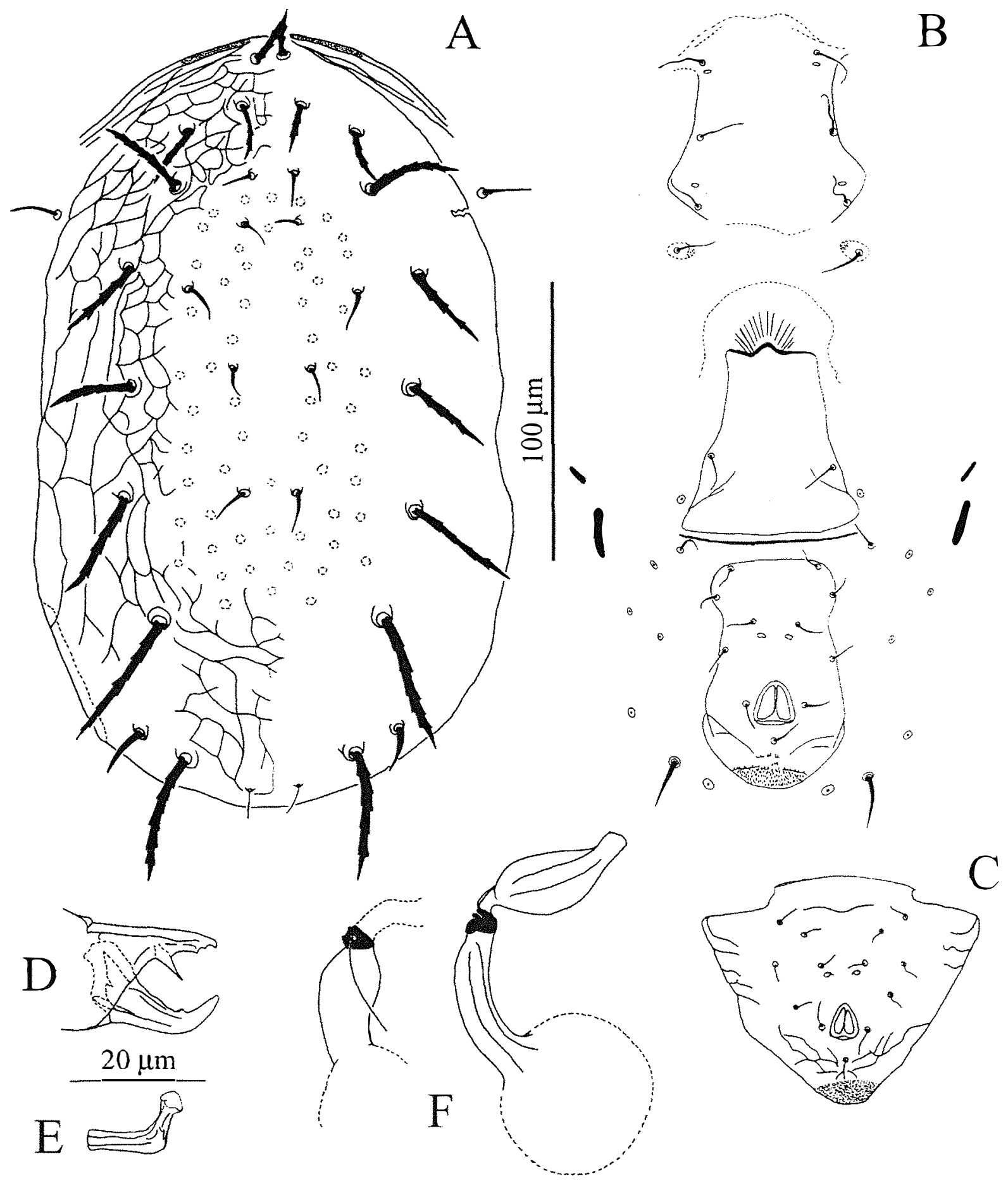

Figura 3: Kampimodromus multicupuli sp. n.: A - Placa dorsal da fềmea; B - Placas ventrais da fềmea; C - Placa ventrianal do macho; D - Quelícera da fềmea; E-Espermadáctilo; F - Espermateca. 


\section{Galendromimus Muma}

Galendromimus Muma, 1961: 297-298.

Chanteius (Deleonseius), Wainstein 1962: 19 (sinonímia segundo Chant \& McMurtry, 1994).

Nothoseius, De Leon 1965: 127-128 (sinonímia segundo Chant \& McMurtry, 1994).

\section{Galendromimus paulista Zacarias \& Moraes, espécie nova (Figura 4)}

DiAGNOSE: Esta espécie difere de G. tunapunensis e G. alveolaris pela ausência de J2; além disso, difere de G. alveolaris por apresentar o peritrema alcançando o nível de j1; difere de G. borinquensis por apresentar Jv3, por não apresentar Jv4 e Zv3 e pelo formato da espermateca.

FÊMEA: Escudo dorsal reticulado; as medições médias de 8 espécimens, seguidas (entre parênteses) pelas respectivas amplitudes são: comprimento do escudo dorsal 312 (308-320), largura do escudo dorsal 173 (167-180), j1 23 (20-26), j3 18 (1519), j4 6 (5-7), j5 6 (5-7), j6 6 (6-7), J5 7 (5-8), z2 36 (32-39), z3 56 (50-62), z4 57 (5460), z5 7 (6-8), Z4 86 (79-92), Z5 89 (84-93), s4 63 (58-68), S2 75 (71-81), S5 14 (1216), r3 30 (28-32). Escudos ventrais são lisos. Escudo esternal pouco esclerotizado, com três pares de setas e dois pares de solenóstomos pouco discerníveis; distâncias entre St1-St3 53 (51-56), St2-St2 65 (60-70) e St5-St5 67 (63-72). Com dois pares de escudos metapodais. Escudo ventrianal com três pares de setas pré-anais e um par de solenóstomos; comprimento do escudo 100 (93-103), largura ao nível de Zv2 69 (6374), largura ao nível do ânus 72 (66-80). Setas Zv1 e Jv5 localizadas no tegumento em torno do escudo ventrianal. Peritrema se estendendo anteriormente a j1. Dígito móvel com comprimento de 25 (24-26), sem dentes; dígito fixo com comprimento de 23 (2225), com 3 dentes. Macrosetas ausentes. Cálice da espermateca tubular alongado, com comprimento de 45 (40-52).

MACHO: Semelhante à fêmea; as medições médias de 4 espécimens, seguidas (entre parênteses) pelas respectivas amplitudes são: comprimento do escudo 
dorsal 239 (227-245), largura do escudo dorsal 145 (138-151), j1 18 (18-19), j3 5 (1415), j4 6 (5-6), j5 6 (6-7), j6 6 (6-7), J5 6 (5-7), z2 27 (26-28), z3 37 (36-38), z4 37 (3638), z5 6 (5-7), Z4 46 (44-48), Z5 52 (44-57), s4 39 (38-41), S2 44 (43-46), S5 11 (1012), r3 24 (21-30). Escudos ventrais lisos. Distâncias entre St1-St3 54 (53-55), St2-St2 60 (57-61) e St5-St5 45 (42-47). Escudo ventrianal liso com 4 pares de setas pré-anais e um par de solenóstomos; comprimento do escudo 100 (94-105), com largura ao nível dos ângulos anteriores 141 (134-146). Peritrema se estendendo anteriormente a j1. Dígito móvel com comprimento de 19 (18-20), com 1 dente; dígito fixo com comprimento de 18 (17-19), com 2 dentes. Macrosetas ausentes. Espermadáctilo com comprimento de 19 (15-22).

LOCALIDADE E MATERIAL TIPO: Holótipo fềmea e alótipo macho mais 4 parátipos fêmeas e 2 machos (ESALQ/USP) coletados em Piracicaba, São Paulo, Brasil, VI-98, M.S. Zacarias, em C. floribundus Spreng. (Euphorbiaceae) (22 42'53" de latitude sul e $47^{\circ} 37^{\prime}$ '19" de longitude oeste) Campus Universitário da Escola Superior de Agricultura "Luiz de Queiroz". 3 parátipos fềmeas e 1 parátipo macho (OSAL), idem.

ETIMOLOGIA: paulista, referente a origem dos espécimens desta nova espécie, Estado de São Paulo.

OBSERVAÇÕES: A ausência da seta J2 nesta espécie é uma característica rara na subfamília Typhlodrominae, apenas $G$. borinquencis também a tem ausente. Não é possível se posicionar esta espécie dentro de nenhum dos subgêneros reconhecidos por Chant \& McMurtry (1994). A presença de Jv3, de poucos dentes no dígito fixo da quelícera, a ausência de Jv4 e Zv3, e a forma do cálice da espermateca a colocaria no subgênero Galendromimus, grupo de espécies alveolaris, não fosse pela ausência da seta J2 e a forma serreada e robusta da seta Jv5. 

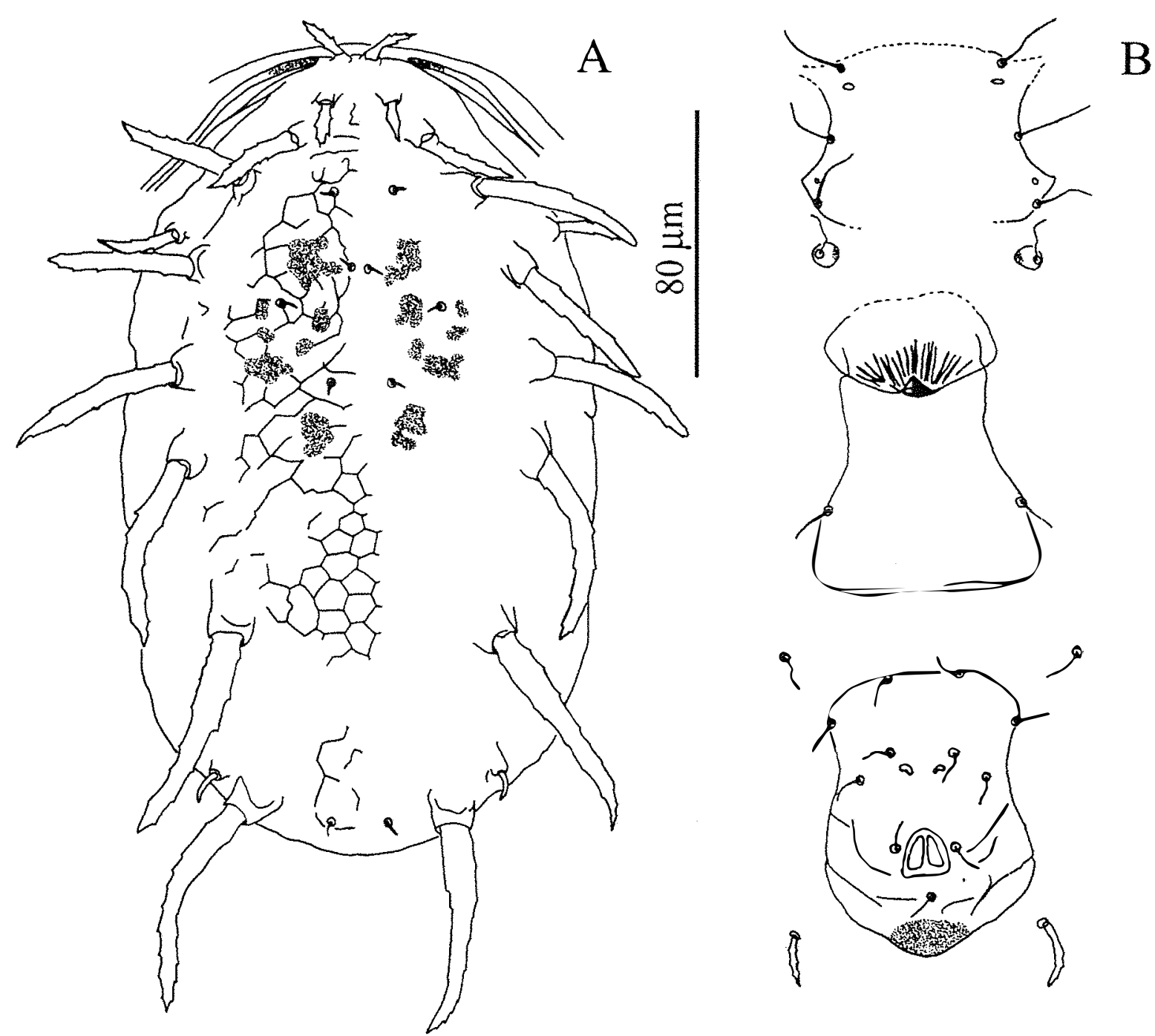

B
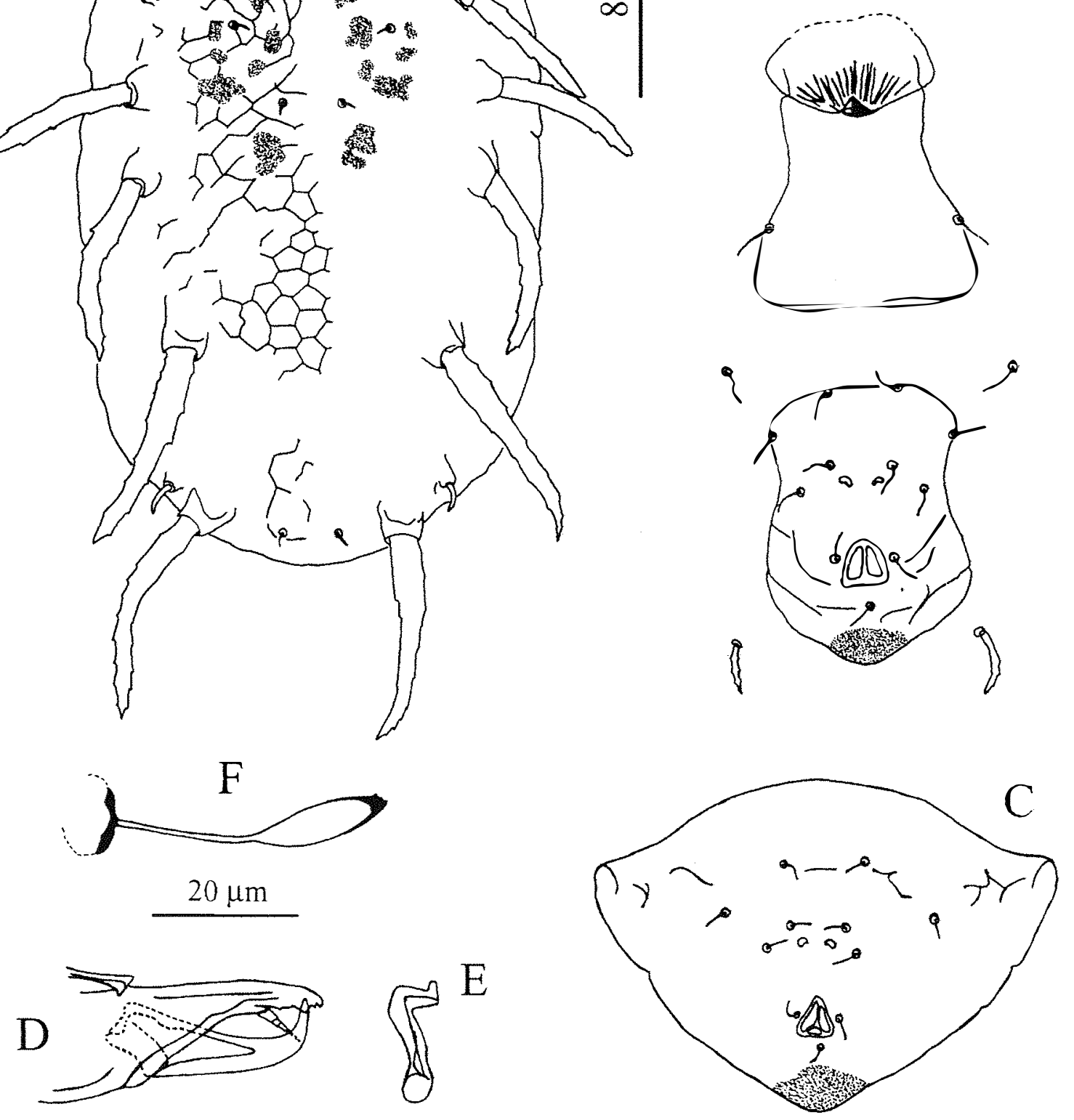

Figura 4: Galendromimus paulista sp. n.: A - Placa dorsal da fềmea; B - Placas ventrais da fềmea; C - Placa ventrianal do macho; D - Quelícera da fềmea; E-Espermadáctilo; F- Espermateca. 


\title{
5 ÁCAROS DA FAMÍLIA TYDEIDAE (ACARI: ACTINEDIDA) ASSOCIADOS A EUFORBIÁCEAS (EUPHORBIACEAE) EM TRÊS LOCALIDADES DO ESTADO DE SÃO PAULO
}

\author{
Autor: MAURICIO SERGIO ZACARIAS \\ Orientador: PROF. DR. GILBERTO JOSÉ DE MORAES
}

\section{RESUMO}

Não apenas no Brasil , mas em todo o mundo, o conhecimento da biologia e diversidade dos ácaros da família Tydeidae ainda é muito fragmentário. Estes estão entre os ácaros mais abundantes, especialmente sobre plantas superiores. $\mathrm{O}$ presente trabalho apresenta uma revisão histórica enfocando as principais publicações que tratam da biologia e sistemática dos ácaros desta família, com ênfase em sua importância como inimigos naturais de outros ácaros. Foram coletados espécimens de 29 espécies pertencentes a 18 gêneros. Vinte e duas destas espécies e 8 destes gêneros são novos para a ciência. Isto significa acrescentar ao menos 26 espécies ao número de espécies já relatadas no Brasil. 


\section{MITES OF THE FAMILY TYDEIDAE (ACARI: ACTINEDIDA) ASSOCIATED WITH EUPHORBIACEOUS PLANTS (EUPHORBIACEAE) IN THREE LOCALITIES OF THE STATE OF SÃO PAULO}

Author: MAURICIO SERGIO ZACARIAS Adviser: PROF. DR. GILBERTO JosÉ DE MORAES

\section{SUMMARY}

Not only in Brazil, but all over the world knowledge of the biology and diversity of mites of the family Tydeidae are still fragmentary. Those are some of the most abundant mites, especially on higher plants. This work presents a historical review on the main publications on biology and systematics of mites of this family, emphasizing their importance as natural enemies of other mites. Tydeids of 29 species belonging to 18 genera were collected. Twenty two of those species and 8 of those genera are new to science. At least 26 of the species have been found for the first time in Brasil. 


\subsection{Introdução}

Apesar de estarem entre os ácaros mais abundantes da natureza, especialmente sobre plantas superiores, o conhecimento da diversidade dos ácaros da família Tydeidae ainda é muito fragmentário, não apenas no Brasil, mas em todo o mundo.

O presente trabalho apresenta inicialmente uma revisão histórica enfocando as principais publicações que tratam de aspectos de biologia e sistemática. Destaque é dado a importância destes ácaros como inimigos naturais de outros ácaros.

Em seguida é apresentada a lista de espécies de ácaros desta família com ocorrência relatada para o Brasil, finalizando-se com a apresentação dos resultados inéditos para o conhecimento destes ácaros do Estado de São Paulo.

As espécies de difícil identificação, principalmente devido às descrições inadequadas, são discutidas com base na literatura disponível. 


\subsection{Revisão da Literatura}

\subsubsection{A família Tydeidae Kramer, 1877}

Apesar de serem ácaros de fácil reconhecimento pelo seu formato geral e especialmente sua forma de locomoção, a família Tydeidae é de difícil caracterização (Baker, 1965).

São pequenos a muito pequenos (entre 150 e $500 \mu \mathrm{m}$ de comprimento), com o tegumento pouco ou não esclerotizado (Baker \& Warton, 1952; Baker, 1965). O tegumento é fino e delicado predominantemente com estriações lobuladas ou, em alguns grupos com padrão reticulado (Baker \& Warton, 1952). Quando vivos, apresentam cor amarela, alaranjada, marrom, preta, vermelha ou verde, sendo esta geralmente devida ao conteúdo alimentar no sistema digestivo.

Apresentam poucas setas táteis no corpo e um único par de tricobótrias no aspidossoma. O aspidossoma e o opistossoma são, geralmente, distinguidos por uma visível sutura transversal. As pernas apresentam 5 ou 6 segmentos distintos e o tarso tem um curto pretarso, composto de duas garras e um pulvilo provido de pelos (as espécies da subfamília Pronematinae não apresentam garras ou pulvilo na perna $\mathrm{I}$, sendo que nas espécies do gênero Proctotydaeus o pulvilo pode estar ausente também nas demais pernas). A quelícera apresenta uma parte basal mais grossa e um dígito fixo bem acentuado do qual um dígito móvel afilado, quase reto e não retrátil, se estende. As bases quelicerais são fundidas ou independentes (Baker, 1965; Krantz \& Lindquist, 1979). Não apresentam ventosas genitais (Baker \& Warton, 1952).

Apesar da família ter sido estabelecida por Kramer em 1877, baseado na 
descrição de Tydeus Koch, 1835 (Baker, 1965; Kazmierski, 1998a), pouco se conhecia a respeito da família Tydeidae até a publicação da monografia de Thor (1933), baseada quase que exclusivamente em pesquisa de literatura. A primeira ampla revisão dos gêneros desta família somente foi realizada por Baker (1965), que considerou válidos 15 gêneros, 6 dos quais foram então descritos. Já nesta ocasião, o autor alertou para a necessidade de se realizar novas coletas em localidades tipo das espécies européias para uma adequada caracterização destas, tendo em vista a grande fragilidade destes ácaros.

Três dos gêneros mais numerosos foram revisados após aquele trabalho: Pronematus Canaestrini, 1886 (Baker, 1968a), apresentando 15 espécies; Lorryia Oudemans, 1925 (Baker, 1968b), dividido em 5 grupos de espécies, totalizando 30 espécies; e Tydeus Koch, 1835 (Baker, 1970), apresentando 3 subgêneros e 26 espécies.

André (1980) conclui a revisão da família Tydeidae em uma série de 4 publicações (André, 1979, 1981a e 1981b) com o estabelecimento de 42 gêneros distribuídos em sete subfamílias, e retornand o o gênero Proctotydeus Berlese da família Iolinidae à família Tydeidae, que havia sido transferido para a primeira por Baker (1965). Kazmierski (1998b) revisou aquele gênero, Proctotydeus Berlese e, neste trabalho, lista todas as espécies, conhecidas pelo mesmo até aquele momento, pertencentes à subfamília Pronematinae, à qual Proctotydeus pertence.

Kazmierski (1989b) iniciou um processo de revisão da subfamília Tydeinae (a mais importante em termos de número de espécies), redefinindo alguns gêneros estabelecidos por André (1980) em desacordo com o Código Internacional de Nomenclatura Zoológica. Este processo terminou em 1998 (Kazmierski, 1998a) com o estabelecimento de 21 gêneros e elaboração de chaves dicotômicas para a identificação destes e das espécies conhecidas do autor até aquele momento.

Kazmierski (1996a) revisou a subfamília Pretydeinae, estabelecendo 15 espécies em 4 gêneros. 


\subsubsection{Aspectos biológicos}

Tideídeos ocorrem em todos continentes e todas zonas climáticas. Muitas espécies são encontradas em musgos, líquens ou nas folhas das plantas em associação com outras colônias de ácaros.

Ácaros tideídeos podem ser os mais abundantes dentre os que ocorrem nas folhas em mata ou em cultivo. Estes foram os ácaros mais abundantes encontrados por Walter \& O'Dowd (1992) em folhas de plantas lenhosas de mata nativa na Austrália (31\% do total) e também por Pallini Filho et al. (1992) em folhas de cafeeiro, especialmente dentro das domáceas.

Autores têm indicado o possível hábito fitófago de certos tideídeos com base na coloração verde que apresentam certas espécies de Lorryia, Paralorryia e Tydeus (Karg, 1975; Krantz \& Lindquist, 1979; Flechtmann \& Arleu, 1984). Estas indicações devem entretanto ser vistas com cautela, McCoy et al. (1967) observaram que Parapronematus acaciae Baker adquire coloração âmbar ao se alimentar de fungos de coloração amarelada, ou coloração verde, ao se alimentar de um fungo que produz conídios verdes. Fungos e liquens são comuns nos ramos e troncos de árvores onde abundam tideídeos (Krantz \& Lindquist, 1979).

Representantes do gênero Pronematus se alimentam, reproduzem e prosperam com pólen de taboa (Typha sp.) em laboratório e no campo (Calvert \& Huffaker, 1974). A abundância de vários pólens dispersos pelo vento na folhagem das árvores pode explicar porque alguns tideídeos podem ser encontrados em grande número nas árvores, como observado em abacate (Fleschner \& Arakawa, 1953), em citros (Gerson, 1968) e em pinheiros e aveleira (Krantz \& Lindquist, 1979). Até o momento nenhuma indicação de que estes ácaros pudessem estar se alimentando destas plantas ou de outros organismos sobre elas tem sido constatada.

Alguns autores relatam a alimentação direta em tecidos verdes de folhas ou frutos jovens por tideídeos em uma grande variedade de hospedeiros; entretanto, observações conflitantes a respeito das mesmas espécies, dão razão a dúvidas. Tydeus californicus (Banks), por exemplo, foi considerado como um predador do ácaro das 
gemas dos citros (Eriophyidae) (Baker \& Warton, 1952), como fitófago em abacate (Fleschner \& Arakawa, 1953), batata doce (Zaher \& Shehata, 1963; Wahab et al.,1974), Hibiscus rosa-sinensis L. e Duranta plumieri Jacq. (Wahab et al.,1974). Tydeus caudatus (Dosse) comprovadamente se alimenta das folhagens de macieiras e pode atingir níveis danosos nesta cultura na Alemanha (Karg, 1971). Uma espécie não identificada pertencente ao gênero Triophtydeus Wood é considerada uma séria praga da videira na Moldávia, causando descoloração característica ao longo das nervuras (Malchenkova, 1967, citada por Baker, 1970 e Krantz \& Lindquist, 1979). Lorryia formosa Cooreman foi observada causando danos em brotações e frutos novos de plantas cítricas em Marrocos e no Brasil (Smirnoff, 1957; Flechtmann, 1973). Flechtmann (1973) acredita que o ácaro se alimenta apenas esporadicamente nos frutos cítricos. Smimoff (1957) observou que a abundância de L. formosa estava correlacionada com a abundância de excreções açucaradas produzidas por ninfas de cochonilhas e com a cobertura preta de micélios que se desenvolvia nas excreções (fumagina), que eram igualmente atrativos como alimento. Gerson (1982) considerou $L$. formosa um agente sanitificante em citros ao comparar dois pomares altamente infestados pela cochonilha Saissetia oleae (Olivier); o pomar menos infestado com fumagina apresentava uma população muito maior do ácaro. Aquele autor conduziu experimentos de exclusão do ácaro com uso de acaricida, que revelaram um aumento significativo na infestação por fumagina.

P. acaciae foi considerado por Baker (1965) como predador de eriofídeos em citros; no entanto estudos de laboratório conduzidos por McCoy et al. (1967) mostraram que este ácaro não preda ácaros eriofideos ou tetraniquídeos, mas se alimenta e se desenvolve em fungos que ocorrem comumente em folhas de citros.

Embora Baker \& Warton (1952) não considerassem os tideídeos importantes no controle de pragas, estudos mais recentes têm refutado esta afirmação. Estes ácaros têm sido considerados como um dos alimentos alternativos mais importantes de ácaros predadores fitoseídeos na América do Norte (Baker, 1970; Knop \& Hoy, 1983b). Pallini Filho et al. (1992) observaram, através da dilaceração de tecidos periféricos de domáceas em folhas de cafeeiro, que ninfas de fitoseídeos se alimentavam 
dos ácaros tideídeos ali presentes.

Homeopronematus anconai (Baker) é uma importante presa alternativa para Typhlodromus occidentalis Nesbitt, fitoseídeo muito utilizado mundialmente no controle de pragas em diferentes culturas. $H$. anconai tem também sido considerado um predador generalista, alimentando-se de ácaros eriofídeos e ovos de Brevipalpus lewisi McGregor (Acari, Tenuipalpidae) em videira (Brodeur et al., 1997; Hessein \& Perring, 1988).

Tydeídeos tem sido encontrados predando eriofídeos especialmente em pomares e hortaliças (Knop \& Hoy, 1983a; Laing \& Knop, 1983; Perring \& McMurtry, 1996). Hessein \& Perring (1986) concluíram que, em condições de plantio em estufa, $H$. anconai causou um impacto significativo em populações do eriofídeo do bronzeamento do tomateiro Aculops lycopercisi (Massee). Perring \& McMurtry (1996) consideram bastante promissor o uso de $H$. anconai para o controle de eriofídeos.

Uma área de estudo ainda quase inexplorada é a da utilização de artrópodos como inimigos naturais de patógenos de plantas. A capacidade e mesmo preferência de várias espécies de tideídeos em se alimentar de esporos e hifas de fungos que se desenvolvem sobre as plantas, deve ser melhor estudada. O tideídeo Tydeus lambi Baker, 1970 (= Orthotydeus lambi), foi capaz de suprimir o desenvolvimento do patógeno causador do míldio da videira (Uncinula necator (Schwein.) Burrill) em videiras selvagens ou cultivadas (English-Loeb et al., 1999) em condições de estufa e de campo.

Proctotydaeus (Neotydaeolus) therapeuticos (Flechtmann \& Camargo, 1974) foi considerado responsável por uma redução drástica da incidência de um fungo, não identificado, causador de morte de crias de Trigona (Scaptotrigona) postica (Latreille) (Flechtmann \& Camargo, 1974).

A fitofagia entre os tideídeos parece ser não obrigatória, um fenômeno incidental que surgiu como uma ramificação da fungivoria, a qual em seu turno provavelmente surgiu de um modo predatório primitivo mais generalizado. A variedade de hábitos alimentares exibidos pelos tideídeos, associada à aparente falta modificações concomitantes na estrutura das quelíceras. Alguém poderia esperar que tideídeos, que 
geralmente apresentam a base das quelíceras fundidas, dígitos fixos das quelíceras e dígitos móveis como agulhas, estariam em uma posição de facilmente se adaptarem à alimentação obrigatória em plantas superiores. No entanto, até o momento, nenhum grupo de tideídeos se tornou especializado em fitofagia. Em geral, tideídeos não são especializados em seus hábitos alimentares e apresentam propensão à fitofagia. Sua falta de especialização sugere que esta família está em uma fase de transição evolucionária e que a fitofagia pode bem ser a principal direção para seu desenvolvimento futuro (Krantz \& Lindquist, 1979).

Apesar de serem de longe mais conhecidos por viver sobre plantas ou no solo, os tideídeos tem sido relatados também em associação com o ser humano e animais domésticos. Tydeus molestus Moniez, é considerado de alguma nocividade ao homem e animais domésticos na Bélgica por causar irritação a estes devido às suas picadas (Baker \& Warton, 1952; Kazmierski, 1998a). Wisniewski et al. (1996) determinaram que algumas espécies de ácaros que ocorrem em feno podem agir como vetores e/ou reservatórios do agente causal da "scrapie", encefalopatia espongiforme que afeta os ovinos, recentemente relatada no Estado do Paraná; dentre aquelas espécies, citam Tydeus interruptus Thor. A identificação desta espécie foi posta em dúvida por Kazmierski (1998a) pelo fato de ser uma espécie inadequadamente descrita, indicando o autor que de qualquer forma se trata de um tideídeo da subfamília Tydeinae.

\subsubsection{Tydeidae no Brasil}

André \& Naudo (1965) descrevem Lorryia schusteri (André \& Naudo) (=Tydeus (Pertydeus) schusteri), o primeiro tideídeo descrito do Brasil, coletado em rochedos à beira-mar em São Sebastião, Estado de São Paulo.

Flechtmann (1971) descreveu "Tydeus (Tydeus)" mali Flechtmann coletado de folhas de macieira em Campos do Jordão, Estado de São Paulo. Kazmierski (1998a) classificou esta espécie no que chamou de Unidade Genérica cf. Nudilorryia, criada para comportar esta espécie, que difere de Nudilorryia s.s. por apresentar a 
fórmula epimeral 3-2-4-2.

Em uma seqüência de trabalhos descrevendo tideídeos encontrados em favos de abelhas nativas sem ferrão da subfamília Meliponinae (Hymenoptera: Apidae), foram descritas mais 4 espécies e um gênero: Proctotydeus (Neotydeolus) therapeutikos (Flechtmann \& Camargo, 1974), em ninhos de Trigona (Scaptotrigona) postica (Latreille) em São Paulo; Proctotydeus (Neotydeolus) partamonae Rosa \& Flechtmann, 1983, em ninho de Partamona (Partamona) sp., Melipona lateralis Erickson em Roraima e ninho de Partamona (Partamona) pearsoni (Schwartz) no Amazonas; Proctotydaeus (Neotydeolus) alveari Rosa, André \& Flechtmann, 1985, em ninho de Melipona pernigra Moure \& Kerr no Amazonas; e Melissotydeus macrosolenus André, 1985. em ninhos de Partamona (Partamona) mourei em Roraima e Frieseomellita modesta no Amazonas.

Flechtmann (1995) descreveu Pretvdeus reticulatus coletado em folhas velhas de bambú no Rio de Janeiro.

Outras espécies relatadas para o Brasil estão relacionadas na Tabela 1. 


\subsection{Metodologia}

Foram realizadas coletas em 3 localidades nos municípios de PariqueraAçu, Cananéia e Piracicaba. Na região de Pariquera-Açu os ácaros foram coletados em áreas de Mata Atlântica dentro na "Estação Experimental J. Cione", pertencente ao Instituto Agronômico de Campinas (2436' 50" de latitude sul, 47 53' 00" de longitude oeste). Em Cananéia, a coleta realizou-se à margem da Rodovia SP-226 já no interior da ilha ( $24^{\circ} 55^{\prime} 00^{\prime \prime}$ de latitude sul, $47^{\circ} 50^{\prime} 00^{\prime \prime}$ de longitude oeste). Em Piracicaba, a coleta foi realizada no Campus Universitário da Escola Superior de Agricultura "Luiz de Queiroz", Universidade de São Paulo (22 $2^{\circ} 42^{\prime} 30^{\prime \prime}$ de latitude sul, $47^{\circ} 37^{\prime} 40^{\prime \prime}$ de longitude oeste) em uma área de vegetação secundária sob influência de um remanescente de Mata Atlântica chamado de "Mata da Pedreira" (Ivanauskas \& Rodrigues, 1995).

O material vegetal coletado de cada planta foi acondicionado em um saco de papel devidamente identificado, que por sua vez foi colocado em um saco plástico e guardado em caixa de isopor com gelo até o retomo ao laboratório, onde foi mantido em refrigerador a aproximadamente $10^{\circ} \mathrm{C}$ para posterior coleta dos ácaros em um período de no máximo uma semana. A montagem dos ácaros foi realizada em lâminas com meio de Hoyer (Flechtmann, 1977).

A nomenclatura das setas utilizada neste trabalho é a de André (1981b) para a quetotaxia das pernas e a de Kazmierski (1989a) para a superfície dorsal e ventral do idiossoma (Figura 6). A descrição dos tipos de estriação e de áreas de reticulação da superfície dorsal do idiossoma é a descrita por Kazmierski (1998a).

Os espécimens representativos deste estudo foram depositados no Setor de Zoologia Agrícola do Departamento de Entomologia, Fitopatologia e Zoologia 
Agrícola da Escola Superior de Agricultura "Luiz de Queiroz" da Universidade de São Paulo, Piracicaba -SP, Brasil (ESALQ-USP). 


\subsection{Resultados e Discussão}

Foram coletados espécimens de 29 espécies pertencentes a 18 gêneros. Destas espécies 22 são novas para a ciência. Daqueles gêneros, 8 são novos para a ciência.

Isto significa acrescentar ao menos 26 espécies à lista apresentada (Tabela $1)$.

\section{SUBFAMÍLIA TYDEINAE}

Afrotydeus Baker, 1970 sensu André, 1980

Afrotydeus sp. $\mathbf{n}$.

Material examinado: Cananéia: P. glabrata. Pariquera-Açu: A. glandulosa; A. triplinervea; A. cordatum; Sebastiania sp..

Idiossoma. Ornamentação dorsal: estriação tipo "Tydeus", formando um padrão em forma de "U" obtuso entre as setas $d_{1}$. Reticulação ausente. Estrias providas de costulae em forma de "I" e bastonetes. Seta botridial (bo) longa, lisa e em forma de chicote, visivelmente maior que as demais setas dorsais. Setas dorsais idiossomais lisas e finas, variando em forma de lanceoladas com ponta arredondada $\left(e x, c_{l}, d_{l}, f_{l}, h_{l}, h_{2}, p s_{l}\right)$ a espatuladas com ponta afilada $(l a, r o)$. Estrias ventrais transversais entre as setas $m t$.

Gnatossoma: não coberto pelo aspidossoma. Estiletes quelicerais menores que o comprimento combinado do tarso do palpo e eupatídia terminal. Eupatídia $(p \zeta)$ reta e simples.

Pernas. Órgão coxal em forma de um " 8 ". Garras empodiais (om) ausentes. Seta $k$ " em formato de "Y".

Quetotaxia genital: $(0-4-4)$ 
Diagnose: Esta espécie é semelhante a A. smileyi Kazmierski, 1998a, diferindo por apresentar as setas dorsais lisas, ausência de garras empodiais (om) e gnatossoma não coberto pelo aspidossoma.

\section{Lorryia Oudemans, 1925 sensu Kazmierski, 1989b}

\section{Lorryia formosa Cooreman, 1958}

Material examinado: Pariquera-Açu: A. glandulosa; $A$. triplinervea; $H$. brasiliensis. Piracicaba: A. glandulosa; A. sidifolia; C. floribundus; H. brasiliensis; H. crepitans; J. princeps; P. longifolium.

Observações: Esta foi a espécie de ácaro mais abundante em seringueiras de PariqueraAçu.

\section{Lorryia sp. n. 1}

Material examinado: Cananéia: $A$. triplinervea; $P$. glabrata. Pariquera-Açu: $A$. glandulosa; A. triplinervea; $A$. cordatum; H. brasiliensis; Sebastiania sp.. Piracicaba: A. glandulosa; A. sidifolia; C. floribundus; C. urucurana; H. brasiliensis; H. crepitans; J. princeps; $P$. longifolium.

Idiossoma. Ornamentação dorsal: estriação tipo "Tydeus". Reticulação ausente. Estrias providas de costulae em forma de "I" e bastonete. Seta botridial (bo) longa, lisa e em forma de chicote. Setas dorsais idiossomais finas, lanceoladas, curvas e finamente serreadas. Estrias ventrais transversais entre as setas $m t$.

Gnatossoma: não coberto pelo aspidossoma. Estiletes quelicerais menores que o comprimento combinado do tarso do palpo e eupatídia terminal. Eupatídia $(p \zeta)$ reta e fendida distalmente; solenídio $\omega$ localizado na porção mediana do tarso.

Pernas. Órgão coxal oval. Garras empodiais (om) pequenas mas visíveis. Seta $k$ ” em formato de "Y".

Quetotaxia genital: (4,0-6-4)

Diagnose: Esta espécie é semelhante a L. zebramontana (Meyer, 1988), diferindo no comprimento e formato das setas dorsais, por apresentar garras empodiais (om) mais conspícuas, pelo formato de $p \zeta$ e de $k$ " e no formato das estrias ventrais entre $m t$. 
Observações: Esta foi a espécie mais abundante, especialmente em seringueiras de Piracicaba, e a que apresentou maior amplitude de hospedeiros neste estudo.

\section{Lorryia sp. n. 2}

Material examinado: Pariquera-Açu: A. glandulosa; A. cordatum.

Idiossoma. Ornamentação dorsal: estriação tipo "Biparalorryia-incerta" com duas áreas de estriação diferenciada ("swirl"), uma entre $d_{1}-c_{2}$ e outra lateral e próxima a $e_{1}$. Estrias providas de costulae em forma de "I" e tubérculos retangulares. Reticulação formada pelas áreas $\mathrm{A}(r o)(l a), \mathrm{A}\left(f_{2}\right)\left(f_{l}\right)$ e $\mathrm{A}\left(h_{2}\right)\left(h_{l}\right)\left(p s_{l}\right)$. Entrelaçamentos entre retículos em forma de "Y". Seta botridial (bo) longa, lisa e em forma de chicote. Setas dorsais idiossomais finas, longas e finamente serreadas. Estrias ventrais transversais entre as setas $m t$.

Gnatossoma: não coberto pelo aspidossoma. Estiletes quelicerais menores que o comprimento combinado do tarso do palpo e eupatídia terminal. Eupatídia $(p \zeta)$ reta e fendida distalmente; seta $d$ fendida distalmente (bífida ou trífida).

Pernas. Orgão coxal em forma de "8". Garras empodiais $(o m)$ pequenas em posição mediana. Seta $k$ " em formato de pequena clava.

Quetotaxia genital: (4,0-6-4)

Diagnose: Esta espécie é semelhante a L. nesziyyonensis (Gerson, 1968) e L. jesionowskii Kazmierski, 1998a, diferindo da primeira no comprimento das setas dorsais e da segunda por não apresentar serreamento tão intenso das mesmas, difere ainda igualmente das duas espécies por apresentar $\mathrm{A}\left(f_{2}\right)\left(f_{l}\right)$.

Lorryia sp. n. 3

Material examinado: Pariquera-Açu: A. glandulosa; A. triplinervea; A. cordatum.

Idiossoma. Ornamentação dorsal: estriação tipo "Veniparalorryia" sem áreas de estriação diferenciada. Estrias providas de costulae em forma de tubérculos semicirculares. Reticulação formada pelas áreas $\mathrm{A}(l a)(r o)(b o), \mathrm{A}\left(e_{l}\right), \mathrm{A}\left(f_{2}\right)\left(f_{l}\right)$ e $\mathrm{A}\left(h_{2}\right)\left(h_{l}\right)\left(p s_{l}\right)$. Entrelaçamentos entre retículos em forma de "Y". Seta botridial (bo) longa, fina, lisa e em forma de chicote. Setas dorsais idiossomais mais grossas que $b o$, 
curtas. finamente serreadas, com extremidades truncadas. arredondadas e levemente dilatadas. Estrias ventrais: transversais entre as setas $m t$.

Gnatossoma: não coberto pelo aspidossoma. Estiletes quelicerais menores que o comprimento combinado do tarso do palpo e eupatídia terminal. Eupatídia $(p \zeta)$ reta e fendida distalmente; seta $d$ fendida distalmente (bífida).

Pernas. Órgão coxal em forma de "8". Garras empodiais $(\mathrm{om})$ pequenas em posição mediana. Seta $k$ " em formato de bastonete.

Quetotaxia genital: $(4,0-6-4)$

Diagnose: Esta espécie é semelhante a Lorryia sp. n. 2 e diferindo desta e de $L$. nesziyyonensis (Gerson, 1968) e L. jesionowskii Kazmierski, 1998 pelo formato das setas idiossomais; difere de L. mexicana (Baker, 1968) por ter $p s_{I}$ em posição ventral e por apresentar setas idiossomais subiguais a bo; difere de $L$. berryi (Baker, 1968) por ter $p s_{\perp}$ em posição ventral. Difere ainda das duas espécies anteriores por apresentar as áreas de reticulação $\mathrm{A}\left(e_{1}\right)$ e $\mathrm{A}\left(f_{2}\right)\left(f_{1}\right)$.

\section{Lorryia sp. n. 4}

Material examinado: Pariquera-Açu: A. cordatum.

Idiossoma. Ornamentação dorsal: estriação tipo "Veniparalorryia" sem áreas de estriação diferenciada. Estrias providas de costulae em forma de tubérculos semicirculares. Reticulação formada pelas áreas $\mathrm{A}(l a)(r o)(b o), \mathrm{A}\left(c_{2}\right), \mathrm{A}\left(\boldsymbol{d}_{l}\right), \mathrm{A}\left(f_{2}\right)\left(f_{l}\right)$ e $\mathrm{A}\left(h_{2}\right)\left(h_{l}\right)\left(p s_{l}\right)$. Entrelaçamentos entre retículos em forma de "Y". Seta botridial (bo) longa, fina, lisa e extremidade truncada. Setas dorsais idiossomais mais grossas que bo, relativamente longas e alcançando a base da seta seguinte, finamente serreadas, com extremidades truncadas e arredondadas. Distância entre as bases das setas ro maior que entre ro e la. Estrias ventrais transversais entre as setas $m t$.

Gnatossoma: não coberto pelo aspidossoma. Estiletes quelicerais menores que o comprimento combinado do tarso do palpo e eupatídia terminal. Eupatídia $(p \zeta)$ reta e fendida distalmente; seta $d$ fendida distalmente (bífida).

Pernas. Orgão coxal em forma de "8". Garras empodiais (om) pequenas mas visíveis. Seta $k$ " em formato de pequena clava. 


\section{Quetotaxia genital: (0-6-4)}

Diagnose: Esta espécie é muito próxima a Looryia sp. n. 3, diferindo por apresentar as áreas de reticulação $\mathrm{A}\left(c_{2}\right)$ e $\mathrm{A}\left(d_{l}\right)$ e não apresentar $\mathrm{A}\left(e_{l}\right)$, por ter $p s_{I}$ em posição dorsal; difere de $L$. berryi (Baker, 1968) por apresentar setas idiossomais maiores que a metade do comprimento de bo. Difere ainda das espécies acima e de L. mexicana (Baker, 1968) por apresentar as áreas de reticulação $\mathrm{A}\left(d_{l}\right)$ e $\mathrm{A}\left(f_{2}\right)\left(f_{l}\right)$ e por apresentar bo com extremidade truncada e não em forma de chicote.

\section{Lorryia sp. n. 5}

Material examinado: Pariquera-Açu: A. cordatum. Piracicaba: C. floribundus.

Idiossoma. Ornamentação dorsal: estriação tipo "Veniparalorryia" sem áreas de estriação diferenciada. Estrias providas de costulae conspícuas em forma de tubérculos semicirculares, de "Y" ou de "X". Reticulação formada pelas áreas $\mathrm{A}(l a)(r o)(b o), \mathrm{A}\left(c_{l}\right)$, $\mathrm{A}\left(\mathrm{c}_{2}\right), \mathrm{A}\left(d_{l}\right), \mathrm{A}\left(e_{l}\right), \mathrm{A}\left(f_{2}\right), \mathrm{A}\left(f_{l}\right)$ e $\mathrm{A}\left(h_{2}\right)\left(h_{l}\right)\left(p s_{l}\right)$. Entrelaçamentos entre retículos em forma de "Y". Seta botridial (bo) longa, fina, lisa e em forma de chicote. Setas dorsais idiossomais mais grossas que bo, relativamente longas mas não alcançando a base da seta seguinte, finamente serreadas, com extremidades truncadas e arredondadas. Distância entre as bases das setas ro maior que entre ro e la. Estrias ventrais transversais entre as setas $p t$ e $m t_{\alpha}$; transversais entre $m t_{\beta}$ e $a g_{l}$.

Gnatossoma: não coberto pelo aspidossoma. Estiletes quelicerais menores que o comprimento combinado do tarso do palpo e eupatídia terminal. Eupatídia $(p \zeta)$ reta afilada distalmente, com ponta arredondada e não fendida; seta $d$ fendida distalmente (bífida).

Pernas. Orgão coxal em forma de "8". Garras empodiais (om) presentes, fortes, grandes e em posição mediana. Seta $k$ " em formato de pequena clava. Solenídios $\omega_{1}$ e $\omega_{11}$ longos (mais longos que a metade da largura do segmento).

Quetotaxia genital: (0-6-4)

Diagnose: Esta espécie é muito próxima às demais descritas anteriormente, diferindo principalmente daquelas por apresentar as áreas de estriação com costulae conspícuas e em forma de "Y", pela ocorrêcia de reticulação $\mathrm{A}\left(c_{2}\right)$ e $\mathrm{A}\left(f_{2}\right), \mathrm{A}\left(f_{l}\right)$ e por ter $p s_{l}$ em 
posição terminal.

\section{Lorryia sp. n. 6}

Material examinado: Pariquera-Açu: A. cordatum.

Idiossoma. Omamentação dorsal: estriação tipo "Veniparalorryia" sem áreas de estriação diferenciada. Estrias providas de costulae em forma de "I" ou bastonetes. Seta botridial (bo) longa, lisa e em forma de chicote. Setas dorsais idiossomais finas, lanceoladas, curvas e finamente serreadas. Estrias ventrais transversais entre as setas $p t \mathrm{e}$ $m t_{\alpha}$; transversais entre $m t_{\beta}$ e $a g_{l}$.

Gnatossoma: não coberto pelo aspidossoma. Estiletes quelicerais menores que o comprimento combinado do tarso do palpo e eupatídia terminal. Eupatídia $(p \zeta)$ reta, ponta arredondada e fendida distalmente.

Pernas. Órgão coxal oval. Garras empodiais $(o m)$ pequenas mas fortes. Seta $k$ " em formato de "Y".

\section{Quetotaxia genital: (0-6-4)}

Diagnose: Esta espécie difere de todas as demais do gênero pela ausência da seta $e_{I}$ no opistossoma. Esta característica é certamente de importância genérica, mas a quetotaxia das pernas corresponde à do gênero Lorryia, portanto assim deve ser considerada até melhor estudo da espécie.

Observação: Esta é a primeira referência em Tydeidae de espécie com a ausência da seta $e_{l}$. Pode ser uma variação individual atípica na espécie, pois apenas um exemplar foi coletado no presente estudo. Portanto uma nova coleta na mesma planta onde este ácaro foi encontrado poderá confirmar se trata-se de uma variação da espécie.

\section{Lorryia sp. n. 7}

Material examinado: Pariquera-Açu: A. glandulosa; A. triplinervea; $A$. cordatum.

Idiossoma. Omamentação dorsal: do tipo "Lorryia" com áreas de reticulação regulares separadas por tegumento estriado. Estrias providas de costulae em forma de "I" e bastonetes. Reticulação formada pelas áreas $\mathrm{A}(l a)(r o)(b o), \mathrm{A} e x, \mathrm{~A}\left(c_{l}\right), \mathrm{A} c_{2}, \mathrm{~A}\left(d_{l}\right), \mathrm{A} e_{1}$, $\mathrm{A}\left(f_{2}\right)\left(f_{l}\right)$ e $\mathrm{A}\left(h_{2}\right)\left(h_{l}\right)\left(p s_{l}\right)$. Entrelaçamentos entre retículos em forma de triângulo ou "I". 
Seta botridial ( $b o$ ) curta, fina, lisa e em forma de chicote. Setas dorsais idiossomais: lanceoladas, mais largas na porção mediana (aspidossomais mais afiladas que opistossomais), curtas, finamente serreadas, curvas, com extremidades afiladas. Estrias ventrais transversais entre as setas $p t$ e $m t_{\alpha}$; transversais formando um " $U$ " obtuso entre $m t_{\beta}$ e $m t_{\alpha}$.

Gnatossoma: não coberto pelo aspidossoma. Estiletes quelicerais menores que o comprimento combinado do tarso do palpo e eupatídia terminal. Eupatídia $(p \zeta)$ reta e fendida distalmente. Tarso do palpo com $\omega$ em posição mediana.

Pernas. Orgão coxal em forma de " 8 ". Garras empodiais $(o m)$ basais e pequenas. Seta $k$ " em formato de pequena clava de ponta afilada. Tarso I com $\omega_{1}$ longa com comprimento equivalente a metade da largura do segmento.

Quetotaxia genital: $(4,0-6-4)$

Diagnose: Esta espécie é semelhante a L. formosa Cooreman, 1958, L. sigthori Baker, 1944, e L. catenulata (Thor, 1931). Difere das duas primeiras pelo formato das setas idiossomais e da última pelo formato das setas idiossomais e por não apresentar o gnatossoma coberto pelo aspidossoma.

\section{Lorryia sp. n. 8}

Material examinado: Pariquera-Açu: A. sidifolia. Piracicaba: $A$. sidifolia; $C$. floribundus; J. princeps.

Idiossoma. Ornamentação dorsal: Estrias providas de costulae em forma de "I" e bastonete. Reticulação formada pelas áreas $\mathrm{A}(l a)(r o)(b o), \mathrm{Aex}, \mathrm{A}\left(c_{l}\right), \mathrm{A} c_{2}, \mathrm{~A}\left(d_{l}\right), \mathrm{A} e_{l}$, $\mathrm{A}\left(f_{2}\right)\left(f_{l}\right)$ e $\mathrm{A} h_{2} h_{l} p s_{l}$. Entrelaçamentos entre retículos em forma de triângulo ou "I". Seta botridial (bo) moderadamente longa (não alcançando a base de seu par), fina, lisa e em forma de chicote. Setas dorsais idiossomais: finas, lanceoladas, curvas e finamente serreadas (aspidossomais mais afiladas que opistossomais), curtas, com extremidades afiladas. Estrias ventrais transversais entre as setas $p t$ e $m t_{\alpha}$; transversais formando um "U" obtuso entre $m t_{\beta}$ e $m t_{\alpha}$.

Gnatossoma: não coberto pelo aspidossoma. Estiletes quelicerais menores que o 
comprimento combinado do tarso do palpo e eupatídia terminal. Eupatídia $(p \zeta)$ reta e fendida distalmente. Tarso do palpo com $\omega$ em posição mediana.

Pernas. Orgão coxal oval. Garras empodiais (om) ausentes. Seta $k$ " em formato de "Y". Tarso I com $\omega_{\text {r }}$ longa com comprimento equivalente a metade da largura do segmento.

Quetotaxia genital: (4,0-6-4)

Diagnose: Esta espécie é semelhante a Lorryia sp. n. 7, da qual difere pelo comprimento e espessura das setas opistossomais, pelo formato do órgão coxal e da seta $k$ "; difere de L. formosa Cooreman, 1958, pelo formato das setas idiossomais; de L. catenulata (Thor, 1931) por não apresentar o gnatossoma coberto pelo aspidossoma; e de todas estas além de L. sigthori Baker 1944, por apresentar $\mathrm{A} h_{2} h_{l} p s_{1}$.

\section{Unidade Genérica cf. Lorryia Kazmierski, 1998a}

Diagnose: Difere de Lorryia s.s. pela ausência de trIII. cf. Lorryia sp. n.

Material examinado: Pariquera-Açu: A. glandulosa.

Obs: Utilizaram-se para a presente descrição, três espécimens macho

Idiossoma. Ornamentação dorsal: reticulação do tipo "Lorryia", com áreas de reticulação regulares separadas por tegumento estriado. Estrias providas de costulae em forma de tubérculos semicirculares ou "X". Reticulação formada pelas áreas $\mathrm{A}(l a)(r o)(b o), \mathrm{A}\left(c_{l}\right), \mathrm{A} c_{2}, \mathrm{~A}\left(d_{l}\right), \mathrm{A} e_{1}, \mathrm{~A}\left(f_{2}\right)\left(f_{l}\right)$ e $\mathrm{A}\left(h_{2}\right)\left(h_{l}\right)\left(p s_{l}\right)$. Entrelaçamentos entre retículos em forma de "Y". Seta botridial (bo) curta, fina, lisa e em forma de chicote. Setas dorsais idiossomais: curtas, grossas e com pontas truncadas, redondas e dilatadas; aspidossomais mais longas que opistossomais; finamente serreadas. Estrias ventrais transversais entre as setas $p t$ e $m t_{\alpha}$; transversais entre $m t_{\beta}$ e $a g_{l}$.

Gnatossoma: não coberto pelo aspidossoma. Estiletes quelicerais menores que o comprimento combinado do tarso do palpo e eupatídia terminal. Eupatídia $(p \zeta)$ reta e fendida distalmente. Tarso do palpo com $\omega$ em posição basal.

Pernas. Orgão coxal em forma de " 8 ". Garras empodiais (om) ausentes. Seta $k$ " em formato de pequena clava com ponta afilada. 


\section{Quetotaxia genital: (4,?-6-4)}

Diagnose: Esta espécie difere de "Tydeus" lundqvisti Momen \& Solhøy, 1996, por apresentar áreas de reticulação; pelo formato das setas idiossomais; pelo comprimento do tarso do palpo; e pelo formato da eupatídia $(p \zeta)$ do palpo.

\section{Unidade Genérica cf. Krantzlorryia And ré}

Aspidossoma - Quetotaxia: 4 (bo, ro, la, ex). Seta botridial (bo) diferente na forma e maior que demais setas aspidossomais.

Opistossoma - Quetotaxia: $10\left(c_{l}, c_{2}, d_{l}, e_{l}, f_{l}, f_{2}, h_{l}, h_{2}, p s_{1}, p s_{2}\right)$. Quetotaxia genital: Adulto (0-4-4). Formula epimeral: Adulto (3-1-4-2).

Pernas - Quetotaxia: Adulto I(8-2+1-2-2-0); II(6-2-1-2-0); III(5-1-0-1-1); IV(5-2-1-1$0)$. Solenidiotaxia: $3\left(\omega, \omega_{11}\right.$ e $\left.\varphi_{1}\right)$.

Gnatossoma - Organotaxia do palpo: $(6-1-2)+\omega$.

Diagnose: Este gênero difere de Krantzlorryia André por apresentar 2 setas na tíbia I, 1 seta no genu da perna III, solenídio $\varphi_{1}$ e 4 pares de setas genitais.

Observações: Foi observada a presença de dois pares ventrais de pequenas setas trífidas, um par na posição distal do coxisterno I e o outro par lateralmente à base do gnatossoma. Não existe relato da ocorrência destas setas em Tydeidae, sendo necessário um estudo mais aprofundado.

\section{cf. Krantzlorryia sp. $\mathrm{n}$.}

Material examinado: Pariquera-Açu: $A$. cordatum.

Idiossoma. Omamentação dorsal: do tipo "Lorryia" com áreas de reticulação regulares separadas por tegumento estriado. Estrias providas de costulae em forma de tubérculos retangulares. Reticulação formada pelas áreas $\mathrm{A}(l a)(r o)(b o), \mathrm{Aex}, \mathrm{A}\left(c_{1}\right), \mathrm{A} c_{2}, \mathrm{~A}\left[c_{2}\right] 0\left[e_{1}\right]$, $\mathrm{A}\left(d_{l}\right), \mathrm{A} e_{l}, \mathrm{~A}\left(d_{l}\right), \mathrm{A} f_{2} f_{l}$ e $\mathrm{A}\left(h_{2}\right)\left(h_{l}\right)\left(p s_{l}\right)$. Entrelaçamentos entre retículos em forma de "Y" ou "I". Seta botridial (bo) moderadamente curta, fina, lisa e em forma de chicote. Setas dorsais idiossomais: curtas, curvas e lisas; do tipo lanceoladas finas e com pontas truncadas e redondas; aspidossomais mais longas que opistossomais. Estrias ventrais transversais entre as setas $p t$ e $m t_{\alpha}$; transversais entre $m t_{\beta}$ e $a g_{l}$. 
Gnatossoma: não coberto pelo aspidossoma. Estiletes quelicerais menores que o comprimento combinado do tarso do palpo e eupatídia terminal. Eupatídia $(p \zeta)$ reta e simples.

Pernas. Orgão coxal não discernivel. Garras empodiais ( om $)$ basais. Seta $k$ ” em formato de "Y".

\section{Unidade Genérica cf. Metalorryia And ré}

Aspidossoma - Quetotaxia: 4 (bo, ro, la, ex). Seta botridial (bo) diferente na forma e maior que demais setas aspidossomais.

Opistossoma - Quetotaxia: $10\left(c_{l}, c_{2}, d_{l}, e_{l}, f_{l}, f_{2}, h_{l}, h_{2}, p s_{l}, p s_{2}\right)$. Quetotaxia genital: Adulto (0-6-4). Formula epimeral: Adulto (3-1-4-2).

Pernas - Quetotaxia: Adulto I(8-2+1-2-2-0); II(6-2-1-2-0); III(5-1-0-1-1); IV(5-2-1-1$0)$. Solenidiotaxia: $3\left(\omega, \omega_{1 I}\right.$ e $\left.\varphi_{1}\right)$.

Gnatossoma - Organotaxia do palpo: (6-2-2) $+\omega$.

Diagnose: Este gênero difere de Metalorryia Baker por apresentar 2 setas nas tíbias das pernas III e IV, nenhuma seta no genu das pernas III e IV, 2 setas na tíbia do palpo e pela presença do solenídio $\varphi$.

\section{cf. Metalorryia sp. n.}

Material examinado: Pariquera-Açu: A. cordatum; Sebastiania sp..

Idiossoma. Ornamentação dorsal: Reticulação do tipo "Lorryia" com área de reticulação cobrindo todo o idiossoma. Estrias ausentes. Entrelaçamentos entre retículos em forma de "Y". Seta botridial ( $b o$ ) moderadamente curta, fina, lisa e em forma de chicote. Setas dorsais idiossomais: curtas, curvas e finamente serreadas; do tipo lanceoladas e afiladas; aspidossomais mais longas que opistossomais. Estrias ventrais transversais entre as setas $p t$ e $m t_{\alpha}$; transversais entre $m t_{\beta}$ e $a g_{I}$.

Gnatossoma: Coberto pelo aspidossoma. Estiletes quelicerais maiores que o comprimento combinado do tarso do palpo e eupatídia terminal. Eupatídia $(p \zeta)$ reta e simples. 
Pernas. Orgão coxal em forma de "8". Garras empodiais (om) basais. Seta $k$ " localizada na porção mediana do segmento, em formato de "Y" e com base coalescente a de $\varphi_{1}$.

\section{Neolorryia And ré, 1980}

Neolorryia sp. $\mathbf{n}$.

Material examinado: Piracicaba: A. glandulosa; P. longifolium.

Idiossoma. Ornamentação dorsal: do tipo "Lorryia" com áreas de reticulação regulares separadas por tegumento estriado. Estrias providas de costulae em forma de "I" e bastonete. Reticulação formada pelas áreas $\mathrm{AA}, \mathrm{A}\left(c_{l}\right), \mathrm{A} c_{2}, \mathrm{~A}\left(d_{l}\right), \mathrm{A} e_{1}, \mathrm{~A}\left(d_{l}\right), \mathrm{A} f_{2} f_{l}$ e $\mathrm{A}\left(h_{2}\right)\left(h_{l}\right)$. Entrelaçamentos entre cada 3 retículos de forma triangular. Seta botridial $(b o)$ moderadamente curta, fina, lisa e em forma de chicote. Setas dorsais idiossomais: curtas, curvas, do tipo lanceolada, largas e serreadas. Estrias ventrais transversais entre as setas $p t$ e $m t_{\alpha}$; transversais entre $m t_{\beta}$ e $a g_{l}$.

Gnatossoma: Coberto pelo aspidossoma. Estiletes quelicerais menores que o comprimento combinado do tarso do palpo e eupatídia terminal. Eupatídia $(p \zeta)$ reta e fendida distalmente.

Pernas. Quetotaxia da perna I: $(7-2+1-2-2-0)$. Orgão coxal em forma de " 8 ". Garras empodiais (om) pequenas, tênues e basais. Seta $k$ " em formato de pequena clava. Quetotaxia genital: (0-4-4)

Diagnose: Apesar de apresentar somente 7 setas no tarso I, em todos os espécimens estudados, todos demais caracteres correspondem ao do gênero Neolorryia, não justificando a criação de um novo gênero, no momento, para esta espécie. Esta espécie difere de $N$. pandana (Baker, 1968) por apresentar reticulação $\mathrm{A}\left(d_{I}\right), \mathrm{A} e_{l}, \mathrm{~A}\left(d_{l}\right)$ e $\mathrm{A} f_{2} f_{1}$; difere das demais espécies do gênero pela quetotaxia genital e por $f_{l}$ ser menor que a distância $f_{1}-h_{l}$.

\section{Paralorryia Baker, 1965 sensu Kazmierski, 1989b}

\section{Paralorryia shawi (Baker, 1943)}

Material examinado: Piracicaba: P. longifolium.

Observações: Este é o primeiro relato desta espécie no Brasil. 


\section{Tydeus Koch, 1835 sensu Kazmierski, 1989b}

Tydeus costensis Baker, 1970

Material examinado: Pariquera-Açu: H. brasiliensis.

Observações: Este é o primeiro relato desta espécie no Brasil.

\section{Tydeus californicus (Banks, 1904)}

Material examinado: Pariquera-Açu: H. brasiliensis.

Observações: Este é o primeiro relato desta espécie no Brasil.

\section{Subfamília Pretydeinae}

Pretydeus André, 1980

Pretydeus curiosa (Ueckermann \& Smith-Meyer, 1979)

Material examinado: Piracicaba: A. glandulosa; H. brasiliensis.

Observações: Este é o primeiro relato desta espécie no Brasil.

\section{Pretydeus reticulatus Flechtmann, 1995}

Material examinado: Pariquera-Açu: A. glandulosa; A. cordatum.

Observações: Espécie descrita de espécimens coletados em bambu em região de Mata Atlântica no Estado do Rio de Janeiro.

\section{Pretydeus sp. n.}

Material examinado: Cananéia: A. triplinervea. Pariquera-Açu: A. glandulosa; $H$. brasiliensis; Sebastiania sp..

Idiossoma. Ornamentação dorsal: Reticulação formada por células irregulares e relativamente pequenas. Ausência de áreas discretas ou escudos. Entrelaçamentos entre retículos de forma irregular. Seta botridial (bo) moderadamente curta, fina e lisa. Setas dorsais idiossomais ro, la, ex, $c_{2}, h_{l}, f_{l}$ e $p s_{l}$ moderadamente longas, retas, grossas, serreadas, cobertas por espículas e alargadas em suas pontas na forma de um pincel; as demais de mesmo tipo porém mais longas. Estrias ventrais transversais entre asetas $\mathrm{mt}$ com a formação de uma área central lisa (sem estrias ou reticulação). 
Gnatossoma: Não coberto pelo aspidossoma. Estiletes quelicerais maiores que o comprimento combinado do tarso do palpo e eupatídia terminal. Eupatídia $(p \zeta)$ reta e fendida distalmente. Palpo e femurogenu curtos e subiguais em comprimento.

Pernas. Orgão coxal em forma de " 8 ". Garras empodiais (om) basais fortes e conspícuas. Seta $k$ " em forma de bastonete e com base coalescente com a de $\varphi_{1}$. Seta $f t^{\prime}$ do tarso I fina e serreada, com comprimento menor que metade do de $f t$ ". Seta $u$ furcada nos tarsos de todas as pernas; esta bifurcação ocorre no primeiro quarto do comprimento total da seta e os ramos são de comprimento subigual.

Quetotaxia genital: (0-5-4)

Diagnose: Espécie semelhante a $P$. heniandrei Kazmierski, 1996a, da qual difere por apresentar as setas ro, la, ex, $c_{2}, h_{l}, h_{2}$ e $p s_{l}$ do mesmo tipo que as demais; por apresentar o gnatossoma não coberto pelo aspidossoma; pelo formato da seta $f t^{\prime}$ do tarso I; pelo formato da seta $u$ (furcada) nos tarsos de todas as pernas; como P. heniandrei difere das demais espécies do gênero pelo tipo das setas idiossomais.

\section{Subfamília Pronematinae}

Parapronematus Baker, 1965

\section{Parapronematus acaciae Baker, 1965}

Material examinado: Cananéia: A. triplinervea. Pariquera-Açu: A. glandulosa; $A$. triplinervea; H. brasiliensis; Sebastiania sp.. Piracicaba: A. glandulosa; C. urucurana; H. brasiliensis; H. crepitans; P. longifolium.

Idiossoma. Ornamentação dorsal: Estriação discernível somente em espécimens macho, sendo semelhante à descrição de BAKER (1965). Reticulação ausente. Seta botridial (bo) moderadamente longa, fina, finamente serreada na metade distal e em forma de chicote. Setas dorsais idiossomais: $e_{I}$ em posição dorsal em linha com $d_{I}$ e $f_{l}$; finas, retas, firmes e finamente serreadas; $f_{l}, f_{2}, h_{l}, h_{2}$, e $p s_{l}$ moderadamente longas, retas; $l a$ e ex subiguais em comprimento; bo subigual em comprimento a $h_{2}$ e duas vezes maior que $l a ; h_{2}$ duas vezes maior que $h_{1} ; f_{2}$ duas vezes e meia maior que $f_{1}$; setas $a g_{3}$ mais longa que $a g_{2}$ e subigual a $a g_{I}$. Estrias ventrais transversais entre as setas $a \mathrm{~g}_{1}$.

Gnatossoma: Não coberto pelo aspidossoma. Estiletes quelicerais menores que o 
comprimento combinado do tarso do palpo e eupatídia terminal. Eupatídia $(p \zeta)$ reta e fendida distalmente. Palpo mais curto que femurogenu.

Pernas. Orgão coxal. Garras empodiais (om) ausentes. Solenídio $\omega$ conspícuo e recumbente. Setas do tarso I finas e serreadas e com comprimento maior que o do segmento, exceto setas $u$ que são diminutas, quase vestigiais. Fêmur IV tão longo quanto largo em machos e mais longos que largos e m fềmeas; seta no femur das pernas III e IV em formato de "Y" podendo seu comprimento ser maior que a largura do segmento em fềmeas e subigual à largura do segmento nos machos; ramificações da seta em "Y" podendo ser subiguais ou uma mais longa e forte que a outra.

Quetotaxia genital: (2,0-0-3); Observação: em vários espécimens macho são bem visíveis estruturas que parecem ser dois pares de setas eugenitais. o que até o momento não foi realatado na subfamília Pronematinae.

Diagnose: Kazmierski (1998b) listou três espécies no gênero Parapronematus: $P$. acaciae Baker 1965, P. geminus Meyer \& Rodrigues 1965 e P. citri Salviejo 1969. Podemos acrescentar outra espécie: $P$. formosanus Tseng, 1985. Apesar de apresentar as setas em forma de "Y" nos fêmures das pernas III e IV, P. geminus apresenta também a seta ro. A quetotaxia das pernas representada nas ilustrações da descrição original de $P$. geminus é: I(8-2-1-2-?), II(6-2-2-2-?), III(5-3-0-2-?) e IV(5-2-1-1-?), enquanto a quetotaxia das pernas apresentada na descrição original de $P$. formosanus por Tseng é: I(8-2-2-2-1), II(8-2-2-2-0), III(5-2-2-2-1) e IV(5-2-1-1-0). Ambos os casos diferem da descrição do gênero (Baker, 1965) e da redescrição feita por André (1980), no que se refere ao número de setas: I(8-3-2-3-1), II(6-2-2-3-0), III(5 ou 6-2-2-2-1) e IV(5 ou 6-21-1-0). P. citri, por outro lado, apresenta quetotaxia típica para o gênero.

Salviejo (1969) distinguiu $P$. citri de $P$. acaciae pela ausência de estrias dorsais visíveis na primeira. A observação dos espécimens coletados indicou a ausência de estrias dorsais nas fềmeas e a presença destas nos machos. Baker (1965) e Salviejo (1969) não indicam que as descrições de $P$. acaciae e $P$. citri, respectivamente, se referem a machos ou fềmeas. De qualquer forma, as descrições originais destas espécies apresentam uma grande diferença em relação à disposição das 3 setas do fềmur I. Em P. citri, as setas estão posicionadas medianamente em relação ao comprimento do fềmur, enquanto que 
em $P$. acaciae tais setas estão dispostas ao longo do comprimento do fềmur: uma seta dorsal em posição mediana, uma ventral em posição medio-proximal e outra ventral em posição medio-distal, como nos espécimens coletados neste estudo.

\section{Pronematus Canestrini, 1886 sensu Baker, 1965}

\section{Pronematus sp. n.}

Material examinado: Piracicaba: $H$. brasiliensis.

Idiossoma. Ornamentação dorsal: Estriação longitudinal no aspidossoma; no opistossoma, longitudinal até $d_{l}$, tranversal entre esta e a seta $e_{l}$, e após esta, forma um "V" invertido. Reticulação ausente. Seta botridial (bo) moderadamente longa, fina, finamente serreada na metade distal e em forma de chicote. Setas dorsais idiossomais: $e_{I}$ em posição dorsal em linha com $d_{l}$ e $f_{l}$; todas finas, retas, firmes e finamente serreadas; $f_{1}, f_{2}, h_{1}, h_{2}$ e $p s_{1}$ longas (maiores que a distância entre suas bases), as demais curtas; $p s_{2}$ presentes, lisas e curtas; setas $c_{l}$ e $c_{2}$ menores que a distância entre suas bases; la e ex subiguais em comprimento a $c_{2}$; ex longa com aproximadamente três quartos do comprimento de bo; setas $f_{1}, f_{2}, h_{1}, h_{2}$ e $p s_{1}$ mais longas que bo. Estrias ventrais transversais entre as setas $p t$ e $m t_{\alpha}$ e anterior a $a g_{l}$.

Gnatossoma: Não coberto pelo aspidossoma. Estiletes quelicerais menores que o comprimento combinado do tarso do palpo e eupatídia terminal. Eupatídia $(p \zeta)$ reta e fendida distalmente. Tarso do palpo mais curto que femurogenu.

Pernas. Garras empodiais (om) ausentes. Solenídio $\omega$ conspícuo e recumbente. Setas do tarso I finas e serreadas ao longo de todo comprimento, com comprimento maior que o do segmento, sendo $f t^{\prime}$ menor; setas $u$ diminutas, quase vestigiais. Seta no femur das pernas III e IV como as demais.

Quetotaxia genital: (0-0-4)

Diagnose: Apenas três espécies são conhecidas neste gênero até o momento (Kazmierski, 1998b). Muitas espécies descritas como pertencentes a este gênero estão com o status genérico colocado em dúvida, pois são espécies descritas inadequadamente para os padrões atuais. Há a necessidade de uma revisão ampla deste gênero. 


\section{Unidade Genérica cf. Pronematus}

Aspidossoma - Quetotaxia: 4 ( $b o, r o, l a, e x)$. Seta botridial (bo) diferente na forma e maior que demais setas aspidossomais. Prodorso procurvado.

Opistossoma - Quetotaxia: $11\left(c_{l}, c_{2}, d_{l}, e_{l}, f_{l}, f_{2}, h_{l}, h_{2}, p s_{l}, p s_{2}, p s_{3}\right) ; e_{l}$ em posição dorsal, não alinhada com $d_{l}$ e $f_{l}$. Quetotaxia genital: Adulto (0-0-3). Formula epimeral: Adulto (3-1-4-2).

Pernas - Apotele I ausente. Quetotaxia Adulto: I(8-3+1-3-3-1); II(7-2-3-3-1); III(6-2-22-1); IV(6-2-1-(1-1)-0). Femur IV dividido. Solenidiotaxia: $3\left(\omega, \omega_{1 \mathrm{II}}\right.$ e $\left.\varphi_{1}\right)$.

Gnatossoma - Organotaxia do palpo: (6-1-2)+ $\omega$.

Diagnose: Difere de Pronematus Canestrini por apresentar as setas $\operatorname{tr} I$ e $\operatorname{trII}, 7$ setas no tarso da perna I, 6 setas nos tarsos das pernas III e IV e por apresentar apenas 3 pares de setas genitais.

\section{cf. Pronematus sp. $\mathrm{n}$.}

Material examinado: Pariquera-Açu: A. cordatum.

Idiossoma. Ornamentação dorsal: estriação longitudinal no aspidossoma; no opistossoma, longitudinal até $f_{l}$ e transversal posteriormente a esta seta. Reticulação ausente. Seta botridial ( $b o$ ) moderadamente longa, fina, finamente serreada na metade distal e em forma de chicote. Setas dorsais idiossomais: $e_{1}$ em posição dorsal não alinhada com $d_{l}$ e $f_{l}$; todas finas, retas, firmes e finamente serreadas; $f_{l}, f_{2}, h_{l}, h_{2}$ e $p s_{l}$ moderadamente longas (maiores que a distância entre suas bases), as demais mais curtas; $p s_{2}$ lisas e curtas; $l a, r o, m t_{\alpha}, m t_{\beta}$ e agenitais subiguais em comprimento; $b o$ duas vezes maior que ex que é duas vezes maior que la e ro. Estrias ventrais transversais anteriormente a $a g_{l}$; setas $m t_{\alpha}, m t_{\beta}$ e $p t$ maiores que a metade da distância que as separa de seus pares.

Gnatossoma: não coberto pelo aspidossoma. Estiletes quelicerais menores que o comprimento combinado do tarso do palpo e eupatídia terminal. Eupatídia $(p \zeta)$ reta e fendida distalmente. Tarso do palpo mais curto que femurogenu.

Pernas. Garras empodiais $(\mathrm{om})$ ausentes. Solenídio $\omega$ conspícuo e recumbente. Setas do 
tarso I finas e serreadas ao longo de todo comprimento, mais longas que o segmento exceto setas $u$ que são diminutas, quase vestigiais; seta $k$ " em formato de pequena clava; setas da perna III mais longas que os respectivos segmentos onde se inserem; setas nos fềmures III e IV não diferenciadas das demais.

\section{Unidade Genérica cf. Homeopronematus André}

Aspidossoma - Quetotaxia: 4 ( $b o, r o, l a, e x)$. Seta botridial (bo) diferente na forma e maior que demais setas aspidossomais. Prodorso procurvado.

Opistossoma - Quetotaxia: $11\left(c_{1}, c_{2}, d_{l}, e_{l}, f_{l}, f_{2}, h_{l}, h_{2}, p s_{2}\right) ; e_{l}$ em posição dorsal e em linha com $d_{l}$ e $f_{l}$. Quetotaxia genital: Adulto (0-0-3). Formula epimeral: Adulto (3-1-42).

Pernas - Apotele I ausente. Quetotaxia Adulto: I(8-3+1-3-3-1 ou 0); II(6-2-3-3-0); III(5-2-2-2-1); IV(5-2-1-2-0). Solenidiotaxia: 3 ( $\omega_{1}, \omega_{11}$ e $\left.\varphi_{1}\right)$.

Gnatossoma - Organotaxia do palpo: (6-1-2)+ + .

Diagnose: Este gênero difere de Homeopronematus André por não apresentar a seta $t r I I$, por apresentar 5 setas nos tarsos das pernas III e IV e por apresentar apenas 3 setas genitais.

\section{cf. Homeopronematus sp. $\mathrm{n}$.}

Material examinado: Piracicaba: H. brasiliensis.

Idiossoma. Ornamentação dorsal: estriação longitudinal tênue no aspidossoma; no opistossoma tênue e longitudinal até $f_{l}$ e tranversal posteriormente. Reticulação ausente. Seta botridial ( $b o$ ) moderadamente longa, fina, levemente serreada na metade distal e em forma de chicote. Setas dorsais idiossomais: $e_{l}$ em posição dorsal em linha com $d_{l}$ e $f_{l}$; todas finas, retas, firmes e finamente serreadas; $f_{2}, h_{1}, h_{2}$ e moderadamente longas (maiores que a distância entre suas bases), as demais mais curtas; $p s_{2}$ lisas e curtas; setas $f_{I}$ menores que a metade da distância entre suas bases; seta $f_{2}$ aproximadamente duas vezes maior que $f_{l}$; seta $r o$ duas vezes maior que $l a$; $b o$ duas vezes maior que $l a$ e $e x$. Estrias ventrais transversais entre $p t$ e $m t_{\alpha}$, e anterior a $a g_{l}$.

Gnatossoma: não coberto pelo aspidossoma. Estiletes quelicerais menores que o 
comprimento combinado do tarso do palpo e eupatídia terminal. Eupatídia $(p \zeta)$ reta e fendida distalmente. Tarso do palpo mais curto que femurogenu.

Pernas. Garras empodiais (om) ausentes. Solenídio $\omega_{1}$ conspícuo e recumbente; solenídio $\omega_{1}$ mais longo que o comprimento do tarso I em espécimens machos. Genu e tíbia I tão longos quanto largos. Setas do tarso I finas e serreadas ao longo de todo comprimento, mais longas que o segmento, exceto setas $u$ que são diminutas, quase vestigiais; seta $k$ " em formato de "Y"; setas da perna III mais curtas que o respectivo segmento em que estão inseridas. Ausência de $t r I$ em machos.

\section{Unidade Genérica cf. Metapronematus André}

Aspidossoma - Quetotaxia: 4 ( $b o, r o, l a, e x)$. Seta botridial (bo) diferente na forma e maior que demais setas aspidossomais. Prodorso procurvado.

Opistossoma - Quetotaxia: $10\left(c_{l}, c_{2}, d_{l}, e_{I}, f_{l}, f_{2}, h_{l}, h_{2}, p s_{l}, p s_{2}\right) ; e_{l}$ em posição dorsal e em linha com $d_{1}$ e $f_{l}$. Quetotaxia genital: Adulto (0-0-3). Formula epimeral: Adulto (3$1-4-2)$.

Pernas - Apotele I ausente. Quetotaxia Adulto: I(8-3+1-3-3-0); II(6-2-3-2-0); III(5-2-22-1); IV(5-2-1-1-0). Solenidiotaxia: 3 ( $\omega_{\mathrm{I}}$, $\omega_{\mathrm{II}}$ e $\left.\varphi_{\mathrm{I}}\right)$.

Gnatossoma - Organotaxia do palpo: $(5-1-2)+\omega$.

Diagnose: Este gênero difere de Metapronematus André por não apresentar as setas $\operatorname{tr} I \mathrm{e}$ trII, por apresentar 2 setas no fềmur da perna II e 5 setas no tarso da perna III.

\section{cf. Metapronematus sp. $\mathrm{n}$.}

Material examinado: Piracicaba: $H$. brasiliensis.

Idiossoma. Ornamentação dorsal: estriação muito pouco discernível. Reticulação ausente. Seta botridial ( $b o$ ) moderadamente longa, fina, levemente serreada na metade distal e em forma de chicote. Setas dorsais idiossomais: $e_{1}$ em posição dorsal em linha com $d_{l}$ e $f_{l}$; todas finas, retas, firmes e finamente serreadas; $f_{l}, f_{2}, h_{l}, h_{2}$ e $p s_{l}$ moderadamente longas (maiores que a distância entre as bases de seus pares), retas, as demais mais curtas; $p s_{2}$ lisas e curtas. Setas $l a$, ro e ex subiguais e com metade do comprimento de $b o ; f_{l}$ menor que a distância $f_{l}-h_{l} ; h_{l}$ maior que a metade da distância $f_{l}$ - 
$h_{l} ; f_{2}$ igual ao dobro do comprimento de $f_{l}$. Estrias ventrais transversais entre $p t$ e $\mathrm{mt}_{\alpha}$. Gnatossoma: não coberto pelo aspidossoma. Estiletes quelicerais menores que o comprimento combinado do tarso do palpo e eupatídia terminal. Eupatídia $(p \zeta)$ reta e fendida distalmente. Tarso do palpo mais curto que femurogenu.

Pernas. Garras empodiais $(\mathrm{om})$ ausentes. Solenídio $\omega$ conspícuo e recumbente. Genu, tíbia e tarso I mais de duas vezes tão longos quanto largos. Setas do tarso I finas e serreadas ao longo de todo comprimento, mais longas que o segmento, exceto setas $u$ que são diminutas, quase vestigiais; setas da perna III ligeiramente mais longas que o respectivo segmento onde se inserem.

\section{Pausia Kuznetzov \& Livshitz, 1972}

Este gênero apresenta apenas 2 espécies segundo Kazmierski (1998b). Este é o primeiro relato de espécie deste gênero no Brasil.

\section{Pausia sp. n.}

Material examinado: Pariquera-Açu: A. cordatum.

Idiossoma. Ornamentação dorsal: estriação longitudinal no aspidossoma e no opistossoma até $d_{l}$, passando a transversal posteriormente. Reticulação ausente. Seta botridial (bo) moderadamente curta, fina, lisa e em forma de chicote. Setas dorsais idiossomais: $e_{l}$ em posição dorsal não em linha com $d_{l}$ e $f_{l}$; todas finas, retas, firmes e finamente serreadas; $h_{2}$ e $p s_{I}$ longas, retas, subiguais, duas vezes maiores que $h_{l}$ e $p s_{2}$ e uma vez e meia maiores que $c_{1}, c_{2}, d_{l}, e_{1}, f_{l}$ e $f_{2}$; setas ro com bases coalescentes; $p s_{2}$ lisa e curta; setas $c_{l}$ e $c_{2}$ menores que a distância entre suas bases; la e ro subiguais em comprimento e menores que ex e $c_{2}$; setas $h_{l}$ e $p s_{I}$ tão longas quanto bo. Estrias ventrais transversais entre as setas $p t$ e $m t_{\alpha}$ e anterior a $a g_{I}$.

Gnatossoma: não coberto pelo aspidossoma. Estiletes quelicerais maiores que o comprimento combinado do tarso do palpo e eupatídia terminal. Eupatídia $(p \zeta)$ reta e afilada distalmente. Tarso do palpo mais curto que femurogenu.

Pernas. Garras tarsais da perna I ausentes; garras empodiais $(\mathrm{om})$ ausentes. Solenídio $\omega$ conspícuo e recumbente. Setas do tarso I finas, lisas e mais curtas que o segmento; setas 
$\boldsymbol{u}$ da perna I pequenas mas conspícuas, bifurcadas desde a base, com uma ramificação mais longa que a outra; seta $k$ " em formato de "Y" e com base coalescente a $\varphi_{\mathrm{s}}$. Tarso da perna III com 5 setas.

\section{Quetotaxia genital: (0-0-4)}

Diagnose: Esta espécie difere de P. taurica Kuznetzov, 1971 e P. magdalenae (Baker \& Delfinado, 1976) por apresentar setas tectais ( $t c$ ' e $t c$ ") do tarso I muito menores, setas $u$ no tarso I bifurcada desde a base (bífida na parte distal em $P$. magdalenae); e setas aspidossomais ro com bases coalescentes.

Observações: O fato do material examinado apresentar apenas 5 setas no tarso da perna III (6 na descrição do gênero) não parece justificar a criação de um novo gênero, visto que no gênero Parapronematus Baker, pertencente à mesma subfamília, isto pode ocorrer também (André, 1980).

\section{SUbFAMÍlia MEYERELLINAE}

Observações: Ácaros desta subfamília são relatados pela primeira vez no Brasil.

\section{Unidade Genérica Meyerellinae 1}

Aspidossoma - Quetotaxia: 4 (bo, ro, la, ex). Seta botridial (bo) semelhante na forma e comprimento às demais setas aspidossomais. Prodorso recurvado.

Opistossoma - Quetotaxia: $11\left(c_{1}, c_{2}, d_{1}, e_{1}, f_{l}, f_{2}, h_{l}, h_{2}, p s_{1}, p s_{2}, p s_{3}\right) ; e_{l}$ em posição dorsal e em linha com $d_{l}$ e $f_{l}$. Quetotaxia genital: Adulto (0-6-5). Formula epimeral: Adulto (3-1-3-3).

Pernas - Fêmur IV dividido. Quetotaxia Adulto: I(9-5+1-4-5-1); II(7-3-2-4-0); III(5-22-2-0); IV(4-2-2-(1+1)-0). Solenidiotaxia: $4\left(\omega_{1}, \omega_{11}, \varphi_{1}\right.$ e $\left.\varphi_{\mathrm{II}}\right)$.

Gnatossoma - Organotaxia do palpo: (6-2-2)+ $\omega$.

Diagnose: Difere do gênero Pseudotriophtydeus André por apresentar 9 setas no tarso da perna I, 5 setas na tíbia da perna I e 3 setas no genu da perna IV.

\section{Meyerellinae 1 sp. $\mathbf{n}$.}

Material examinado: Piracicaba: A. glandulosa.

Idiossoma. Ornamentação dorsal: estriação longitudinal no aspidossoma e nas laterais 
do opistossoma; transversais entre as seta $c_{l}, d_{l}, e_{l}$ e $f_{l}$. Reticulação ausente. Seta botridial (bo) simples, fina, levemente serreada na metade distal. Setas dorsais idiossomais: $e_{l}$ em posição dorsal e em linha com $d_{l}$ e $f_{l}$; todas finas, retas, firmes e finamente serreadas; $f_{2}, h_{1}, h_{2}$, e $p s_{1} 50 \%$ mais longas que as demais. Setas $l a$, ro e ex subiguais e com dois terços do comprimento de $b o ; f_{l}$ menor que a distância $f_{l}-h_{l} ; h_{l}$ maior que a metade da distância $f_{l}-h_{l}$. Estrias ventrais transversais entre $p t$ e $m t_{\alpha}$ e na região anterior a $a g_{l}$.

Gnatossoma: não coberto pelo aspidossoma. Estiletes quelicerais menores que o comprimento combinado do tarso do palpo e eupatídia terminal. Eupatídia $(p \zeta)$ reta e arredondada distalmente. Tarso do palpo mais curto que femurogenu.

Pernas. Garras empodiais (om) ausentes. Setas do tarso I finas e serreadas ao longo de todo comprimento, mais curtas que o segmento; seta $k$ " em forma de pequena clava com base coalescente a de $\varphi_{1}$. Fêmur IV dividido.

\section{Unidade Genérica Meyerellinae 2}

Aspidossoma - Quetotaxia: 4 (bo, ro, la, ex). Seta botridial (bo) semelhante na forma e comprimento às demais setas aspidossomais. Prodorso recurvado.

Opistossoma - Quetotaxia: $11\left(c_{l}, c_{2}, d_{l}, e_{1}, f_{l}, f_{2}, h_{l}, h_{2}, p s_{l}, p s_{2}, p s_{3}\right) ; e_{l}$ em posição dorsal e em linha com $d_{l}$ e $f_{l}$. Quetotaxia genital: Adulto (6,0-6-5). Formula epimeral: Adulto (3-1-3-3).

Pernas - Fêmur IV dividido. Quetotaxia Adulto: I(9-5+1-4-5-1); II(6-3-2-4-1); III(5-22-2-1); IV(5-2-2-(1+1)-0). Solenidiotaxia: $4\left(\omega_{1}, \omega_{11}, \varphi_{1} \mathrm{e} \varphi_{\mathrm{II}}\right)$.

Gnatossoma - Organotaxia do palpo: $(6-2-2)+\omega$.

Diagnose: Difere de Unidade Genérica Meyerellinae 1 por apresentar 7 setas no tarso da perna II, 4 setas no tarso da perna IV e pela ausência das setas $t r I I$ e $\operatorname{trIII}$.

\section{Meyerellinae 2 sp. $\mathbf{n}$.}

Material examinado: Pariquera-Açu: $A$. cordatum. Piracicaba: $H$. crepitans.

Idiossoma. Ornamentação dorsal: estriação dorsal longitudinal no aspidossoma e lateralmente no opistossoma, transversais entre as setas $c_{l}, d_{l}, f_{l}, h_{l}$ e $p s_{l}$ e em forma de 
um "U" invertido entre $e_{I}$. Reticulação ausente. Seta botridial (bo) simples, fina, levemente serreada na porção distal. Setas dorsais idiossomais: $e_{1}$ em posição dorsal em linha com $d_{l}$ e $f_{l}$; todas finas, retas, firmes e finamente serreadas; Setas bo, la, ro, ex, $c_{l}$, $c_{2}, d_{1}, e_{1}$ e $p s_{3}$ subiguais; $f_{1}, h_{1}, h_{2}, p s_{2}$ e $p s_{2} 50 \%$ mais longas que $e_{1}$. Seta $f_{2}$ duas vezes mais longa que $f_{l}$. Estrias ventrais transversais entre $p t$ e $m t_{\alpha}$ e na região anterior a $a g_{l}$.

Gnatossoma: não coberto pelo aspidossoma. Estiletes quelicerais ligeiramente menores que o comprimento combinado do tarso do palpo e eupatídia terminal. Eupatídia $(p \zeta)$ reta e arredondada distalmente. Tarso do palpo mais curto que femurogenu.

Pernas. Garras empodiais (om) ausentes. Solenídio $\omega$ reto e curto. Setas $f t, v$ e $u$ do tarso I finas e serreadas ao longo de todo comprimento, mais curtas que o segmento; as demais setas ( $t c$ e $p$ ) lisas de ponta truncada e arredondada; seta $k$ " em forma de pequena clava. Fêmur IV dividido. Garras tarsais com espículas ventrais.

\section{Subfamília Triophtydeinae}

\section{Triophtydeus Wood, 1965 sensu André, 1985}

\section{Triophtydeus sp.}

Material examinado: Cananéia: $P$. glabrata. Pariquera-Açu: A. cordatum. Piracicaba: C. floribundus.

Idiossoma. Ornamentação dorsal: estriação longitudinal no aspidossoma e lateralmente no opistossoma, transversal na região central entre $c_{l}$ e $h_{l}$. Reticulação ausente. Seta botridial (bo) simples, fina, levemente serreada na porção distal. Setas dorsais idiossomais: $e_{I}$ em posição dorsal em linha com $d_{l}$ e $f_{l}$; todas finas, retas, firmes e finamente serreadas; setas ventrais $50 \%$ menores que $l a$; bo $50 \%$ maior que $h_{2} ; f_{2}, h_{1}$ e $h_{2}$ duas vezes maiores que as demais, que são subiguais em comprimento. Estrias ventrais transversais entre $p t$ e $m t_{\alpha}$ e na região anterior a $a g_{l}$.

Gnatossoma: não coberto pelo aspidossoma. Estiletes quelicerais menores que o comprimento combinado do tarso do palpo e eupatídia terminal. Eupatídia $(p \zeta)$ tripla. Tarso do palpo mais curto que femurogenu.

Pernas. Garras empodiais (om) ausentes. Solenídio $\omega$ reto e curto. Setas do tarso I finas 
e serreadas ao longo de todo comprimento, mais curtas que o segmento; seta $k$ " em forma de "Y"; fềmur IV dividido.

Quetotaxia genital: (0-4-4)

Observações: Alguns espécimens coletados em Pariquera-Açu e um em Cananéia apresentaram apenas 3 setas na tíbia I, ao invés de 4 setas, esperado para os ácaros deste gênero. Como todas as outras características eram muito uniformes para todos os exemplares coletados, estes foram considerados pertencentes a uma mesma espécie. 


\subsection{Conclusões}

- É bastante elevado o número de taxa não descritos de Tydeidae encontrados em euforbiáceas no Estado de São Paulo.

- O grupo mais diverso de Tydeidae em Euphorbiaceae na Mata Atlântica do Estado de São Paulo pertence ao gênero Lorryia. 


\title{
6 OUTROS ÁCAROS (ARTHROPODA: ACARI) ASSOCIADOS A EUFORBIÁCEAS (EUPHORBIACEAE) EM TRÊS LOCALIDADES DO ESTADO DE SÃO PAULO
}

\author{
Autor: MAURICIO SERGIO ZACARIAS \\ Orientador: PROF. DR. GILBERTO JosÉ DE MORAES
}

\section{RESUMO}

Pouco se sabe sobre a diversidade de ácaros em plantas nativas do Brasil. O presente trabalho teve como objetivo o estudo da diversidade de espécies de ácaros das subordens Acaridida, Actinedida e Gamasida, além daqueles já tratados em capítulos anteriores, em plantas nativas da família Euphorbiaceae e em plantas de seringueira cultivada, Hevea brasiliensis (H.B.K.) M. Arg.. O estudo foi conduzido em três localidades do Estado de São Paulo (Pariquera-Açu, Cananéia e Piracicaba). Foram coletados ácaros de 47 espécies, pertencentes a 42 gêneros em 14 diferentes famílias. De todas as espécies, 15 foram coletados em seringueira, sendo 6 de espécies predadoras (das famílias Ascidae, Stigmaeidae, Cunaxidae e Cheyletidae) e 4 de fitófagas (das famílias Tetranychidae, Tenuipalpidae e Eriophyidae). 


\section{OTHER MITES (ARTHROPODA: ACARI) ASSOCIATED WITH EUPHORBIACEOUS PLANTS (EUPHORBIACEAE) IN THREE LOCALITIES OF THE STATE OF SÃO PAULO}

Author: MAURICIO SERGIO ZACARIAS Adviser: Prof. DR. GILBERTo JosÉ DE MORAES

\section{SUMMARY}

Little is known about the diversity of mite species in Brazil. The objective of this work was to study the diversity of mite species of the suborders Acaridida, Actinedida and Gamasida, in addition to those already mentioned in previous chapters, on plants of the family Euphorbiaceae and on rubber tree, Hevea brasiliensis (H.B.K) M. Arg.. The study was conducted in 3 localities of the State of São Paulo (Pariquera-Açu, Cananéia and Piracicaba). Mites of 47 species belonging to 42 genera in 14 families were collected. Fifteen species were collected on rubber tree; 6 of those are predators (from the families Ascidae, Stigmaeidae, Cunaxidae, Cheyletidae) and 4 are phytophagous (from the families Tetranychidae, Tenuipalpidae and Eriophyidae). 


\subsection{Introdução}

Pouco se sabe sobre a diversidade de ácaros em plantas nativas do Brasil. O presente trabalho teve como objetivo o estudo da variedade de espécies de ácaros das subordens Acaridida, Actinedida e Gamasida, além daqueles já tratados em capítulos anteriores, em plantas nativas da família Euphorbiaceae e em plantas de seringueira cultivada, Hevea brasiliensis (H.B.K.) M. Arg., no Estado de São Paulo.

Diversas espécies de ácaros têm sido encontrados sobre a seringueira, muitos dos quais pertencem a famílias cujos componentes são fitófagos. Dentre estas espécies, algumas, como Calacarus heveae Feres, da família Eriophyidae, tem sido mencionados como muito danosas à seringueira. Severa desfolha da seringueira devido a C. heveae foi relatada no Estado de São Paulo pela primeira vez entre 1990 e 1991 (Feres, 1992).

São diversas as possibilidades pelas quais $C$. heveae tenha passado a causar danos significativos à seringueira nos últimos anos. É possível que este ácaro já estivesse associado à seringueira em sua região de origem, no norte de Brasil, onde entretanto não atingiria níveis notáveis devido à ação de seus inimigos naturais. A introdução de $C$. heveae nas regiões Centro-oeste e Sudeste sem que tivesse sido acompanhado de seus inimigos naturais pode ter propiciado a este ácaro a chance de atingir estas altas populações. Como a seringueira passou a ser cultivada extensivamente no Centro-oeste e Sudeste do Brasil apenas nos últimos 20 anos, é possível que $C$. heveae já estivesse antes presente nestas regiões, sobre outras espécies de plantas hospedeiras, nas quais também estaria sendo mantido a níveis baixos pela ação de inimigos naturais. A determinação da possibilidade mais plausível é importante, para se determinar os locais onde deveria ser concentrada a busca de inimigos naturais 
promissores, a serem considerados em um futuro programa de controle biológico desta praga.

Com este trabalho, pretende-se dar o primeiro passo neste estudo, através da determinação das espécies de ácaros associados a euforbiáceas nativas e à seringueira, em três localidades do Estado de São Paulo, apresentando-se aqui os grupos não tratados nos capítulos anteriores. 


\subsection{Metodologia}

Foram escolhidas 3 localidades para amostragem, nos municípios de Pariquera-Açu, Cananéia e Piracicaba. A escolha de Pariquera-Açu e Cananéia baseouse na presença de extensos remanescentes de Mata Atlântica (matas primárias ombrófilas e de restinga, respectivamente) com bom grau de preservação na região, e na disponibilidade de infraestrutura logística na região, representada pela "Estação Experimental J. Cione", pertencente ao Instituto Agronômico de Campinas. O "Parque Phillipe Westin Cabral de Vasconcellos", comumente conhecido como Parque da ESALQ, no Campus Universitário da Escola Superior de Agricultura "Luiz De Queiroz" , Universidade de São Paulo, em Piracicaba, foi escolhido por apresentar uma grande riqueza florística que conta com espécies nativas e exóticas. Este Parque sofre influência de um remanescente de Mata Atlântica (formação florestal de planalto) chamado de Mata da Pedreira (Ivanauskas \& Rodrigues, 1995). Ivanauskas \& Rodrigues (1995) citam a ocorrência de 12 espécies de euforbiáceas arbustivo-arbóreas, pertencentes a 11 gêneros diferentes no Parque da ESALQ.

Na região de Pariquera-Açu, tomaram-se vários pontos na "Estação

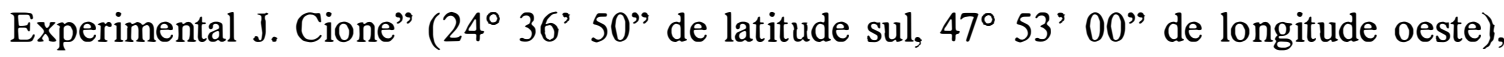
onde foram procuradas plantas da família desejada para amostragem. Em Cananéia, a coleta foi realizada em pontos à margem da Rodovia SP-226, já no interior da ilha (24 $55^{\prime} 00^{\prime \prime}$ de latitude sul, $47^{\circ} 50^{\prime} 00^{\prime \prime}$ de longitude oeste). Em Piracicaba, as plantas foram amostradas em caminhamento pelo Campus da ESALQ $\left(22^{\circ} 42^{\prime} 30^{\prime \prime}\right.$ de latitude sul, $47^{\circ}$ 37 ' 40 " de longitude oeste).

As espécies vegetais amostradas foram: Alchornea glandulosa Poepp. e Endl., A. sidifolia M. Arg., A. triplinervea M. Arg., Aparisthmium cordatum (A. Juss.) 
Baill., Croton floribundus Spreng., C. urucurana Baill., Hevea brasiliensis (H.B.K.) M. Arg. clones C7 e 527-A, Hura crepitans Linn., Joannesia princeps Vell. e Pachystroma longifolium M. Arg., Pera glabrata (Schott) Baill., Sebastiania sp..

O material vegetal coletado de cada planta foi acondicionado em um saco de papel devidamente identificado, que por sua vez foi colocado em um saco plástico e guardado em caixa de isopor com gelo até o retorno ao laboratório, onde foi mantido em refrigerador a aproximadamente $10^{\circ} \mathrm{C}$ para posterior coleta dos ácaros em um período de no máximo uma semana. A montagem dos ácaros foi realizada em lâminas com meio de Hoyer (Flechtmann, 1977), exceto os eriofídeos, que foram montados em meio de Berlese modificado (Jeppson et al., 1975; Amrine \& Manson, 1996).

As espécies de ácaros encontrados no presente trabalho são relacionadas com suas respectivas plantas hospedeiras, localidade e observações pertinentes. As plantas de Cananéia e Pariquera-Açu foram amostradas em abril de 1998 e as de Piracicaba, em junho do mesmo ano.

Espécimens representativos deste estudo foram depositados no Setor de Zoologia Agrícola do Departamento de Entomologia, Fitopatologia e Zoologia Agrícola da Escola Superior de Agricultura "Luiz de Queiroz" da Universidade de São Paulo, Piracicaba - SP, Brasil (ESALQ-USP). 


\subsection{Resultados e Discussão}

Foram encontrados ácaros pertencentes a 47 espécies, de 42 gêneros e 14 diferentes famílias, como indicado a seguir.

\section{ACARIDIDA}

ACARIDAE Ewing e Nesbitt, 1954

Neotropacarus sp.

Material examinado: Cananéia: A. triplinervea. Pariquera-Açu: A. glandulosa, $A$. sidifolia, A. triplinervea, $A$. cordatum, $H$. brasiliensis, Sebastiania sp.. Piracicaba: $A$. glandulosa, A. sidifolia, C. urucurana, C. floribundus, $H$. brasiliensis, J. princeps, $P$. longifolium.

\section{WINTERSCHMIDTIIDAE Oudemans, 1923}

Czenspinskia sp.

Material examinado: Cananéia: A triplinervea. Pariquera-Açu: A. glandulosa, $A$. sidifolia, A. triplinervea, A. cordatum, H. brasiliensis. Piracicaba: A. glandulosa, A. sidifolia, C. floribundus, C. urucurana, H. brasiliensis, $H$. crepitans, $P$. longifolium.

\section{Oulenzia sp.}

Material examinado: Pariquera-Açu: A. glandulosa, A. sidifolia, H. brasiliensis. Piracicaba: A. glandulosa, A. sidifolia, C. floribundus, H. crepitans, J. princeps, $P$. longifolium. 


\section{ACTINEDIDA}

CUNAXIDAE Thor, 1902

Cunaxa sp.

Material examinado: Piracicaba: C. floribundus.

Observacões: Esta foi a única espécie de cunaxídeo encontrada nas plantas de Piracicaba.

\section{Cunaxoides sp.}

Material examinado: Pariquera-Açu: Sebastiania sp..

Neocunaxoides sp.

Material examinado: Pariquera-Açu: A. glandulosa, A. sidifolia, A. triplinervea, Sebastiania sp..

\section{Pulaeus sp.}

Material examinado: Pariquera-Açu: A. glandulosa, A. sidifolia, A. triplinervea,A. cordatum, H. brasiliensis.

Scirula sp.

Material examinado: Cananéia: A. triplinervea. Pariquera-Açu: A. glandulosa, Sebastiania $\mathrm{sp.}$.

Observações: Esta foi a única espécie de cunaxídeo encontrada em plantas de Cananéia.

Scutopalus sp.

Material examinado: Pariquera-Açu: A. glandulosa, A. triplinervea, A. cordatum, $H$. brasiliensis, Sebastiania $\mathrm{sp..}$

CHEYLETIDAE Leach, 1815

Cheyletia sp.

Material examinado: Piracicaba: C. floribundus, H. brasiliensis, H. crepitans, $P$. longifolium. 
STIGMAEIDAE Oudemans, 1931

Agistemus sp.

Material examinado: Cananéia: A. triplinervea. Pariquera-Açu: A. glandulosa, $A$. triplinervea, A. cordatum, $H$. brasiliensis, Sebastiania sp.. Piracicaba: A. glandulosa, C. floribundus, C. urucurana, H. brasiliensis, H. crepitans, J. princeps, P. longifolium.

Eryngiopus sp.

Material examinado: Piracicaba: P. longifolium.

Observações: Somente um espécimen coletado.

Ledermuelleria sp.

Material examinado: Piracicaba: A. glandulosa.

Observações: Somente um espécimen coletado.

\section{Zetzellia sp.}

Material examinado: Cananéia: $A$. triplinervea. Pariquera-Açu: A. cordatum. Piracicaba: $H$. brasiliensis, $H$. crepitans, P. longifolium.

\section{EUPALOPSELLIDAE Willmann, 1952}

Exothorhis sp.

Material examinado: Piracicaba: C. floribundus.

Observações: Somente do is indivíduos deste gênero foram coletados.

EUPODIDAE Koch, 1842

Eupodes sp.

Material examinado: Pariquera-Açu: A. glandulosa, A. cordatum, Sebastiania sp.. Piracicaba: A. glandulosa, C. floribundus. 
TARSONEMIDAE Kramer, 1877

Daidalotarsonemus sp.

Material examinado: Pariquera-Açu: A. cordatum, Sebastiania sp.. Piracicaba: $C$. floribundus.

Fungitarsonemus sp.

Material examinado: Cananéia: $P$. glabrata. Pariquera-Açu: A. glandulosa, $A$. cordatum, Sebastiania sp.. Piracicaba: A. glandulosa, J. princeps.

Tarsonemus (Tarsonemus) spp.

Material examinado: Cananéia: $A$. triplinervea. Pariquera-Açu: A. glandulosa, $A$. sidifolia, A. triplinervea, A. cordatum, H. brasiliensis, Sebastiania sp.. Piracicaba: $A$. glandulosa, A. sidifolia, C. floribundus, C. urucurana, H. crepitans, J. princeps, P. longifolium.

Observações: Provavelmente tratam-se de várias espécies.

\section{Xenotarsonemus sp. 1}

Material examinado: Pariquera-Açu: $A$. cordatum.

Observações: Esta espécie é bastante abundante em $A$. cordatum, caracterizando-se por apresentar setas dorsais bastante longas (maiores que metade do comprimento do ácaro) e robustas.

\section{Xenotarsonemus sp. 2}

Material examinado: Pariquera-Açu: $A$. glandulosa, A. triplinervea, A. cordatum, $H$. brasiliensis.

Observações: Esta espécie apresenta todas as setas dorsais curtas, com o comprimento inferior a metade do comprimento da respectiva placa onde se inserem. 
Xenotarsonemus sp.3

Material examinado: Pariquera-Açu: A. cordatum.

Observações: Esta espécie apresenta todas as setas dorsais curtas, diferindo de Xenotarsonemus sp.2 por estas serem quase tão longas quanto o comprimento da respectiva placa onde se inserem.

\section{Xenotarsonemus sp.4}

Material examinado: Pariquera-Açu: A. glandulosa.

Observações: Esta espécie apresenta todas as setas dorsais curtas, com o comprimento inferior a metade do comprimento da respectiva placa onde se inserem, diferindo de Xenotarsonemus sp.2 por apresentar a tégula mais longa que a perna IV.

\section{Xenotarsonemus sp.5}

Material examinado: Piracicaba: A. glandulosa.

Observações: Esta espécie apresenta as setas dorsais das placas $\mathrm{D}, \mathrm{EF}$ e $\mathrm{H}$ mais longas que a respectiva placa onde se inserem e por apresentar as setas $t c$ " e $v$ 'Ti da perna IV muito longas, sendo a primeira tão longa quanto o comprimento total do espécimen estudado.

TENUIPALPIDAE Berlese, 1913

Brevipalpus sp.

Material examinado: Pariquera-Açu: A. sidifolia, A. triplinervea, A. cordatum, $H$. brasiliensis, Sebastiania sp.. Piracicaba: A. glandulosa, C. floribundus, C. urucurana, J. princeps, P. longifolium.

Tenuipalpus sp.

Material examinado: Piracicaba: A. glandulosa.

Observações: Apenas um espécimen deste gênero foi coletado durante o presente estudo. 
TETRANYCHIDAE Donnadieu, 1875

Allonychus reisi Paschoal

Allonychus reisi Paschoal, 1970: 446.

Material examinado: Pariquera-Açu: A. cordatum. Piracicaba: A. glandulosa, $C$. urucurana, $J$. princeps.

Eutetranychus banksi (McGregor, 1914)

Tetranychus banksi McGregor, 1914: 358.

Anychus banksi, McGregor, 1919: 644.

Eutetranychus banksi, McGregor, 1950:268; Pritchard e Baker, 1955: 115; Flechtmann e Baker, 1970: 156; Flechtmann e Baker, 1975: 112.

Material examinado: Pariquera-Açu: A. cordatum, $H$. brasiliensis. Piracicaba: $H$. brasiliensis.

Observações: Os espécimens coletados em $A$. cordatum em Pariquera-Açu encontravamse aparentemente infectados por um patógeno não identificado.

Neotetranychus sp. $\mathrm{n}$.

Material examinado: Piracicaba: C. floribundus.

Observações: Os espécimens coletados neste estudo correspondem à espécie descrita por Feres (1984) coletada em Bauhinia sp., e provavelmente à citada por Feres \& Moraes (1998) coletada em A. glandulosa.

\section{Oligonychus gossypii (Zacher)}

Paratetranychus gossypii Zacher, 1920: 181-187.

Oligonychus gossypii, Pritchard \& Baker, 1955: 359.

Material examinado: Piracicaba: A. sidifolia, C. urucurana, H. brasiliensis.

\section{Oligonychus sp.}

Material examinado: Pariquera-Açu: A. glandulosa, A. sidifolia, A. cordatum.

Observações: Não foi possível a identificação ao nível de espécie devido à falta de 
espécimens machos.

Tetranychus (Tetranychus) sp.

Material examinado: Pariquera-Açu: A. cordatum. Piracicaba: $H$. crepitans.

Observações: Não foi possível a identificação ao nível de espécie devido à falta de espécimens machos.

\section{DIPTILOMIOPIDAE Keifer, 1944}

Diptilomiopinae sp.

Material examinado: Piracicaba: Alchornea glandulosa.

Observações: Trata-se, provavelmente de um novo gênero.

Asetadiptacus sp.

Material examinado: Pariquera-Açu: $A$. glandulosa, $A$. triplinervea. Piracicaba: $A$. sidifolia, $C$. floribundus, $P$. longifolium.

ERIOPHYIDAE Nalepa, 1898

Calacarus heveae Feres, 1992

Calacarus heveae Feres, 1992: 62.

Material examinado: Pariquera-Açu: H. brasiliensis. Piracicaba: H. brasiliensis.

\section{Calacarus sp.}

Material examinado: Pariquera-Açu: $A$. cordatum.

Observações: Vários espécimens pertencentes a esta espécie foram coletados nesta espécie vegetal. São extremamente semelhantes a $C \cdot$ heveae. Entretanto a confirmação da espécie só será possível após uma comparação com o tipo de $C$. heveae.

A. cordatum foi a espécie de euforbiácea mais comumente encontrada nos remanescentes de Mata Atlântica de Pariquera-Açu neste trabalho, sendo dominante na subcopa da maioria das áreas estudadas. Esta planta ocorre nas áreas de florestas desde a Costa Rica ao norte passando por Panamá, Colômbia, Equador, Peru, Venezuela e 
Bolívia ao sul (Missouri Botanical Garden, 2001) e no Brasil. ao menos no Estado de São Paulo.

Em uma coleta posterior realizada em julho do mesmo ano, outros espécimens foram encontrados em A. cordatum, em Pariquera-Açu, e em A. glandulosa, de Pariquera-Açu e Piracicaba. A. glandulosa tem sido relatada principalmente na floresta pluvial da encosta Atlântica desde os Estados do Rio de Janeiro e Minas Gerais até o de Rio Grande do Sul (Lorenzi, 1992). Sua ocorrência também é relatada no Suriname, Guiana Francesa e Guiana (Missouri Botanical Garden, 2001).

\section{Eriophyes sp.}

Material examinado: Piracicaba: P. longifolium.

$$
\text { Epitrimerus goniathrix Micos e Flechtmann }
$$

Epitrimerus goniathrix Micos e Flechtmann, 1999: 134.

Material examinado: Piracicaba: H. crepitans.

Phyllocoptinae sp.1

Material examinado: Pariquera-Açu: A. sidifolia. Piracicaba: A. glandulosa, $A$. sidifolia.

Observações: Trata-se de novo gênero, próximo de Spinacus e Vittacus.

Phyllocoptinae sp.2

Material examinado: Piracicaba: A. glandulosa, A. sidifolia.

Observações: Trata-se de um novo gênero.

Paraphytoptus sp.

Material examinado: Piracicaba: C. floribundus.

Shevtchenkella sp.

Material examinado: Piracicaba: A. glandulosa, C. floribundus. 
Observações: Trata-se de uma espécie diferente de S. petiolula Feres (1998), descrita de seringueiras dos Estados de São Paulo e Mato Grosso do Sul.

\section{Tegonotus sp.}

Material examinado: Piracicaba: P. longifolium.

\section{Paraphvtella sp.}

Material examinado: Piracicaba: $C \cdot$ urucurana.

Eriophyidae sp.

Material examinado: Piracicaba: P. longifolium.

Observações: Não foi possível se posicionar esta espécie em nenhuma das subfamílias conhecidas.

\section{GAMASIDA}

AMEROSEIIDAE Evans, 1963

?Epicriopsis sp.

Material examinado: Piracicaba: $C \cdot$ floribundus.

Observações: Provavelmente trata-se de um novo gênero, próximo a Epicriopsis (G.W. KRANTZ, 2000 comunicação pessoal).

\section{ASCIDAE}

\section{Asca sp.}

Material examinado: Cananéia: $A$. triplinervea, $P$. glabrata. Pariquera-Açu: $A$. glandulosa, A. sidifolia, A. triplinervea, A. cordatum, H. brasiliensis, Sebastiania sp.. Piracicaba: A. glandulosa.

Observações: Aparentemente, duas espécies diferentes pertencentes a este gênero foram encontradas em plantas do gênero Alchornea em Pariquera-Açu e Piracicaba e em $A$. cordatum em Pariquera-Açu. Estas espécies parecem diferir no comprimento e forma das setas dorsais. 
Além do fato de ter sido realizada em três localidades diferentes, as diferenças na conformação estrutural das folhas (domáceas, pilosidade, tamanho, etc.), das diversas espécies amostradas neste estudo, podem explicar a grande diversidade obtida. Aquelas diferenças podem afetar tanto a diversidade como a freqüência de espécies (Walter e O’Dowd, 1992a e b).

De todas as espécies, 15 foram coletadas em seringueira, sendo 6 de grupos distintamente predadores (pertencentes às famílias Ascidae, Stigmaeidae, Cunaxidae e Cheyletidae) e 4 de grupos distintamente fitófagos (pertencentes às famílias Tetranychidae, Tenuipalpidae e Eriophyidae); as demais pertencem a grupos cujos hábitos são pouco conhecidos. Este estudo acrescenta 7 espécies de ácaros à relação apresentada por Feres (2000) para a seringueira. 


\subsection{Conclusões}

- Dentre as famílias consideradas neste estudo, Eriophyidae e Tarsonemidae são as que apresentam a maior diversidade em euforbiáceas nas regiões estudadas.

- Dentre os taxa considerados neste estudo, Neotropacarus sp. (Acaridae), Czenspinskia sp. (Winterschmidtiidae) e Agistemus sp. (Stigmaeidae) estão entre as espécies que habitam as maiores diversidades de hospedeiros. 


\title{
7 DIVERSIDADE DE ÁCAROS (ARTHROPODA: ACARI) EM EUFORBIÁCEAS DE TRÊS LOCALIDADES DO ESTADO DE SÃO PAULO
}

\author{
Autor: MAURICIO SERGIO ZACARIAS \\ Orientador: PROF. DR. GILBERTO JosÉ DE MORAES
}

\section{RESUMO}

No contexto do controle biológico de pragas agrícolas, a manutenção de estações de refúgio tem função fundamental na preservação da diversidade de inimigos naturais. Plantas da família Euphorbiaceae são bastante comuns e freqüentes em ecossistemas naturais e mesmo em sistemas regenerados no Estado de São Paulo. Estas plantas podem atuar como reservatórios naturais dos ácaros fitófagos e seus inimigos naturais que ocorrem ou possam vir a ocorrer em plantas cultivadas, principalmente da mesma família. O presente trabalho teve por objetivo comparar a riqueza relativa, diversidade e uniformidade de espécies de ácaros em plantas nativas da família Euphorbiaceae (seringueira, Hevea brasiliensis (H.B.K.) M. Arg., entre estas), assim como a similaridade entre estas plantas em relação às espécies de ácaros que abrigam. Foram coletados 31.603 ácaros de 105 diferentes espécies pertencentes a 74 gêneros e 16 famílias. Deste total de espécies 21 pertencem a famílias essencialmente fitófagas (Tenuipalpidae, Tetranychidae, Diptilomiopidae e Eriophyidae) e 43 a predadoras (Ameroseiidae, Ascidae, Cunaxidae, Cheyletidae, Eupalopsellidae, Stigmaeidae e Phytoseiidae), as demais (41 espécies) são compostas principalmente por ácaros que são principalmente detritívoros, algívoros, fungívoros, bacteriófagos e polenófagos. As plantas estudadas se apresentam em 3 grupos distintos em relação às suas similaridades da acarofauna que abrigam. As plantas do Grupo "Piracicaba" apresentam maior proporção de ácaros de espécies fitófagas. Aquelas do Grupo "Pariquera-Açu" apresentam maior proporção de ácaros de espécies predadoras, e a única planta do Grupo "Pera glabrata (Schott) Baill." apresenta maior proporção de espécies de ácaros generalistas que os demais grupos. As plantas do Grupo "Pariquera-Açu" apresentam, 
em média, maior diversidade, uniformidade e riqueza de espécies que os demais grupos. As seringueiras do Grupo "Pariquera-Açu" apresentam alta similaridade com as demais plantas do mesmo grupo, indicando que a interação entre estas deve ser responsável pelos maiores índices de diversidade, uniformidade e riqueza de espécies em comparação às seringueiras do Grupo "Piracicaba". 


\section{MITE DIVERSITY (ARTHROPODA: ACARI) ON EUPHORBIACEOUS PLANTS (EUPHORBIACEAE) IN THREE LOCALITIES OF THE STATE OF SÃO PAULO}

Author: MAURICIO SERGIO ZACARIAS Adviser: Prof. Dr. Gilberto José DE MORAES

\section{SUMMARY}

In relation to the biological control of agricultural pests, the preservation of natural reserves plays a fundamental role in the conservation of the diversity of natural enemies. Plants of the family Euphorbiaceae are very common and frequent in natural ecosystems and even in regenerated systems of the State of São Paulo. Those plants may function as reservoirs of phytophagous mites and their natural enemies that occur now or may occur in the future on cultivated plants, especially of the same family. The objective of this work was to compare the relative mite species richness, diversity and uniformity, and plant similarity in relation to the mite species they harbored. A total of 31,603 mites belonging to 105 species within 74 genera of 16 families were collected. Twenty one of the species collected belonged to families composed of essentially phytophagous species (Tenuipalpidae, Tetranychidae, Diptilomiopidae and Eriophyidae) and 43 belonged to families composed of essentially predaceous species (Ameroseiidae, Ascidae, Cunaxidae, Cheyletidae, Stigmaeidae, Eupalopsellidae and Phytoseiidae). The remaining 41 species contain mainly plant mites that are mostly detritivorous, algivorous, fungivorous, bacteriophagous and pollenophagous. The plants studied were classified in 3 groups, according to their similarities in relation to the mite fauna they harbored. Plants of the "Piracicaba" Group have higher proportion of phytophagous mites. Those of the "Pariquera-Açu" Group have higher proportion of predaceous mites, and the only plant of the "Pera glabrata" Group have a higher proportion of generalist mites than other plant groups. Plants of the "Pariquera-Açu" Group have on the average higher diversity, uniformity and species richness than other groups. Rubber trees of 
Pariquera-Açu have higher similarities with plants of the same group, indicating that the interaction between them should be responsible for the higher indexes of diversity, uniformity and species richness in comparison with the rubber trees of the "Piracicaba" Group. 


\subsection{Introdução}

Pouco se sabe sobre a diversidade de ácaros em plantas nativas no Brasil.

Em sua maioria, os apelos pela conservação da biodiversidade na superfície terrestre veiculados nos meios de comunicação são emocionais e alertam para o perigo de extinção que sofrem principalmente grandes mamíferos, répteis, peixes e certos vegetais. Ecologistas estimulam os estudos dos recursos de emprego imediato (frutos diversos, borracha, etc.) presentes e importantes para as comunidades humanas nas florestas. Também tem se discutido a pesquisa de potencial dos fármacos de origem vegetal. Todos estes recursos de nossa vegetação natural tem forte apelo visual no dia a dia.

Já, aqueles organismos não vistosos, aqueles que não são utilizados na alimentação e aqueles de porte pequeno, especialmente os artrópodes, tem pouco destaque, por serem seus efeitos não diretamente visíveis ao público leigo. No entanto, estes podem ser muito sensíveis ao menor distúrbio nos ambientes naturais.

No contexto do controle biológico de pragas agrícolas, a manutenção de estações de refúgio tem função fundamental na preservação da diversidade de inimigos naturais. Pesquisas têm demonstrado que tanto o tamanho quanto a proximidade das estações entre si são importantíssimos na manutençào a longo prazo da diversidade dos organismos aí presentes.

Plantas da família Euphorbiaceae são bastante comuns e freqüentes em ecossistemas naturais e mesmo em sistemas regenerados no Estado de São Paulo (Nogueira, 1976; Cesar \& Leitão Filho, 1990; Salis et al., 1994). Estas plantas podem atuar como reservatórios naturais de ácaros fitófagos e de seus inimigos naturais que ocorrem ou possam vir a ocorrer em plantas cultivadas, principalmente da mesma 
família. Isto se reveste de importância se levarmos em consideração a tendência ao monocultivo em larga escala e a destruição concomitante de ecossistemas naturais, com a diminuição da diversidade dos inimigos naturais de organismos que aí ocorrem.

De um ponto de vista aplicado, as constantes e rápidas alterações por que passam nossos sistemas de cultivo bem como a introdução de novas espécies cultivadas demandam espécies de inimigos naturais com diversidade genética que permita o estabelecimento de populações adaptadas a diferentes condições ambientais e diferentes pragas (Lasalle \& Gauld, 1991).

Como parte da estratégia de conservação e aumento de inimigos naturais, a prática de manutenção de áreas de vegetação natural próxima aos cultivos visa fornecer habitats apropriados à preservação de inimigos naturais. Estas criam condições favoráveis à manutenção, proliferação e diversificação dos inimigos naturais. Estas áreas de vegetação são comumente referidas como "estações de refúgio".

Muitos estudos documentam a importância das "estações de refúgio" na perpetuação de inimigos naturais de pragas que se movem para os cultivos próximos (Altieri, 1994). Vegetações naturais ao redor dos cultivos fornecem alimento alternativo e habitat para inimigos naturais de pragas agrícolas, assim provendo recursos sazonais para que estes atravessem períodos desfavoráveis à sua manutenção nas culturas de interesse em certas épocas do ano (Altieri, 1994).

Vários estudos indicam que a abundância e a diversidade de insetos entomófagos em um campo determinado estão intimamente relacionadas à natureza da vegetação circundante. Esta pode também determinar as taxas de colonização de inimigos naturais em uma cultura particular, numa eventual redução ou eliminação destes organismos na cultura considerada (Altieri \& Todd, 1981 citados por Altieri, 1994).

Outra função importante destas estações é a manutenção de inimigos naturais ainda pouco ou não estudados. Novas pragas podem vir a surgir no futuro e mesmo pragas atuais podem vir a desenvolver alguma forma de resistência aos inimigos naturais atualmente conhecidos e, então, torna-se necessário retornar aos habitats naturais à procura de novas opções para uso prático. 
O presente trabalho teve por objetivo comparar a riqueza relativa, diversidade e uniformidade de espécies de ácaros em plantas da família Euphorbiaceae de ocorrência natural no Estado de São Paulo, e da seringueira, Hevea brasiliensis (H.B.K.) M. Arg, tendo em vista um aprofundamento do conhecimento da acarofauna do Estado de São Paulo. Procurou-se também realizar uma análise ecológica dos dados apresentados nos capítulos anteriores, buscando-se relacionar entre si as espécies encontradas e relacionar as mesmas às espécies de plantas estudadas e aos ambientes incluídos no estudo. 


\subsection{Metodologia}

Foram escolhidas 3 localidades para amostragem, nos municípios de Pariquera-Açu, Cananéia e Piracicaba. A escolha de Pariquera-Açu e Cananéia baseouse na presença de extensos remanescentes de Mata Atlântica (matas primárias ombrófilas e de restinga, respectivamente) com bom grau de preservação na região, e na disponibilidade de infraestrutura e de apoio logístico, representada pela "Estação Experimental J. Cione", pertencente ao Instituto Agronômico de Campinas. O Parque "Phillipe Westin Cabral de Vasconcellos" (comumente conhecido como Parque da ESALQ), no Campus Universitário da Escola Superior de Agricultura "Luiz De Queiroz", Universidade de São Paulo, em Piracicaba, foi escolhido por apresentar uma grande riqueza florística que conta com espécies nativas e exóticas. Este sofre influência de um remanescente de Mata Atlântica (formação florestal de planalto) chamado de Mata da Pedreira (Ivanauskas \& Rodrigues, 1995). Ivanauskas \& Rodrigues (1995) citam a ocorrência de 12 espécies de euforbiáceas arbustivo-arbóreas, pertencentes a 11 gêneros diferentes no Parque da ESALQ.

Na região de Pariquera-Açu, tomaram-se vários pontos na a $24^{\circ} 36^{\prime} 50^{\prime \prime}$ de latitude sul e $47^{\circ} 53^{\prime} 00^{\prime \prime}$ de longitude oeste, onde foram procuradas plantas da família desejada para amostragem. Em Cananéia, a coleta foi realizada em pontos à margem da Rodovia SP-226 já no interior da ilha. Em Piracicaba (24 55'00" de latitude sul, $47^{\circ} 50^{\prime} 00^{\prime}$ de longitude oeste), as plantas foram amostradas em caminhamento pelo Campus da ESALQ (22 $42^{\prime} 30^{\prime \prime}$ de latitude sul, $47^{\circ} 37^{\prime} 40^{\prime \prime}$ de longitude oeste).

Como o número de espécimens vegetais amostrados estava na dependência de sua disponibilidade nas áreas consideradas, não foi possível obter 
homogeneidade neste número. Assim, para a maioria das espécies vegetais foi possível amostrar 4 plantas enquanto que para outras este número foi menor. No total, foram amostradas 49 plantas pertencentes a 12 espécies de 9 gêneros diferentes, como indicado a seguir:

Piracicaba: Alchornea glandulosa Poepp. \& Endl. (3 plantas), A. sidifolia M. Arg. (1 planta), Croton floribundus Spreng. (4 plantas), C. urucurana Baill. (2 plantas), Hevea brasiliensis (H.B.K.) M. Arg. clone 527-A (4 plantas), Hura crepitans Linn. (2 plantas), Joannesia princeps Vell. (4 plantas) e Pachystroma longifolium M. Arg. (4 plantas).

Pariquera-Açu: A. glandulosa (2 plantas), A. sidifolia (2 plantas), Alchornea triplinervea M. Arg. (4 plantas), Aparisthmium cordatum (A. Juss.) Baill. (4 plantas), H. brasiliensis clone C7 (4 plantas), Sebastiania sp. (4 plantas).

Cananéia: A. triplinervea (2 plantas), Pera glabrata (Schott) Baill. (3 plantas).

As amostragens foram conduzidas em meados de 1998, na subcopa, a uma altura média de $6 \mathrm{~m}$, tomando-se um número variável de folhas de cada planta, de acordo com o tamanho daquelas: 20 folhas pequenas (A. triplinervea e $P$. glabrata de Cananéia, Sebastiania sp. de Pariquera-Açu; 15 folhas médias (A. triplinervea de Pariquera-Açu, A. glandulosa e A. sidifolia de Pariquera-Açu e Piracicaba, , $C$. urucurana e $H$. crepitans de Piracicaba) e 10 folhas grandes (A. cordatum, $C$. floribundus e $H$. brasiliensis (das duas localidades)). Estes correspondem ao número total de folhas coletado em cada uma de duas regiões dos ramos das plantas: região apical (entre as primeiras 5 folhas a partir do ponteiro) e região mediana (folhas totalmente formadas e não senescentes) de cada planta.

O material vegetal coletado foi individualizado por planta em sacos de papel devidamente identificados, por sua vez foram colocados em sacos plásticos e guardados em caixa de isopor com gelo até o retorno ao laboratório, onde então foram mantidos em refrigerador a aproximadamente $10^{\circ} \mathrm{C}$. No laboratório, as folhas foram inicialmente examinadas com auxílio de microscópio estereoscópico, até no máximo 1 semana após a coleta. Os ácaros da superfamília Eriophyoidea foram coletados com 
auxílio de um pincel fino, enquanto os demais ácaros foram coletados com o auxílio de um coletor por sucção (Zacarias \& Oliveira, 2000). Todo o material de Pariquera-Açu e Cananéia foi processado dessa maneira. Após a coleta em duas espécies de plantas de Piracicaba ( $H$. crepitans e $A$ sidifolia), foi verificada a inviabilidade de se continuar a coleta através daquele método, devido à grande incidência de eriofídeos. Passou-se então a utilizar uma metodologia, tão eficiente quanto a anterior, porém mais rápida, que envolve a lavagem das folhas com licor de Keifer (Jeppson et al., 1975). De forma similar ao método descrito por Krantz (1978), uma pisseta contendo o licor é apertada vigorosamente para produzir um forte jato sobre a superficie foliar causando uma lavagem da folha. O licor contendo os ácaros, e demais organismos que estejam nas folhas escorre e é coletado em papel de filtro em um funil com filtragem a vácuo. $O$ material retido no papel de filtro é então passado para um frasco (também através de lavagem com a pisseta contendo o licor de Keifer), para armazenagem até que sejam montados. Procedeu-se a montagem dos ácaros em lâminas com meio de Hoyer (Flechtmann, 1977), exceto os eriofideos, que foram montados em meio de Berlese modificado (Jeppson et al., 1975; Amrine \& Manson, 1996) para posterior identificação específica.

No caso de espécies com um número muito grande de indivíduos (acima de 150), apenas uma subamostra foi montada, correspondendo aos ácaros presentes em $10 \%$ do meio preservativo. Os ácaros encontrados foram contados, multiplicando-se por dez os valores obtidos para uma estimativa do total de cada espécie na amostra inicial.

Determinou-se a diversidade através do índice de Shannon-Weiner (Odum, 1988), a riqueza de espécies e a unformidade através dos índices de Pielou (Odum, 1988). Para todos os índices utilizou-se nas formulas o logarítmo de base 10 $\left(\log _{10}\right)$. Determinaram-se também os índices de similaridade de Mountford (Silveira Neto et al., 1976) das espécies vegetais, de acordo com as espécies de ácaros que abrigavam. 


\subsection{Resultados e Discussão}

Foram coletados 31.603 ácaros de 105 diferentes espécies pertencentes a 74 gêneros e 16 famílias (Tabela 2). Deste total de espécies, 21 pertencem a famílias essencialmente fitófagas (Tenuipalpidae, Tetranychidae, Diptilomiopidae e Eriophyidae) e 43 a famílias essencialmente predadoras (Ameroseiidae, Ascidae, Cunaxidae, Cheyletidae, Stigmaeidae, Eupalopsellidae e Phytoseiidae). As demais espécies encontradas (41 espécies) pertencem a famílias de hábitos alimentares variados e/ ou pouco conhecidos, assumindo-se que sejam principalmente detritívoros, algívoros, fungivoros, bacteriófagos ou polenófagos (Walter \& O’Dowd, 1995). No presente estudo, estas são consideradas generalistas. Algumas espécies em Tydeidae podem ser predadoras obrigatórias, predadoras facultativas ou fitófagas, enquanto algumas de espécies de Tarsonemidae podem ser fitófagas. No entanto, não se conhecem os hábitos alimentares das espécies encontradas neste estudo, elas são aqui consideradas como generalistas.

Do total de espécies fitófagas, 1 foi encontrada em Cananéia, 9 em Pariquera-Açu, e 19 em Piracicaba. Destas, 7 foram comuns a Pariquera-Açu e Piracicaba e a única de Cananéia foi comum a Pariquera-Açu e Piracicaba.

Dentre as espécies predadoras, 28 foram coletadas em Pariquera-Açu e 25 em Piracicaba, sendo 10 comuns às duas localidades, 7 ocorreram em Cananéia mas nenhuma exclusivamente nesta localidade, sendo 3 em comum com Pariquera-Açu e as outras 4 comuns às 3 localidades.

Dentre as espécies generalistas, 34 foram coletadas em Pariquera-Açu, 22 em Piracicaba e 9 em Cananéia sendo que esta última localidade não apresentou espécies exclusivas sendo 3 em comum com Pariquera-Açu e 7 comum às três localidades. Em 
Pariquera-Açu 16 foram exclusivas e 8 em comum com Piracicaba. Há que se considerar entretanto que o número de plantas amostradas não foi o mesmo nas três áreas de coleta. O número plantas amostradas foi maior em $\mathrm{P}$ iracicaba e menor em Cananéia, o que não permite uma comparação direta entre as três regiões em termos de números absolutos de espécies encontradas em qualquer das categorias.

No que se refere à seringueira, $H$. brasiliensis, levando-se em consideração o número de indivíduos coletados por espécie, observa-se que em Piracicaba as espécies fitófagas compreenderam uma maior proporção $(29,5 \%)$ que as espécies predadoras (6,0\%), enquanto em Pariquera-Açu as espécies predadoras ocorreram em maior proporção $(27,6 \%)$ que as fitófagas (11,3\%). As espécies generalistas apresentaram proporções semelhantes (64,5\% e 61,1\% respectivamente) em Piracicaba e Pariquera-Açu. Em seringueiras de Piracicaba, $85 \%$ dos espécimens coletados corresponderam a apenas duas espécies, o tideídeo Lorryia sp. n. 1 (58,2\% do total) e o eriofídeo Calacarus heveae Feres, 1992 (27\% do total). Em Pariquera-Açu, $50,2 \%$ dos espécimens coletados corresponderam a apenas duas espécies, o tideídeo Lorryia formosa Cooreman, 1958 (29,7\%) e o fitoseídeo Typhlodromips sp. (20,5\%).

A análise da similaridade entre as espécies de plantas, de acordo com as espécies de ácaros que apresentavam em comum, possibilitou a delimitação de 3 grupos de espécies vegetais distintos (Figura 7): Grupo "Pariquera-Açu" composto por todas espécies vegetais de Pariquera-Açu mais $A$. triplinervea de Cananéia; Grupo "Piracicaba" composto por todas espécies vegetais de Piracicaba e Grupo "P. glabrata (Schott) Baill." composto pelas plantas desta espécie vegetal de Cananéia.

A caracterização dos dois principais grupos encontrados ("Piracicaba" e "Pariquera-Açu") pode ser devida aos diferentes fatores abióticos determinados pela localização geográfica dos locais estudados, às diferentes composições das comunidade vegetais em cada local, ou ainda à influência das atividades humanas, de forma mais intensa em Piracicaba que nas demais localidades. A espécie vegetal P. glabrata diferenciou muito de outros dois grupos (somente $1,62 \%$ de similaridade) e isto pode ser devido às características morfológicas ou fisiológicas da planta, que a tornam muito diferente das outras plantas em relação à comunidade de ácaros que abriga. 
Em relação às espécies de ácaros predominantes em cada grupo de plantas, observa-se que no Grupo "Pariquera-Açu" as espécies fitófagas compreenderam apenas $8,7 \%$ e as predadoras $52,1 \%$ dos ácaros coletados. Já no Grupo "Piracicaba", as espécies fitófagas compreendem $72,9 \%$ e as predadoras 5,2\% dos ácaros coletados, sendo que a maioria das espécies fitó fagas pertenciam à família Eriophyidae.

Uma análise da similaridade entre espécies vegetais nos grupos observados (Figura 7) indica que se poderia esperar menos problemas com ácaros fitófagos em seringueiras na região de Pariquera-Açu que na região de Piracicaba; é de se esperar um fluxo maior de inimigos naturais da vegetação nativa às plantas de seringueira na primeira que na segunda região. Há que se ressaltar que em ambas as regiões o estudo foi feito em plantios de seringueira de idades próximas ( 7 anos em Pariquera-Açu e 9 anos em Piracicaba) e feitos em monocultivo. A diferença maior, entretanto, era que em Pariquera-Açu o cultivo de seringueira está circundado em grande parte por mata pouco alterada, enquanto em Piracicaba o plantio está em sua maior parte circundado por culturas anuais ou cafezal.

A espécie vegetal que apresentou o maior índice de diversidade no Grupo "Pariquera-Açu" foi $A$. triplinervea $(H=1,21)$ e no Grupo "Piracicaba", foi $A$. glandulosa $(H=0,92)$ (Tabela 3).

Ao se comparar a riqueza de espécies entre as plantas que ocorrem em mais de uma localidade (A. glandulosa, A. sidifolia e H. brasiliensis em Pariquera-Açu e Piracicaba e $A$. triplinervea em Pariquera-Açu e Cananéia), verifica-se que esta foi sempre maior em Pariquera-Açu. Com relação ao índice de diversidade, o resultado se repete para $A$. sidifolia, $H$. brasiliensis e $A$. triplinervea, porém não para $A$. glandulosa, que apresentou o mais baixo índice em Pariquera-Açu, isto devido à sua baixa uniformidade $(0,42)$. Apesar disso este índice de diversidade é superior ao de todas as outras espécies vegetais de Piracicaba, e a uniformidade é superior às de 5 das 8 espécies vegetais desta mesma localidade.

De maneira geral, pode-se dizer que o Grupo "Pariquera-Açu" apresentou diversidade média $\left(H_{\text {média }}=0,98\right)$ ligeiramente superior à do Grupo P. glabrata $(H=$ $0,84)$ e 1,8 vezes maior que aquela do Grupo "Piracicaba" $\left(H_{\text {média }}=0,54\right)$. Também a 
riqueza de espécies apresentou padrão semelhante com o Grupo "Pariquera-Açu", que apresentou uma riqueza $\left(d_{\text {média }}=4,20\right)$ aproximadamente 1,7 vezes maior que os demais.

Tabela 3. Número total de espécimens $(N)$, número total de espécies $(S)$, índice de diversidade de espécies de Shannon-Weiner $(H)$, índice de uniformidade de espécies de Pielou (e) e índice de riqueza de espécies de Pielou $(d)$ para as espécies de ácaros (Arthropoda: Acari) coletados em euforbiácaeas (Euphorbiaceae) de três localidades do Estado de São Paulo (Cananéia, Pariquera-Açu e Piracicaba).

\begin{tabular}{llccccc}
\hline Localidade & \multicolumn{1}{c}{$\begin{array}{c}\text { Espécie } \\
\text { Vegetal }\end{array}$} & $\boldsymbol{N}$ & $\boldsymbol{S}$ & $\begin{array}{c}\text { Shannon- } \\
\text { Weiner }(\boldsymbol{H})\end{array}$ & $\begin{array}{c}\text { Pielou } \\
(\boldsymbol{e})\end{array}$ & $\begin{array}{c}\text { Pielou } \\
(\boldsymbol{d})\end{array}$ \\
\hline Cananéia & A. triplinervea & 138 & 12 & 0.80 & 0.74 & 2,23 \\
& P. glabrata & 33 & 9 & 0,84 & 0,88 & 2,29 \\
\hline Pariquera-Açu & A. glandulosa & 305 & 36 & 0,65 & 0,42 & 6,12 \\
& A. sidifolia & 269 & 19 & 1,05 & 0,82 & 3,22 \\
& A. triplinervea & 178 & 24 & 1,21 & 0,88 & 4,44 \\
& A. cordatum & 1254 & 40 & 1,20 & 0,75 & 5,47 \\
& H. brasiliensis & 522 & 26 & 0,99 & 0,70 & 4,00 \\
& Sebastiania sp. & 152 & 20 & 0,92 & 0,70 & 3,78 \\
\hline \multirow{2}{*}{ Piracicaba } & A. glandulosa & 3220 & 32 & 0,92 & 0,61 & 3,84 \\
& A. sidifolia & 4797 & 15 & 0,48 & 0,41 & 1,65 \\
& C. floribundus & 11247 & 32 & 0,52 & 0,34 & 3,32 \\
& C. urucurana & 1984 & 14 & 0,46 & 0,40 & 1,71 \\
& H. brasiliensis & 1477 & 18 & 0,58 & 0,46 & 2,33 \\
& H. crepitans & 2295 & 15 & 0,50 & 0,42 & 1,81 \\
& J. princeps & 511 & 14 & 0,22 & 0,19 & 2,08 \\
& P. longifolium & 3221 & 26 & 0,64 & 0,45 & 3,10 \\
\hline
\end{tabular}




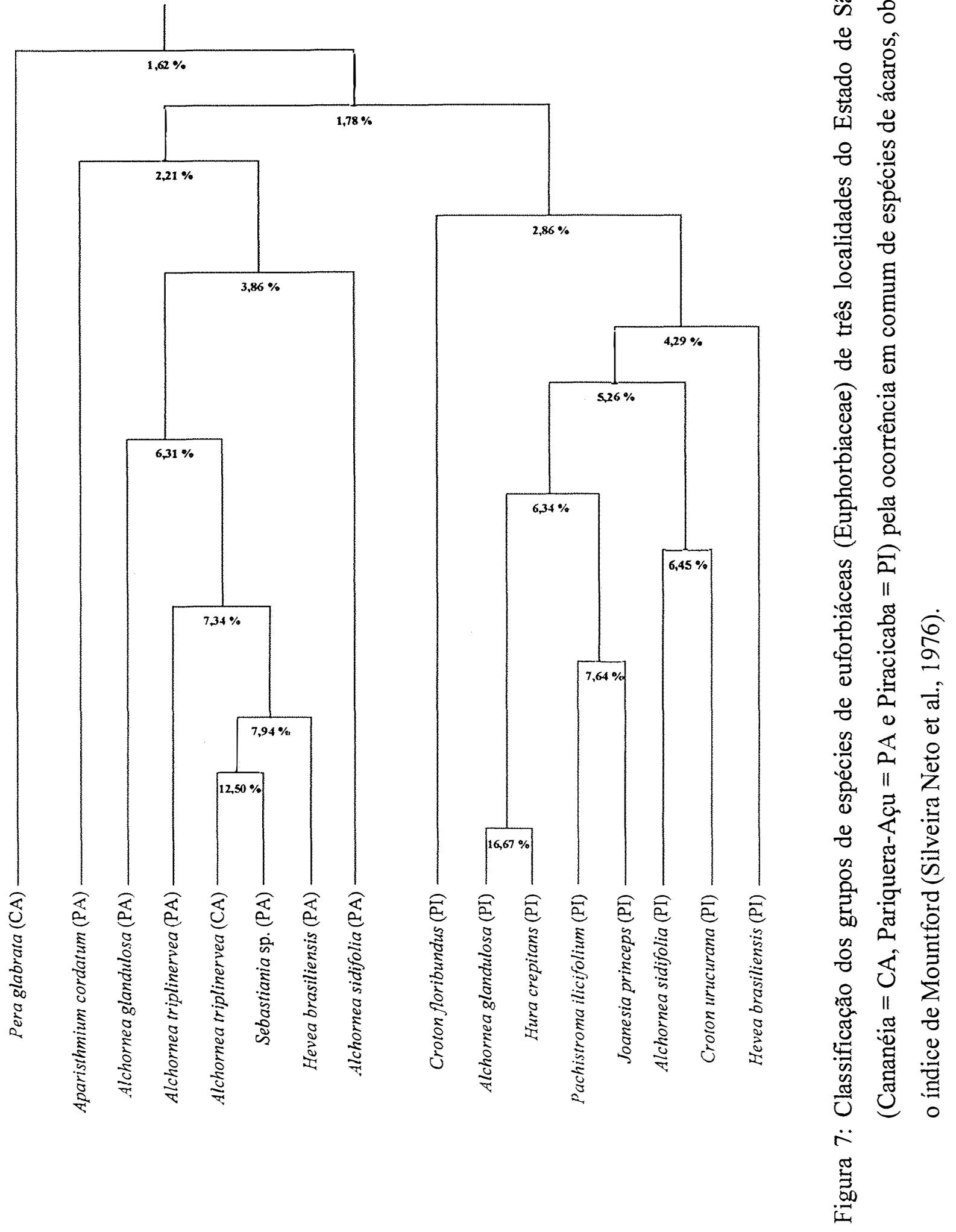

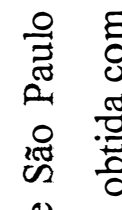

응 융

药

(I)

0.

बु है

$=$

\&

욤

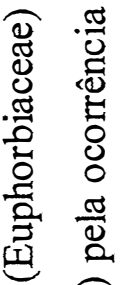

合

\& I

惑

1 .

$0 \div$

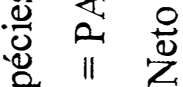

के गे

0 $\frac{1}{2}$

2 它

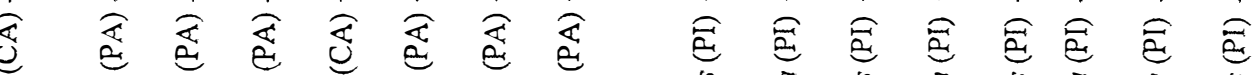

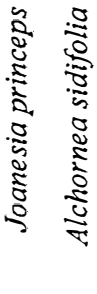

号 ¿

खृ

总 总

$\ddot{r}$ 


\subsection{Conclusões}

- As plantas estudadas apresentam 3 grupos distintos em relação à similaridade das espécies de ácaros que abrigam.

- Os grupos "Pariquera-Açu" e "Pera glabrata" apresentam maior proporção de espécies generalistas que de predadoras ou fitófagas, enquanto o Grupo "Piracicaba" apresenta maior proporção de espécies fitófagas.

- As plantas do Grupo "Pariquera-Açu" apresentam maior proporção de espécies predadoras que de fitófagas.

- As plantas do Grupo "Pariquera-Açu" apresentam, em média, maior diversidade, uniformidade e riqueza de espécies que os demais grupos.

- As seringueiras do Grupo "Pariquera-Açu" apresentam alta similaridade em relação às das demais plantas da mesma comunidade, indicando maior possibilidade de fluxo de espécies de ácaros entre estas do que o que se espera entre as seringueiras do Grupo "Piracicaba" e as demais euforbiáceas desta região. 


\section{CONCLUSÕES GERAIS}

- As espécies vegetais Pera glabrata e Alchornea triplinervea em Cananéia e A. glandulosa, A. triplinervea e Sebastiania sp. em Pariquera-Açu abrigam o fitoseídeo mais abundante em seringueiras de Pariquera-Açu (Typhlodromips sp.).

- As espécies vegetais Hura crepitans, Joanesia princeps e Pachistromma longifolium em Piracicaba abrigam o fitoseídeo mais abundante em seringueiras daquela localidade (Typhlodromina camelliae (Chant \& Yoshida-Shaul, 1983b)).

- As espécies de fitoseídeos encontradas em seringueira de Pariquera-Açu são distintas daquelas encontradas na mesma planta em Piracicaba.

- É bastante elevado o número de taxa não descritos de Tydeidae encontrados em euforbiáceas no Estado de São Paulo.

- O grupo mais diverso de Tydeidae em Euphorbiaceae na Mata Atlântica do Estado de São Paulo pertence ao gênero Lorryia.

- As espécies de ácaros mais abundantes em seringueiras de Pariquera-Açu e Piracicaba foram os tideídeos Lorryia formosa Cooreman, 1958, e Lorryia sp. n. 1, respectivamente. 
- Dentre as famílias consideradas neste estudo, Phytoseiidae e Tydeidae são as que apresentam a maior diversidade em euforbiáceas nas regiões estudadas.

- Dentre os taxa considerados neste estudo, Lorryia sp. n. 1 (Tydeidae), Neotropacarus sp. (Acaridae), Czenspinskia sp. (Winterschmidtiidae), Tarsonemus (Tarsonemus) spp. (Tarsonemidae) e Agistemus sp. (Stigmaeidae) estão entre as espécies que habitam as maiores diversidades de hospedeiros.

- As plantas estudadas apresentam 3 grupos distintos em relação à similaridade das espécies de ácaros que abrigam.

- Os grupos "Pariquera-Açu" e "Pera glabrata" apresentam maior proporção de espécies generalistas que de predadoras ou fitófagas, enquanto o Grupo "Piracicaba" apresenta maior proporção de espécies fitófagas.

- As plantas do Grupo "Piracicaba" apresentam maior proporção de espécies fitófagas que de predadoras, as do Grupo "Pariquera-Açu" apresentam maior proporção de espécies predadoras que de fitófagas.

- As plantas do Grupo "Pariquera-Açu" apresentam, em média, maior diversidade, uniformidade e riqueza de espécies que os demais grupos.

- As seringueiras do Grupo "Pariquera-Açu" apresentam alta similaridade em relação às das demais plantas da mesma comunidade, indicando maior possibilidade de fluxo de espécies de ácaros entre estas do que o que se espera entre as seringueiras do Grupo "Piracicaba" e as demais euforbiáceas desta região. 
ANEXO: Tabelas 


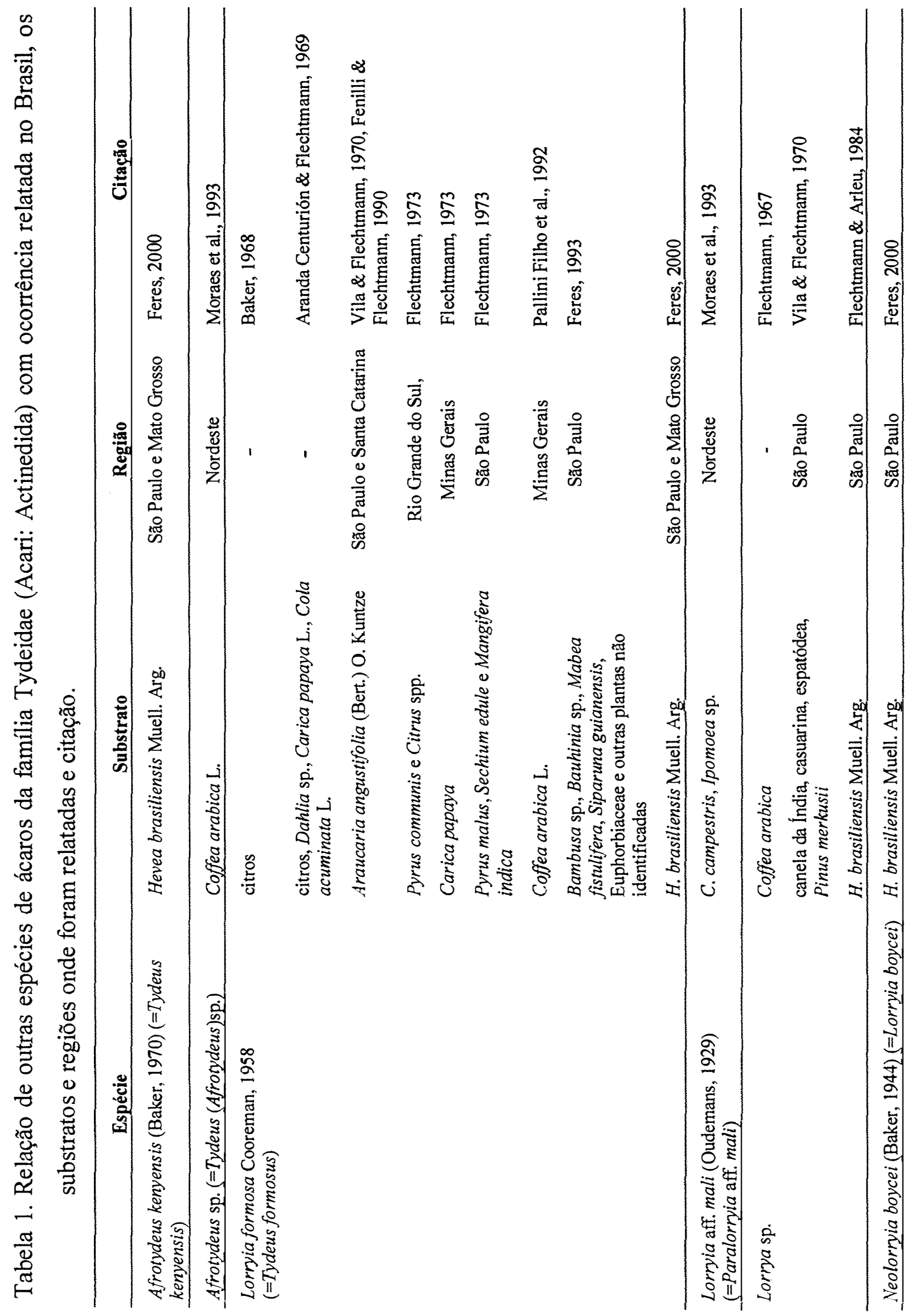




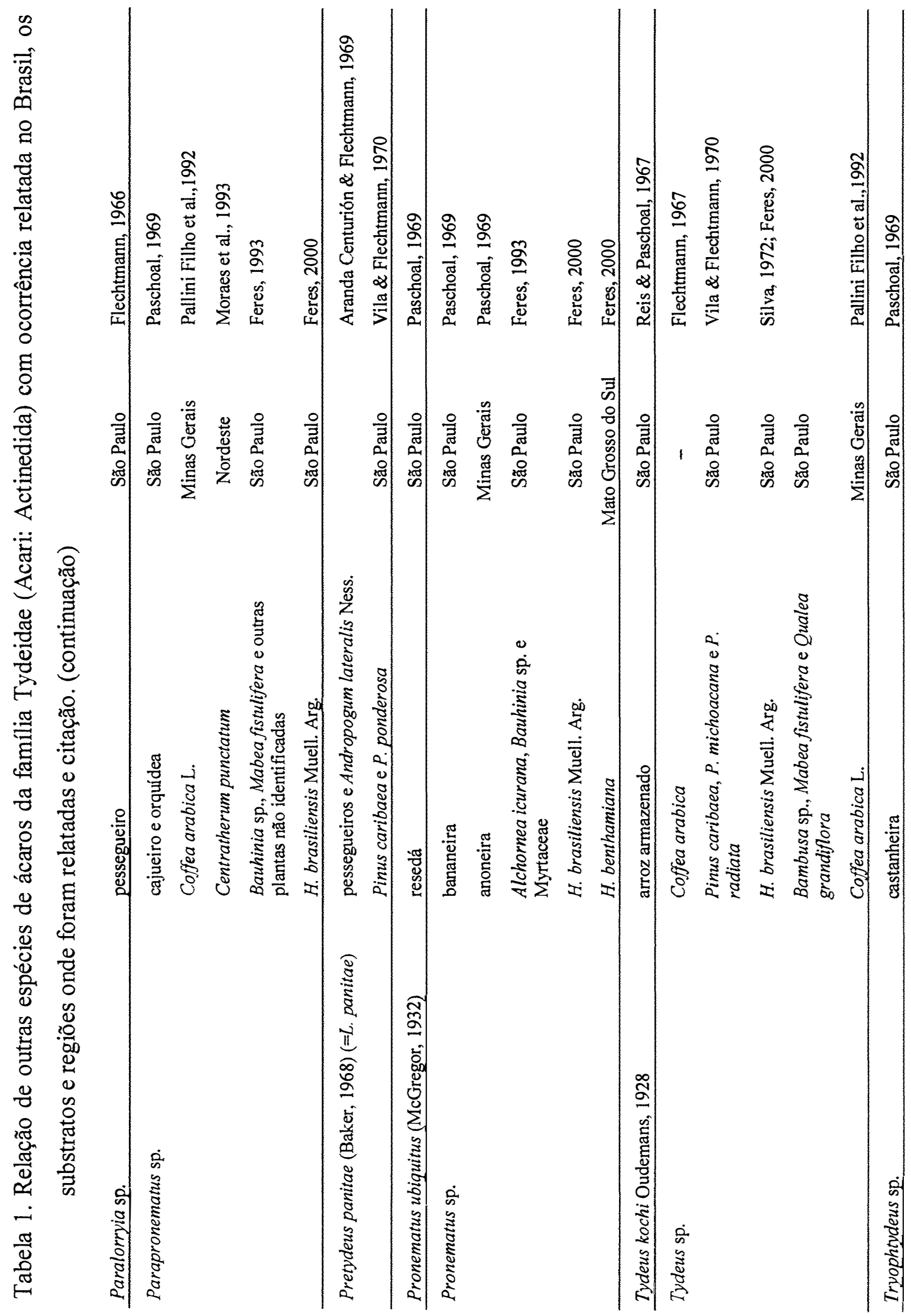




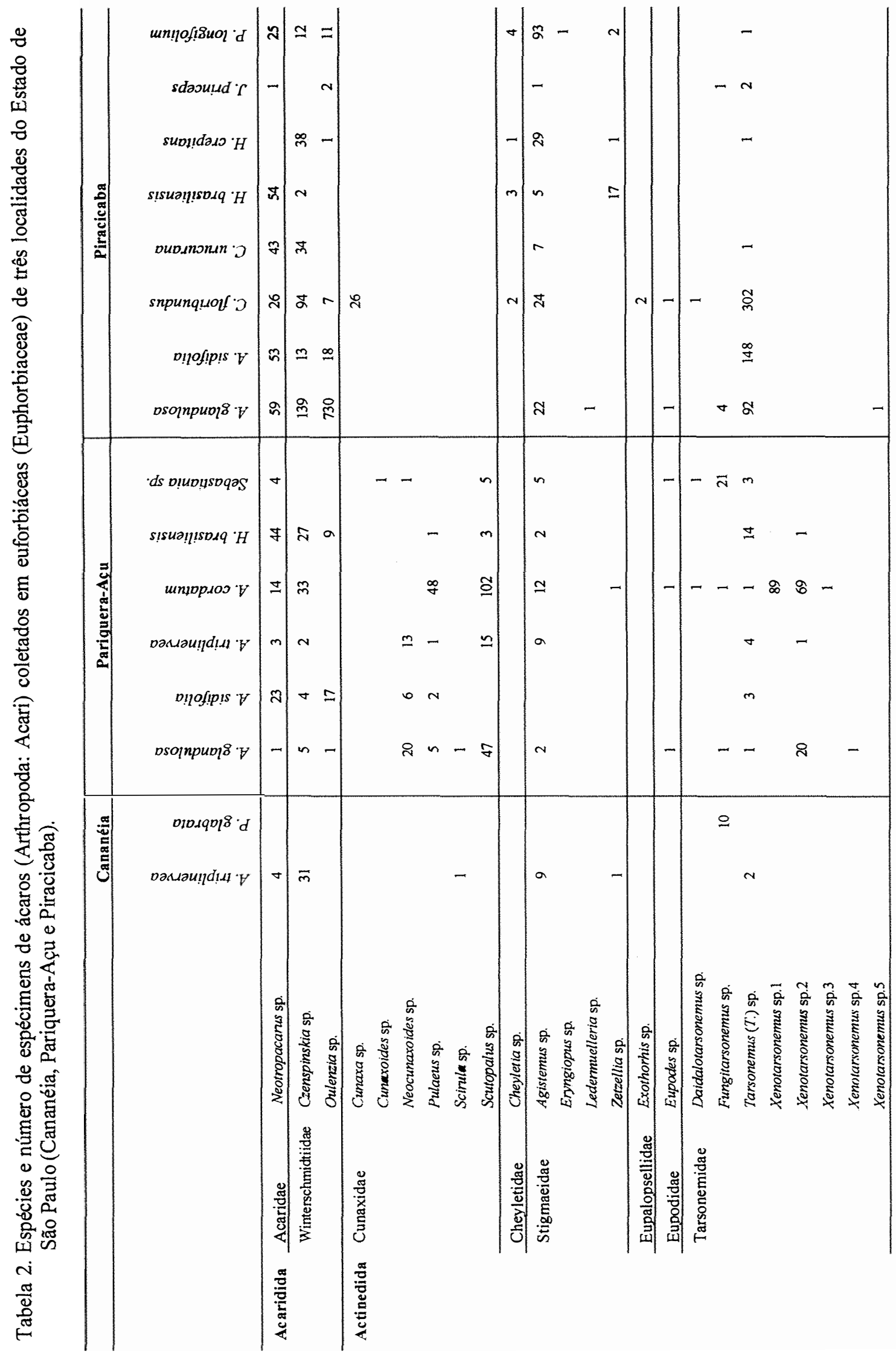




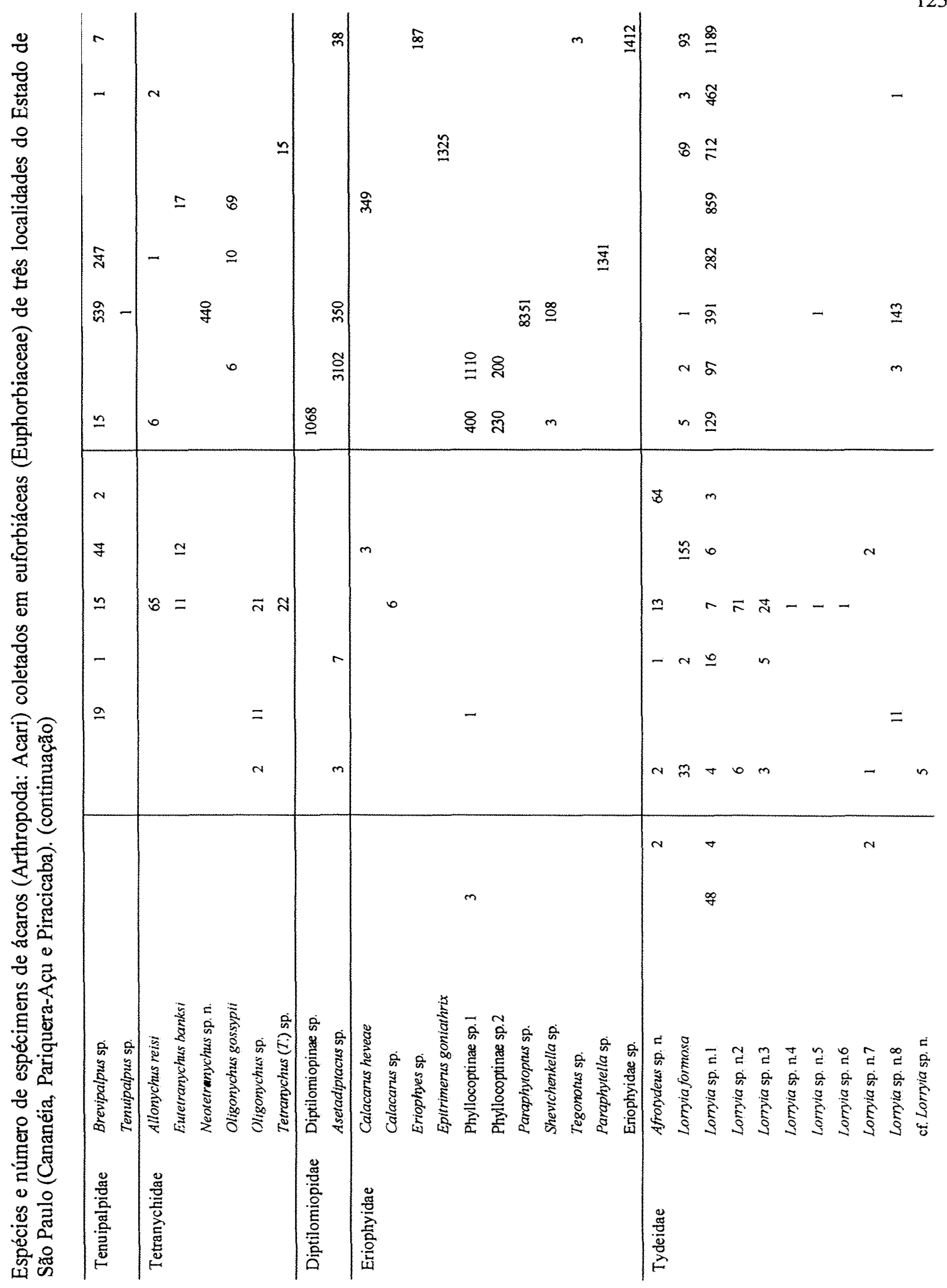

$\frac{\pi}{8}$ 


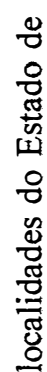

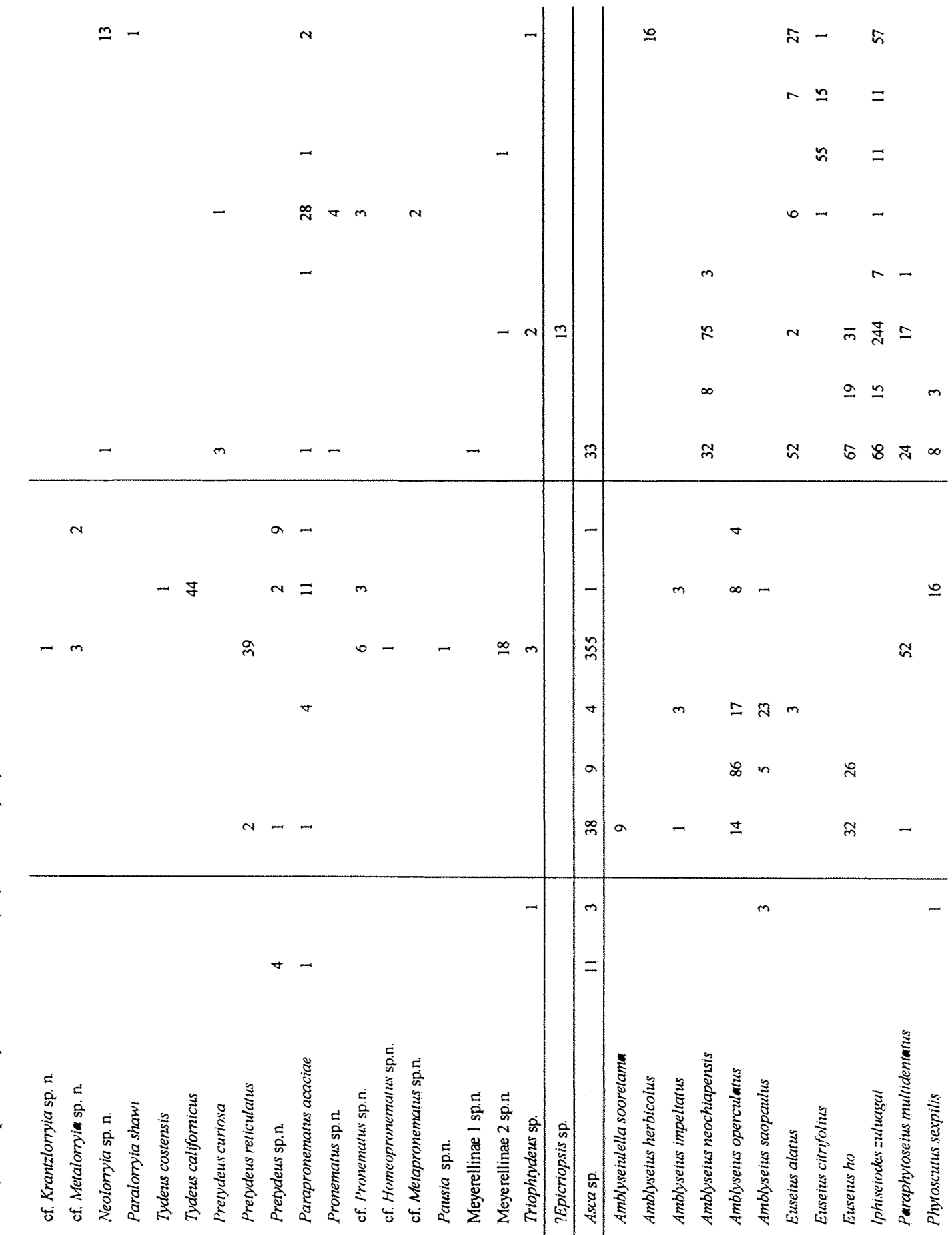

䡈

它

인

突

รี้

용

壱

을

ठ

号嵒

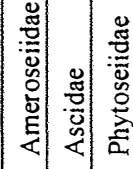

需 


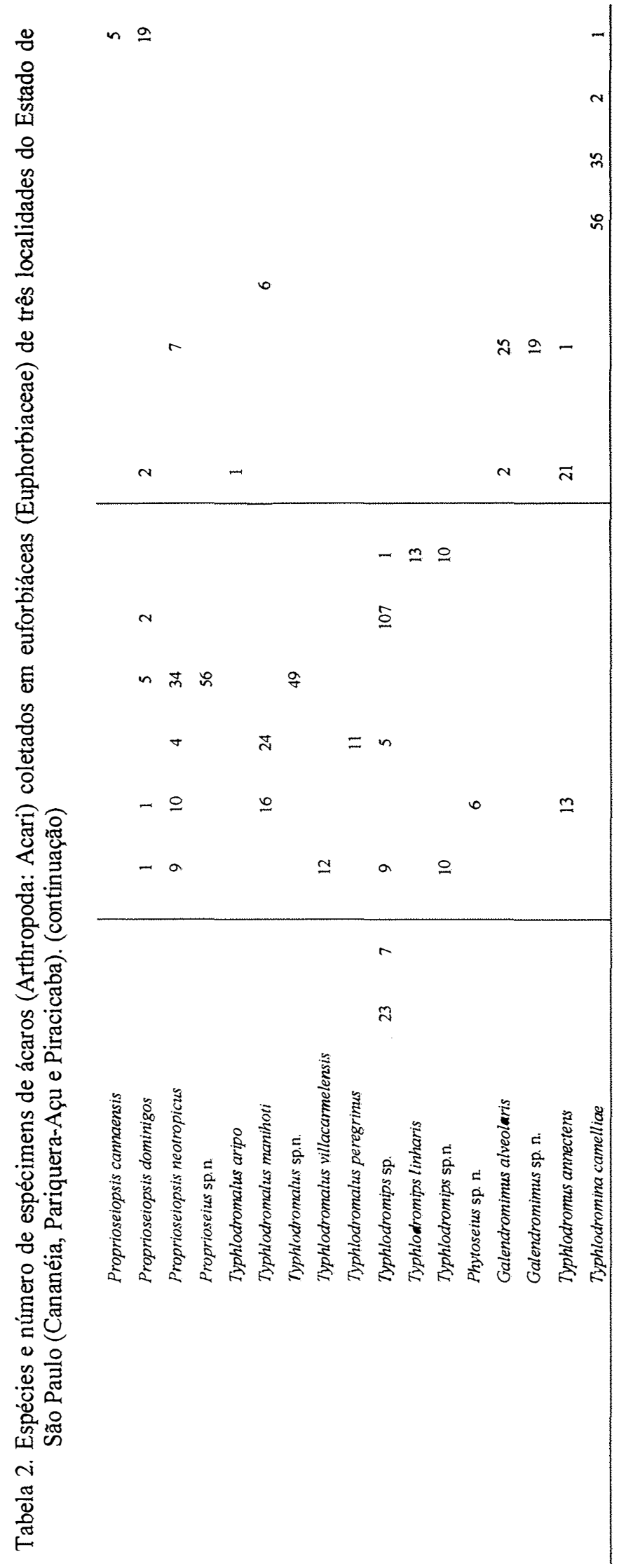




\section{REFERÊNCIAS BIBLIOGRÁFICAS}

ALTIERI, M.A.. The agroecosystem: determinants, resources and processes. In: ALTIERI, M.A. (Ed.). Agroecology. The scientific basis of alternative agriculture. Westview Press, Boulder, CO. p. 29-45, 1987

ALTIERI, M.A. Biodiversity and pest management in agroecosystems. Food Products Press, NY. 185 p., 1994.

AMRINE Jr., J.W.; MANSON, D.M.C. Preparation, mounting and description study of Eriophyiod mites. In: LINDQUIST, E.E.; SABELIS, M.W.; BRUIN, J. (Ed.). Eriophyioid mites: their biology, natural enemies and control. Amsterdan: Elsevier, 1996. p. 383-396.

ANDOW, D.A. Vegetational diversity and arthropod population response. Annual Review of Entomology, v. 36, p. 561-586, 1991.

ANDRÉ, H.M. A generic revision of the family Tydeidae (Acari: Actinedida). I. Introduction, paradigms and general classification. Annales de la Societe royale de Zoologie Belge, v. 108, n. 3-4, p. 189-208, 1979.

ANDRÉ, H.M. A generic revision of the family Tydeidae (Acari: Actinedida). IV. Generic descriptions, keys and conclusions. Bulletin et Annales de la Societe Royale Belge d'Entomologie, v. 116, n. 7-9, p. 103-168, 1980. 
ANDRÉ, H.M. A generic revision of the family Tydeidae (Acari: Actinedida). II. Organotaxy of the idiosoma and gnathosoma. Acarologia, v. 22, n. 1, p.31-46, 1981a.

ANDRÉ, H.M. A generic revision of the family Tydeidae (Acari: Actinedida). III. Organotaxy of the legs. Acarologia, v. 22, n. 2, p. 165-178, 1981 b.

ANDRE, H.M. Redefinition of the Iolinidae (Acari: Actinedida) with a discussion of their familial and superfamilial status. Acarology, v. 6, n. 1, p. 180-185, 1984.

ANDRÉ, H.M. Acari domum meliponinarum brasiliensium habitantes. 10. Melissotydeus macrosolenus gen.n., sp.n. (Acari: Tydeidae). Bulletin et Annales de la Societe Royale Belge d'Entomologie, v. 121, p. 243-246, 1985.

ANDRÉ, H.M. Redefinition of the genus Triophtydeus Thor, 1932 (Acari: Actinedida). Zoologische Mededelingen, v. 59, n. 16, p. 189-195, 1985.

ANDRÉ, M.; NAUDO, M.H. Pertydeus schusteri n.sgen., n. sp., nouveau Tydeus a griffe pulvillaire (Tydeidae). Acarologia, v. 7, n. 4, p. 673-682, 1965.

APONTE, O.; McMURTRY, J.A. Revision of the genus Iphiseiodes DeLeon (Acari: Phytoseiidae). International Journal of Acarology, v.21, p.165-183, 1995.

ARANDA CENTURIÓN, B.R.; FLECHTMANN, C.H.W. Ácaros do Gênero Lorryia no Brasil e Paraguay (Acarina, Tydeidae). In: REUNIAO ANUAL DA SOCIEDADE BRASILEIRA DE ENTOMOLOGIA, 2. Recife, 1969. Resumos. Recife: SBE, 1969. v. 2, p. 41-42.

BAKER, E.W. Nuevos Tydeidae mexicanos (Acarina). Revista de la Sociedad Mexicana de Historia Natural, v. 4, n. 3-4, p. 181-189, 1943. 
BAKER, E.W. Seis especies de Lorryia (Acarina, Tydeidae). Anales del Instituto de Biología, Universidad Autónoma de Mexico, v. 15, n. 1, p. 215-222, 1944.

BAKER, E.W. A review of the genera of the family Tydeidae (Acarina). Advances in Acarology, p. 95-133. 1965

BAKER, E.W. The genus Pronematus Canestrini. Annals of the Entomological Society of America,.v. 61, n. 5, p. 1091-1097, 1968a.

BAKER, E.W. The genus Lorryia.. Annals of the Entomological Society of America. v. 61, n. 4 , p. $986-1008.1968$ b.

BAKER, E.W. The genus Tydeus: subgenera and species groups with descriptions of new species (Acari: Tydeidae). Annals of the Entomological Society of America, v. 63 , n. 1 , p. $163-177,1970$.

BAKER, E.W.; DELFINADO, M.D. Notes on the genus Naudea Meyer and Rodrigues, with description of a new species (Acarina: Tydeidae). International Journal of Acarology. v. 2, n. 1, p. 35-38, 1976.

BAKER, E.W.; WHARTON, G.W. An Introduction to Acarology. New York: The Macmillan Co., 1952. 465p.

BANKS, N. Four new species of injurious mites. Journal of the New York Entomological Society, v. 12, p. 53-56, 1904.

BANKS, N. Descriptions of some new mites. Proceedings Entomological Society of Washington, v.7, p.133-142, 1905. 
BANKS, N. The Acarina or mites. A review of the group for the use of economic entomologist. U.S. Department of Agricu Iture Republic, v.108, p.1-153, 1915.

BRICKHILL, C.D. Biological studies of two species of tydeid mites from California. Hilgardia, v. 27, n. 20, p. 601-620, 1958.

BRODEUR, J.; BOUCHARD, A.; TURCOTTE, G. Potential of four species of predatory mites as biological control agents of the tomato russet mite, Aculops lycopersici (Massee)(Eriophyidae). Canadian Entomologist, v.129, n.1, p.1-6, 1997.

BROWN Jr., K.S. Diversity, disturbance, and sustainable use of Neotropical forests: insects as indicators for conservation monitoring. Journal of Insect Conservation. v. 1, p. $25-42,1997$.

CALIS, J.N.M.; OVERMEER, W.P.J.; Van der GEEST, L.P.S. Tydeids as alternative prey for phytoseiid mites in apple orchards. Mededelingen van de Faculteit Landbouwwetenschappen, Rijksuniversiteit Gent , v. 53, n. 2b, p. 793-798, 1988.

CALVERT, D.J.; HUFFAKER, C.B. Predator (Metaseiulus occidentalis) prey (Pronematus spp.) interactions under sulfur and cattail pollen applications in a noncommercial vineyard. Entomophaga v. 19, n. 3, p. 361-369, 1974.

CESAR, O.; LEITÃO FILHO, H.F. Estudo florístico quantitativo de mata mesófila semidecídua na fazenda Barreiro Rico, município de Anhembi, SP. Revista Brasileira de Biologia, v. 50, n. 1, p. 133-147, 1990.

CHANT, D.A. Phytoseiid mites (Acarina: Phytoseiidae). Part I. Bionomics of seven species in southeastern England. Part II. A taxonomic review of the family Phytoseiidae, with descriptions of thirty-eight new species. Canadian Entomologist, Supplement, v. 12, p.1-166, 1959. 
CHANT, D.A.; BAKER, E.W. The Phytoseiidae (Acarina) of Central America. Memoirs of the Entomological Society of Canada. v.41, p.1-56, 1965.

CHANT, D.A.; HANSELL, R.I.C. The genus Amblyseius (Acarina: Phytoseiidae) in Canada and Alaska. Canadian Journal of Zoology, v.49, p.703-758, 1971.

CHANT, D.A.; McMURTRY, J.A. A review of the subfamilies Phytoseiinae and Typhlodrominae (Acari: Phytoseiidae). In ternational Journal of Aca rology, v.20, p. 223-310. 1994.

CHANT, D.A.; YOSHIDA-SHAUL, E. A world review of five similar species groups in the genus Typhlodromus Scheuten: Part I. The regularis and theodoliticus groups (Acarina: Phytoseiidae). Canadian Journal of Zoology. v.61, p.1032-1040, 1983a.

CHANT, D.A.; YOSHIDA-SHAUL, E. A new subfamily Cydnodromellinae, in the family Phytoseiidae (Acarina: Gamasina). Canadian Journal of Zoology, v. 64, p. 2811-2823. 1983a.

CHANT, D.A.; YOSHIDA-SHAUL, E. A world review of five similar species groups in the genus Typhlodromus Scheuten. Part II. The conspicuus and cornus groups (Acarina: Phytoseiidae. Canadian Journal of Zoology. v.61, p.1041- 1057, 1983 b.

CHANT, D.A.; YOSHIDA-SHAUL, E. A world review of the occidentalis species group in the genus Typhlodromus Scheuten (Acarina: Phytoseiidae). Canadian Journal of Zoology. v.62, p.1860- 1871, 1984.

CHANT, D.A.; YOSHIDA-SHAUL, E.. A world review of the ecclesiasicus species group in the genus Typhlodromus Scheuten (Acarina: Phytoseiidae). Canadian Journal of Zoology, v. 64, p. 447-466, 1986. 
CHANT, D.A.; YOSHDA-SHAUL, E. Adult ventral setal patterns in the family Phytoseiidae (Acari: Gamasina). Internaltional Journal of Aca rology, v.17, p.187, 1991.

CHAUDHRI, W.M. Six new species of mites of the genus Amblyseius (Phytoseiidae) from Pakistan. Aca rologia, v.10, p.550-562, 1968.

COOREMAN, J. Note et observations sur les acariens. VII. Photia graeca n. sp. (Acarididae, Canestriniidae) et Lorryia formosa n. sp. (Stomatostigmata, Tydeidae). Institut Royal des Sciences Naturelles de Belgique.Bulletin v.34, n.8, p.1-10, 1958.

COSTA, M.B.B. da. Princípios da agricultura alternativa. In: SIMPÓSIO DE AGRICULTURA ECOLOGICA, 1., Campinas, 1993. Anais. Campinas: Fundação Cargill, 1993. p.1-16.

DANESHVAR, H.; DENMARK, H.A. Phytoseiids of Iran (Acarina: Phytoseiidae). International Journal of Aca rology, v.8, p.3-14, 1982.

DEBACH, P. The scope of biological control. In: DeBACH, P. (ed.). Biological control of insect pests and weeds. New York: Reinhold Publ., 1964. p. 3-20

DeLEON, D. Three new Typhlodromus from southern Florida (Acarina: Phytoseiidae). Florida Entomologist. v.40 p. 141-144. 1957.

DeLEON, D. Four new Typhlodromus from southern Florida (Acarina: Phytoseiidae). Florida Entomologist. v.41, p. 73-76. 1958.

DeLEON, D. Eight new Amblyseius from Mexico with collection notes on two other species (Acarina: Phytoseiidae). Florida Entomologist. v.44, p. 85-91. 1961. 
DeLEON, D. The cervix of some Phytoseiid type specimes (Acarina: Phytoseiidae). Acarologia, v.4, p.174-176, 1962.

DeLEON, D. Phytoseiid mites from Puerto Rico with descriptions of new species (Acarina: Mesostigmata). Florida Entomologist, v.48, p.121-131, 1965a.

DeLEON, D. Ten new species of Phytoseius (Pennaseius) from Mexico, TrinidadTobago, and British Guiana with a key to species Acari: Phytoseiidae). Entomological News, v.76, p.11-21, 1965 b.

DeLEON, D. Phytoseiidae of British Guyana with keys to species (Acarina: Mesostigmata). Studies on the Fauna of Suriname and other Guyanas. v.8, p. 81102. 1966.

DeLEON, D. Some mites of the Caribbean Area. Part I. Acarina on plants in Trinidad, West Indies. Kansas: Allen Press, 1967. 66p.

DENMARK, H.A. Revision of the genus Phytoseius Ribaga, 1904 (Acarina: Phytoseiidae). Florida Department Agriculture Bulletin, v.6, p.1-105, 1966.

DENMARK, H.A. Revision of Galendromus Muma, 1961 (Acarina: Phytoseiidae). International Journal of Acarology, v.8, p.133-167, 1982.

DENMARK, H.A.; EVANS, G.A.; AGUILAR, H.; VARGAS, C.; OCHOA, R. Phytoseiidae of Central America (Acari: Mesostigmata). Michigan: Indira Publishing House, 1999. 125p.

DENMARK, H.A., MUMA, M.H. Some phytoseiid mites of Paraguay (Phytoseiidae: Acarina). Florida Entomologist, v.53, p. 219-227. 1970. 
DENMARK, H.A., MUMA, M.H. Some Phytoseiidae of Colômbia (Acarina: Phytoseiidae). Florida Entomologist. v..55, p. 19-29. 1972.

DENMARK, H.A., MUMA, M.H. Phytoseiid mites of Brasil (Acarina: Phytoseiidae). Florida Entomologist, v. 33, p. 235-276. 1973.

DENMARK, H.A.; MUMA, M.H. Phytoseiidae of Jamaica, an annotated list (Acari: Mesostigmata). International Journal of Acarology, v.41, p.1-22, 1978.

DENMARK, H.A.; MUMA, M.H. A revision of the genus Amblyseius Berlese, 1914 (Acari: Phytoseiidae). Ocasional Papers of the Florida State Collection of Arth ropods, v.4, p.1-149, 1989.

EHARA, S. Some predatory mites of the genera Typhlodromus and Amblyseius from Japan (Phytoseiidae). Acarologia, v.1, p.285-295, 1959.

EHARA, S. Some mites associated with plants in the state of São Paulo, Brazil, with a list of plant mites of South America. Japanese Journal of Zoology, v.15, p.129-150, 1966.

El-BENHAWY, E.M. Description of some unknown phytoseiid mites from Brazil (Mesostigmata: Phytoseiidae). Acarologia, v.20, p.477-484, 1978.

El-BENHAWY, E.M. Description of some phytoseiidae mites from Brazil (Acarina: Phytoseiidae). Aca rologia, v.25, p.125-144, 1984.

ENGLISH LOEB, G.; NORTON, A.P.; GADOURY, D.M.; SEEM, R.C.; WILCOX, W.F. Control of powdery mildew in wild and cultivated grapes by a tydeid mite. Biological Control v.14, p. 97-103, 1999. 
EVANS, G.O. Principles of Acarology. Wallingford: CAB International, 1992. 563p.

FENILLI, R.; FLECHTMANN, C.H.W. Mites (Acari) from Araucaria angustifolia in Lages, Santa Catarina, southern Brazil. Anais da Escola Superior de Agricultura Luiz de Queiroz, v.47, n.1, p.243-250, 1990.

FERES, R.J.F. Ácaros (Acari, Arachnida) associados a plantas silvestres no município de São José do Rio Preto, Estado de São Paulo. Botucatu, 1993. 179p. Tese (Doutorado) - Universidade Estadual Paulista "Júlio de Mesquita Filho".

FERES, R.J.F. A new species of Calacarus Keifer (Acari, Eriophyidae, Phyllocoptinae) from $H$. brasiliensis Muell. Arg. (Euphorbiaceae) from Brazil. International Journal of Acarology, v.18, n.1, p. 61-65. 1992.

FERES, R.J.F. Two new species Phyllocoptine Mites (Acari: Eriophydae) from Hevea brasiliensis Muell. Arg. (Euphorbiaceae) from Brazil. International Journal of Acarology, v.24, n.1, p.69-74, 1998.

FERES, R.J.F. Levantamento e observaçòes naturalísticas da acarofauna (Acari, Arachnida) de seringueiras cultivadas (Hevea spp., Euphorbiaceae) no Brasil. Revista Brasileira de Zoologia, v. 17, n.1, p.157-173, 2000.

FERES, R.J.F.; MORAES, G.J. de. Phytoseiid mites (Acari: Phytoseiidae) from woody areas in the State of São Paulo, Brazil. Systematic and Applied Acarology, v.3, p.125-132, 1998.

FLECHTMANN, C.H.W. Ácaros encontrados em algumas plantas do Estado de São Paulo. Revista de Agricultura, v. 41, n. 4, p. 161-162, 1966. 
FLECHTMANN, C.H.W. Contribuição para o conhecimento dos ácaros de plantas de algumas regiões do Estado de São Paulo, 1967. 47p. Tese (Doutorado) - Escola Superior de Agricultura "Luiz de Queiroz", Universidade de São Paulo.

FLECHTMANN, C.H.W. Phytoseiidae do Estado de São Paulo (Acarina: Mesostigmata). Anais da Escola Superior de Agricultura"Luiz de Queiroz", v.24, p.247-248, 1967.

FLECHTMANN, C. H. W. Alguns trombidiformes do Brasil e do Paraguai (Acari). Piracicaba, 1971. 79p. Tese (Livre Docente) - Escola Superior de Agricultura "Luiz de Queiroz", Universidade de São Paulo.

FLECHTMANN, C.H.W. Lorryia formosa Cooreman, 1958 - Um ácaro dos citros pouco conhecido no Brasil. Ciência e Cultura, v. 25, n. 12, p. 1179-1181, 1973.

FLECHTMANN, C.H.W. Ácaros de importância agrícola. São Paulo: Nobel, 1977. $189 \mathrm{p}$.

FLECHTMANN, C.H.W. On the measurements of Tydeus formosus (Cooreman, 1958) (Acari, Prostigmata, Tydeidae). International Journal of Acarology, v. 13, n. 3, p. 217-218, 1987.

FLECHTMANN, C.H.W. On the mite fauna of bamboo leaves in the Parque Nacional do Itatiaia, Rio de Janeiro, Brazil. International Journal of Acarology. v.21, n.4, p. 243-252. 1995.

FLECHTMANN, C.H.W.; ABREU, J.M. Ácaros Fitófagos do Estado da Bahia, Brasil. (Notas Preliminares). Ciência e Cultura. v.25, n.3, p. 243-251. 1973. 
FLECHTMANN, C.H.W.; ARLEU, R.J. Ologonychus coffeae (Nietner, 1861), um ácaro tetraniquídeo da seringueira (Hevea brasiliensis) novo para o Brasil e observações sobre outros ácaros desta planta. Ecossistema, v. 9, p. 123-125, 1984.

FLECHTMANN, C.H.W.; BAKER, E.W. A preliminary report on the Tetranychidae (Acarina) of Brazil. Annals of the Entomological Society of America, v. 63, n. 1, p. 156-163, 1970.

FLECHTMANN, C. H. W.; CAMARGO, C.A. de. Acari associated with stingless bees (Meliponidae, Hymenoptera) from Brazil. In: Proccedings of the 4th International Congress of Acarology. 1974, pp. 315-319.

FLESCHNER, C.A.; ARAKAWA, K.Y. The mite Tydeus californicus on citrus and avocado leaves. Journal of Economic Entomology, v. 45, n. 6, p. 1092, 1953.

GALLO, D.; NAKANO, O.; SILVEIRA NETO, S.; CARVALHO, R.P.L.; BATISTA, G.C.; BERTI FILHO, E.; PARRA, J.R.P.; ZUCCHI, R.A.; ALVES, S.B.; VENDRAMIM, J.D. Manual de Entomologia Agrícola (2a ed.). São Paulo: Ed. Agronômica Ceres Ltda., 1988. 649 p.

GARCIA, R.; CALTAGIRONE, L.E.; GUTIERREZ, A.P. Comments on a redefinition of biological control. BioScience, v. 38, n. 10, p. 692-694. 1988.

GASTON, K.J. What is biodiversity. In: GASTON, K.J. (ed.) Biodiversity. a biology of numbers and difference. Berlin: Blackwell Science Ltd., 1996. p. 169-201.

GERSON, U. Five tydeid mites from Israel (Acarina: Prostigmata). Israel Journal of Zoology, v. 17, n. 191-198, 1968. 
GONDIM JUNIOR, M.G.C. Ácaros de palmeiras (Arecaceae) em áreas dos Estados de São Paulo e Pernambuco. Piracicaba, 2000. 161p. Tese (Doutorado) - Escola Superior de Agricultura "Luiz de Queiroz", Universidade de São Paulo.

HARPER, J.L.; HAWKSWORTH, D.L. Preface. In: HAWKSWORTH, D.L. (Ed.) Biodiversity: measurement and estimation. London: Chapman \& Hall , 1996. p. 512.

HESSEIN, N.A. E PERRING, T.M. Feeding habits of the Tydeidae with evidence of Homeopronematus anconai (Acari: Tydeidae) predation on Aculops lycopersici (Acari: Eriophyidae). International Journal of Acarology, v.12, n.4, p. 215-221. 1986.

HESSEIN, N.A.; PERRING, T.M. Homeopronematus anconai (Baker) (Acari: Tydeidae) predation on citrus flat mite, Brevipalpus lewisi McGregor (Acari: Tenuipalpidae). International Journal of Acarology, v. 14, n. 2, p. 89-90, 1988.

HIRSCHMANN, W. Gangsystematik der Parasitiformes. Acarologie Sch riften reihe fur vergleichende Milbenkunde, Hirschmann-Verlag, Furth/Bay. v.5, p.1-80, 1962.

IVANAUSKAS, N.M.; RODRIGUES, R.R. Identificação em campo de 284 espécies de árvores e arbustos do Parque da ESALQ/USP. Boletim Técnico $\mathrm{n}^{\circ} 9$. Piracicaba: PCLQ/USP, 1995. 85p.

JEPPSON, L.R.; KEIFER, H.H.; BAKER, E.W. Mites injurious to economic plants. Berkeley: University of California Press, 1975. 679p. 
KARG, W. Investigations on the mite fauna of apple orchards with reference to the transition from standard spray programmes to integrated treatment measures. Archiv fu r Pflanzenschutz, v.7, n.4, p.243-279, 1971.

KARG, W. To the knowledge of the tydeids (Acarina, Trombidiformes) from apple orchards. Zoologischer Anzeiger, v.194, n.1-2, p.91-110, 1975.

KAZMIERSKI, A. Morphological studies on Tydeidae (Actinedida, Acari). I .Remarks about the segmentation, chaetotaxy and poroidotaxy of idiosoma. Acta Zoologica Cracoviensia,. v.32, n.4, p.69-83, 1989a.

KAZMIERSKI, A. Revision of the genera Tydeus Koch sensu André, Homeotydeus André and Orthotydeus André with description of a new genus and four new species of Tydeinae (Acari: Actinedida: Tydeidae). Mitteilungen aus dem Hamburgischen Zoologischen Museum und Institut, v. 86, p.289-314, 1989b.

KAZMIERSKI, A. A revision of the subfamilies Pretydeinae and Tydeinae (Acari, Actinedida: Tydeidae). Part II. The subfamily Pretydeinae André, 1979 - new taxa, species review, key and considerations. Mitteilungen aus dem Hamburgischen Zoologischen Museum und Institut, v.93, p.171-198, 1996a.

KAZMIERSKI, A. A revision of the subfamilies Pretydeinae and Tydeinae (Acari: Actinedida: Tydeidae). Part III. Seven new genera and some species of the Tydeinae, with a generic key. Mitteilungen aus dem Hamburgischen Zoologischen Museum und Institut, v. 93, p.199-227, 1996b.

KAZMIERSKI, A. Tydeinae of the world: Generic relationships, new and redescribed taxa and keys to all species: A revision of the subfamilies Pretydeaniae and Tydeinae (Acari: Actinedida: Tydeidae) - part IV. Acta Zoologica Cracoviensia, v.41, n.2, p.283-455, 1998a. 
KAZMIERSKI, A. A review of the genus Proctotydaeus Berlese (Actinedida: Tydeidae: Pronematinae). Acarologia, v.39, n.1, p.33-47, 1998b.

KNOP, N.F.; HOY, M.A. Factors limiting the utility of Homeopronematus anconai (Acari: Tydeidae) in integrated pest management in San Joaquin Valley vineyards. Journal of Economic Entomology, v. 76, n. 5, p. 1181-1186, 1983a.

KNOP, N.F.; HOY, M.A. Biology of a tydeid mite, Homeopronematus anconai (n. comb.) (Acari: Tydeidae), important in San Joaquin Valley vineyards. Hilgardia, v. 51, n. 5, p. 1-30, 1983 b.

KNOP, N.F.; HOY, M.A. Tydeid mites in vineyards. California Agriculture v.37, n.11-12, p.16-18, 1983c.

KRANTZ, G.W. A Manual of Acarology. 2d. Ed. Corvallis: Oregon State University Book Stores Inc., 1978. 509p.

KRANTZ, G.W.; LINDQUIST, E.E. Evolution of Phytophagous Mites (Acari). Annual Review of Entomology, v.24, p.121-158, 1979.

KREITER, S.; MORAES, G.J. de. Phytoseiid mites (Acari: Phytoseiidae) from Guadaloupe and Martinique. Florida Entomologist, v.80, p.376-382, 1997.

KUNIN, W.E.; LAWTON, J.H. Does biodiversity matter? Evaluating the case for conserving species. In: GASTON, K.J. (ed.) Biodiversity. a biology of numbers and difference. Berlin: Blackwell Science Ltd., 1996. p. 283-308.

KUZNETZOV, N.N. Seven species of the genus Lorryia (Tydeidae) from Crimea and Georgia. Zoologichesky Zhurnal, v. 50, p.1740-1746, 1971. 
KUZNETZOV, N.N.; LIVSHITZ, I.Z. A new genus and species of Tydeidae (Acariformes) from Crimea. Zoologichesky Zhurnal, v.51, n.11, p.1738-1740, 1972.

LAING, J.E.; KNOP, N.F. 1983. Potencial use of predaceous mites other than Phytoseiidae for biological control of orchard pests. In: HOY, M.A.; CUNNINGHAM, G.L.; KNUTSON, L. (Ed.) Biological Control of Pests by Mites. Berkeley: Univ. California, Spec. Public., 1983. n. 3304, p. 28-35.

LASALLE, J.; GAULD, I.D. Hymenoptera: their diversity, and their impact on the diversity of other organisms. In: LASALLE, J.; GAULD, I.D. (Ed.) Hymenoptera and Biodiversity. Wellington: CAB International, 1991. p. 01-26.

LASALLE, J.; GAULD, I.D. Parasitic Hymenoptera and the biodiversity crisis. Redia, v. 74, n. 3, p. 315-334, 1992.

LOFEGO, A.C. Caracterização morfológica e distribuição geográfica das espécies de Amblyseiinae (Acari: Phytoseiidae) no Brasil. São Paulo, 1998. 167p. Dissertação (Mestrado) - Instituto de Biociências, Universidade de São Paulo.

LOFEGO, A.C.; MORAES, G.J. de; McMURTRY, J.A. Three New species of Phytoseiid Mites (Acari: Phytoseiidae) from Brazil. Anais da Sociedade Entomológica do Brasil, v.29, n.3, p.461-467, 2000.

LORENZI, H. Árvores Brasileiras: manual de identificação e cultivo de plantas arbóreas nativas do Brasil. Nova Odessa: Editora Plantarum Ltda, 1992. 368p.

MATTHYSSE, J.G.; DENMARK, H.A. Some phytoseiids of Nigeria (Acarina: Phytoseiidae). Florida Entomologist, v.64, p.340-357, 1981. 
McCOY, C.W.; SELHIME, A.G.; KANAVEL, R.F. The feeding behavior and biology of Parapronematus acaciae (Acarina: Tydeidae). The Florida Entomologist v.52, n.1, p.13-19, 1967.

McGREGOR, E.A. Four new tetranychids. Annals of the Entomological Society of America, v. 7, p.354-364, 1914.

McGREGOR, E.A. The red spiders of America and a few european especies likely to be introduced. Proceedings of the National Museum, v.56, p. 641-679, 1919.

McGREGOR, E.A. Mites of the family Tetranychidae. American Middland Naturalists, v. 44, n. 2, p. 257-420, 1950.

McGREGOR, E.A. Two new mites in the genus Typhlodromus (Acarina: Phytoseiidae). Bulletin of the California Academy of Sciences Society, v.53, p.89-92, 1954.

McMURTRY, J.A. Phytoseiid mites from Guatemala, with descriptions of two new species and redefinitions of the genera Euseius, Typhlodromus and the Typhlodromus occidentalis species group (Acari: Mesostigmata). International Journal of Entomology, v.25, p.249-272, 1983.

McMURTRY, J.A.; CROFT, B.A. Life-styles of phytoseiid mites and their roles in biological control. Annual Review of Entomology, v. 42, p. 291-321. 1997.

McMURTRY, J.A.; MORAES, G.J. de. Some phytoseiid mites from the South Pacific, with descriptions of new species and a definition of the Amblyseius largoensis species group. International Journal of Acarology, v.10, p.27-37, 1984. 
McMURTRY, J.A.; MORAES, G.J. de. Some phytoseiid mites from Peru with descriptions of four new species (Acari: Phytoseiidae). International Journal of Acarology, v.15, p.179-188, 1989.

MENDEL, Z.; GERSON, U. Is the mite Lorryia formosa Cooreman (Prostigmata: Tydeidae) a sanitizing agent in citrus groves? Acta Oecologica, Oecologia Applicata v.3, n.1, p.47-51, 1982.

MEYER, M.K.P.S.; UECKERMANN, E.A. South african Acari. III. On the mites of the Mountain Zebra National Park. Koedoe, v. 31, p. 1-29, 1988.

MICOS, O.; FLECHTMANN, C.H.W. A new species of Epitrimerus from Brazil (Acari: Prostigmata: Eriophyidae). Acarologia, v. 40, n. 2, p. 133-135, 1999.

MISSOURI BOTANICAL GARDENS. Flora Mesoamericana: lista anotada. http://www.mobot.org/manual.plantas (24 Jan. 2001).

MOMEN, F.M.; SOLHØY, T. A first record of the genus Tydeus in Himalaya, Tydeus lundqvisti nov. spec. (Acari: Actinedida: Tydeidae). Acarologia, v.37, n.1, p.23-25, 1996.

MORAES, G.J. de; DENMARK, H.A.; GUERRERO, J.M. Phytoseiid mites of Colômbia (Acarina: Phytoseiidae). International Journal of Acarology, v.8, p.15$22,1982$.

MORAES, G.J. de; DENMARK, H.A.; MCMURTRY, J.A. A catalog of the mite family Phytoseiidae. References to taxonomy, synonymy, distribution and habitat. Brasilia: EMBRAPA-DDT, 1986. 353 p. 
MORAES, G.J. de; DENMARK, H.A.; Van der BERG, H.; BELLOTTI, A. Some phytoseiidae mites (Acari: Phytoseiidae) from the far east, with description of a new species. International Jou rnal of Aca rology, v.15, p.129-133, 1989.

MORAES, G.J. de; KREITER, S.; LOFEGO, A.C. Plant mites (Acari) of the French Antilles. 3. Phytoseiidae (Gamasida). Acarologia, v. 15, p. 237-264. 2000.

MORAES, G.J. de; McMURTRY, J.A. Phytoseiid mites (Acarina) of Northeastern Brazil with descriptions of four new species. International Journal of Acarology, v.9, p.131-148, 1983.

MORAES, G.J. de; MESA, N.C. Mites of the family Phytoseiidae (Acari) in Colômbia, with descriptions of three new species. International Journal of Acarology, v.14, p.71-88, 1988.

MORAES, G.J. de; MESA, N.C.; BRAUN, A. Some phytoseiid mites of Latin America (Acari: Phytoseiidae). International Jou rnal of Acarology, v.17, p.117-139, 1991.

MORAES, G.J. de; MESA, N.C.; BRAUN. A.; MELO, E.L. Definition of the Amblyseius limonicus species group (Acari: Phytoseiidae), with description of two new species and new records. International Journal of Acarology. v.20, p.209-217. 1994.

MORAES, G. J. de; ALENCAR, J. A. de; LIMA, J. L. S. de; YANINEK, J. S.; DELALIBERA JUNIOR, I. Alternative plant habitats for common phytoseiid predators of the cassava green mite (Acari: Phytoseiidae, Tetranychidae) in Northeast Brazil. Experimental and Applied Acarology, v. 17, n. 1-2, p.77-90, 1993.

MUMA, M.H. Phytoseiidae (Acarina) associeted with citrus in Florida. Annals Entomological Society of America, v.48, p.262-272, 1955. 
MUMA, M.H. Subfamiles, genera, and species of Phytoseiidae (Acarina: Mesostigmata). Florida State Museum Bulletin Biology Sciences, v.5, p.267-302, 1961.

MUMA, M.H. New Phytoseiidae (Acarina: Mesostigmata) from Florida. Florida Entomologist, v.45, p.1-10, 1962.

MUMA, M.H. The genus Galendromus Muma, 1961 (Acarina: Phytoseiidae). Florida Entomologist, Supple. 1, p.15-41, 1963.

MUMA, M.H.; DENMARK, H.A. Phytoseiidae of Florida. Arthropods of Florida and neighboring land areas. Gainnesville: Florida Department Agriculture Cons. Serv., Div. Plant Ind., 1970. 150p.

MUMA, M.H.; DENMARK, H.A. Some generic descriptions and name changes in the family Phytoseiidae (Acarina: Mesostigmata). Florida Entomologist, v.51, p.229$240,1968$.

MUMA, M.H.; DENMARK, H.A. The conspicua species-group of Typhlodromina Muma, 1961. Annals Entomological Society of America, v.62, p.406-413, 1969.

MYERS, N. The biodiversity crisis and the future of evolution. The Environmentalist. v. 16, p. 49-53. 1996.

NESBITT, H.H.J. A taxonomic study of the Phytoseiinae (Family: Laelaptidae) predaceous upon Tetranychidae of economic importance. Zoologischer Verhandelingen, v.12, p.1-64. 1951.

NOGUEIRA, J.C.B. A flora do município de Bauru. Silvicultura de São Paulo, v. 10, p. $45-54,1976$. 
ODUM, E.P. Ecologia. Rio de Janeiro: Ed. Guanabara S.A., 1988. 434p.

PALLINI FILHO, A.; MORAES, G.J. de; BUENO, V.H.P. Ácaros associados ao cafeeiro (Coffea arabica) no sul de Minas Gerais. Ciência e Prática. v. 16, p. 303307. 1992.

PARRA, J.R.P. O controle biológico aplicado e o manejo integrado de pragas. In: SIMPÓSIO DE AGRICULTURA ECOLÓGICA, 1, Campinas, 1993. Anais. Campinas: Fundação Cargill, 1993. p.116-139

PASCHOAL, A.D. Ácaros encontrados em plantas do Estado de São Paulo. Revista de Agricultura, v. 44, n. 2-3, p. 76-78, 1969.

PASCHOAL, A.D. New brazilian spider mites (Acarina: Tetranychidae). Anais da Escola Superior de Agricultura "Luiz de Queiroz", v. 27, p. 439-455, 1970.

PASCHOAL, A.D. New list of mites on plants in Brazil. Revista Peruana de Entomologia. v.14, p. 174-176. 1971.

PERRING, T.M.; McMURTRY, J.A. Other predatory arthropods. In: LINDQUIST, E.E.; SABELIS, M.W.; BRUIN, J. (Ed.) World Crop Pests. Eriophyoid Mites. Their Biology, Natural Enemies and Control. Amsterdam: Elsevier Sicences, 1996. p. 471-479.

PRITCHARD, A.E.; BAKER, E.W. A revision of the spider mite family Tetranychidae. San Francisco: The Pacific Coast Entomological Society, 1955. $472 \mathrm{p}$. 
REIS, P.R.: PASCHOAL. A.D. Alguns ácaros de produtos armazenados do Estado de São Paulo. In: REUNIÃO ANUAL DA SOCIEDADE BRASILEIRA DE ENTOMOLOGIA, 1. Piracicaba, 1968. Anais. Piracicaba: SEB , 1968. p. 63-64.

ROSA, A.E.; FLECHTMANN, C.H.W. Acari domum meliponinarum brasiliensium habitantes. III. Proctotydeus partamonae, sp. n. (Acari: Acariformes, Tydeidae). Revista Brasileira de Biologia. v.43, n.3, p. 273-276. 1983.

ROSA, A.E.; ANDRÉ, H.M.; FLECHTMANN, C.H.W. Acari domum meliponinarum brasiliensium habitantes. 8. Proctotydaeus alvearii sp. n. (Acari: Acariformes: Tydeidae). Revista Brasileira de Biologia, v. 45, n. 1-2, p. 79-83, 1985.

ROWELL, H.J.; CHANT, D.A.; HANSELL, R.I.C. The determination of setal homologies and setal patterns on the dorsal shield in the family Phytoseiidae (Acari: Mesostigmata). Canadian Entomologist, v.110, p.859-876, 1978.

SALIS, S.M.; TAMASHIRO, J.Y.; JOLY, C.A. Florística e fitossociologia do estrato arbóreo de um remanescente de mata ciliar do rio Jacaré-Pepira, Brotas, SP. Revista Brasileira de Botânica, v. 17, n. 2, p. 93-103, 1994.

SALVIEJO, P.B. Some philippine tydeid mites (Tydeidae: Acarina). The Philippine En tomologist. V. 1, n. 4, p. 261-277, 1969.

SCHICHA, E. Five known and five new species. of phytoseiid mites from Australia and the South Pacific. General and Applied of Entomology. v.13, p.29-46, 1981.

SCHICHA, E.; ELSHAFIE, M. Four new species of phytoseiid mites from Australia, and three species from America redescribed (Acari: Phytoseiidae). Journal Australian of Entomological Society, v.19, p.27-36, 1980. 
SILVA, P. Pragas da seringueira no Brasil, problemas e perspectivas. In: SEMINÁRIO NACIONAL DA SERINGUEIRA, 1. Cuiabá, 1972. Anais. Cuiabá: , 1972. p. $143-$ 152.

SILVEIRA NETO, S.; NAKANO, O.; BARBIN, D.; VILLA NOVA, N.A. Manual de Ecologia dos Insetos. São Paulo: Ed. Agronômica Ceres Ltda., 1976. 419 p.

SMIRNOFF, W.A. An undescribed species of Lorryia (Acarina, Tydeidae) causing injury to citrus trees in Morocco. Journal of Economic Entomology, v. 50, n. 3, p. 361-362, 1957.

SWIRSKI, E.; R. SHECHTER. Some phytoseiid mites (Acarina: Phytoseiidae) of Hong-Kong, with a description of a new genus and seven new species. Israel Journal of Agricultural Research, v. 11, p. 97-117. 1961.

THOR, S. Norwegische Tydeidae. I-VII, mit Kennzeichnung vier neuer Gattungen. Zoologischer Anzeiger, v. 94, n. 3-4, p. 89-104, 1931.

THOR, S. Tydeidae, Ereynetidae. Das Tierreich. Berlin:Walter de Gruyter \& Co., v. 60, p. 1-84, 1933.

TSENG, Y.H. Systematics of the mite family Phytoseiidae from Taiwan, with a revised key to genera of the world (II). Journal Agriculture Association of China, New Series, v.94, p.85-128, 1976.

TSENG, Y. A taxonomic study of the Tydeidae from Taiwan (Acarina: Trombidiformes) (Part II). Journal of the Taiwan Museum, v. 38, n. 2, p. 65-93, 1985. 
UECKERMANN, E.A.; MEYER, M.K.P.S. African Tydeidae (Acari). II. The genus Paralorryia Baker, 1965. Phytophylactica, v.11, p.117-127. 1979.

Van den BOSCH, R.; MESSENGER, P.S.; GUTIERREZ, A.P. An introduction to biological control. Plenum Press, New York. 247p. 1982.

Van der MER WE, G.G. A taxonomic study of the family Phytoseiidae (Acari) in South Africa with contributions to the biology of two species. South Africa Department of Agriculture Technology Services, Entomol. Mem., v.18, p.1-198, 1968.

VILA, W.M.; FLECHTMANN, C.H.W. Ácaros em essências florestais. Silvicultura em São Paulo. v.799, p.102. 1970.

WAHAB, A.E.A.; YOUSSEF, A.T.A.; HEMEDA, H.M. Biological studies on the Tydeid mite, Tydeus californicus (Banks) (Acarina : Tydeidae). Buletin de la Societé Entomologique d'Egypte v.58, p. .349-535. 1974.

WAINSTEIN, B.A.. Some new predatory mites of the family Phytoseiidae (Parasitiformes) of the USSR fauna. Entomological News. v. 41, :p. 139-146. 1962.

WALTER, D.E. Living on Leaves: Mites, Tomenta, and Leaf Domatia. Annual Review of Entomology, v.41, p. 101-114. 1996.

WALTER, D.E.; O'DOWD, D.J. Leaves with domatia have more mites. Ecology. v. 73, n. 4, p. 1514-1518. 1992a.

WALTER, D.E.; O'DOWD, D.J. Leaf morphology and predators: effect of leaf domatia on the abundance of predatory mites (Acari: Phytoseiidae). Environmental Entomology, v. 21, n. 3, p. 478-484, 1992 b. 
WALTER, D.E.; O'DOWD, D.J. Life on the forest phylloplane: hairs, little houses, and myriad mites. In: LOWMAN, M.D. ; NADKARNI, N.M. (Ed.) Forest Canopies. San Diego: Academic Press, 1995. p. 325-351.

WISNIEWSKI, H.M.; SIGURDARSON, S.; RUBENSTEIN, R.; KASCSAK, R.J.; CARP, R.I. Mites as vectors for scrapie. Lancet (British edition), v. 347 n..9008, p.1114, 1996.

WOOD, T.G. New and redescribed species of Tydeidae (Acari) from moorland soils in Britain. Acarologia, v. 7, n. 4, p. 663-672, 1965.

YOSHIDA-SHAUL, E.; CHANT, D.A. A world review of the genus Phytoscutus Muma (Phytoseiidae: Acari). Acarologia, v.38, p.219-238, 1997.

ZACARIAS, M.S.; OLIVEIRA, A.R. Coletor de ácaros por sucção. Anais da Sociedade Entomológica do Brasil, v. 29, n. 4, p. 827-830, 2000.

ZAHER, M.A.; SHEHATA, K.K. Biological Studies on Tydeus californicus (Banks) in Egypt (U.A.R.). Bulletin de la Societé Entomologique d'Egypte, v. 47, p. 297-300, 1963. 


\section{APÊNDICE}

Figuras 

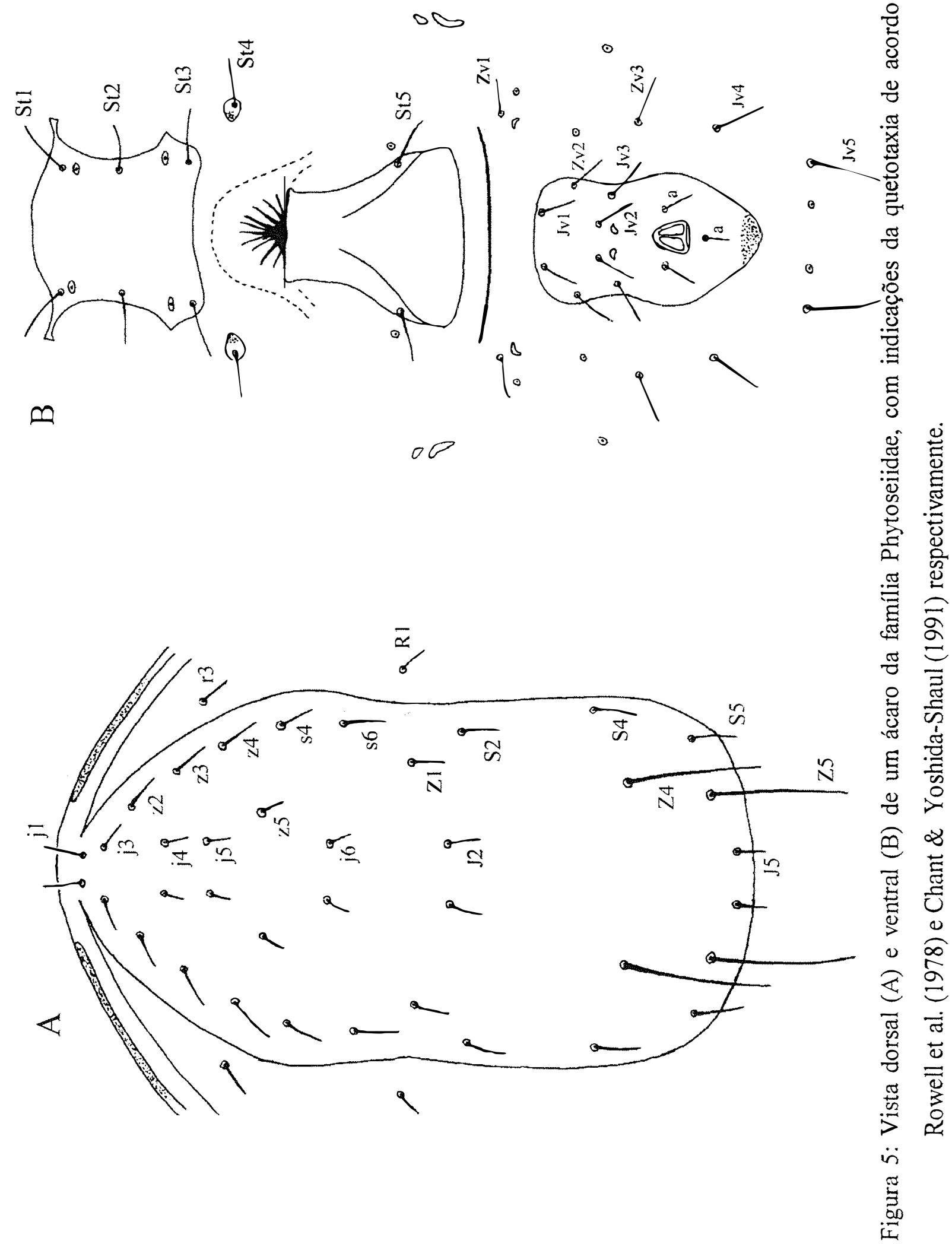


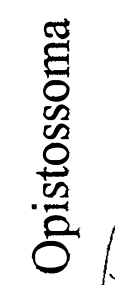

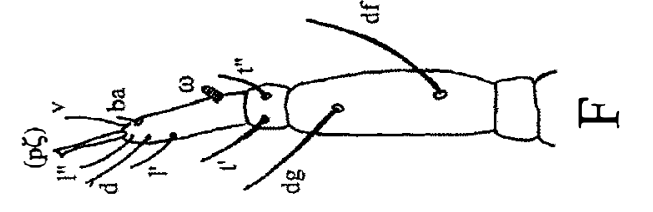

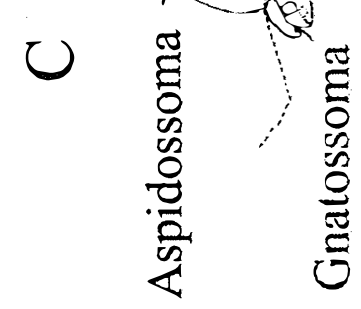

$\theta$ (1)

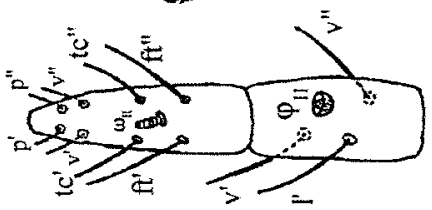

(I)

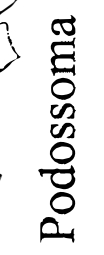

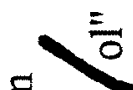
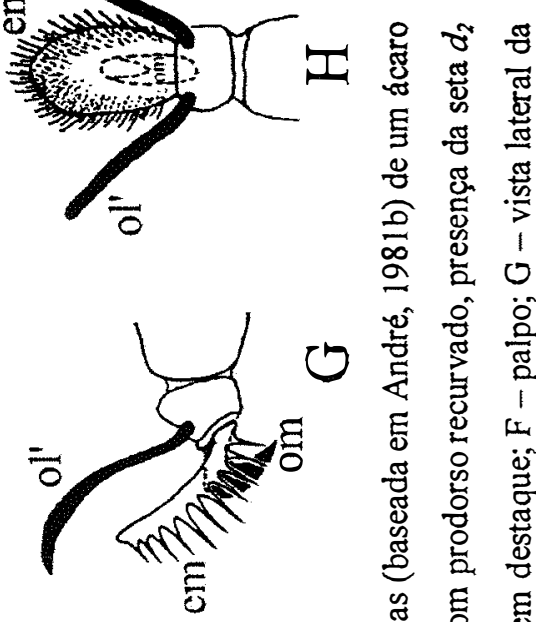

0

- 0
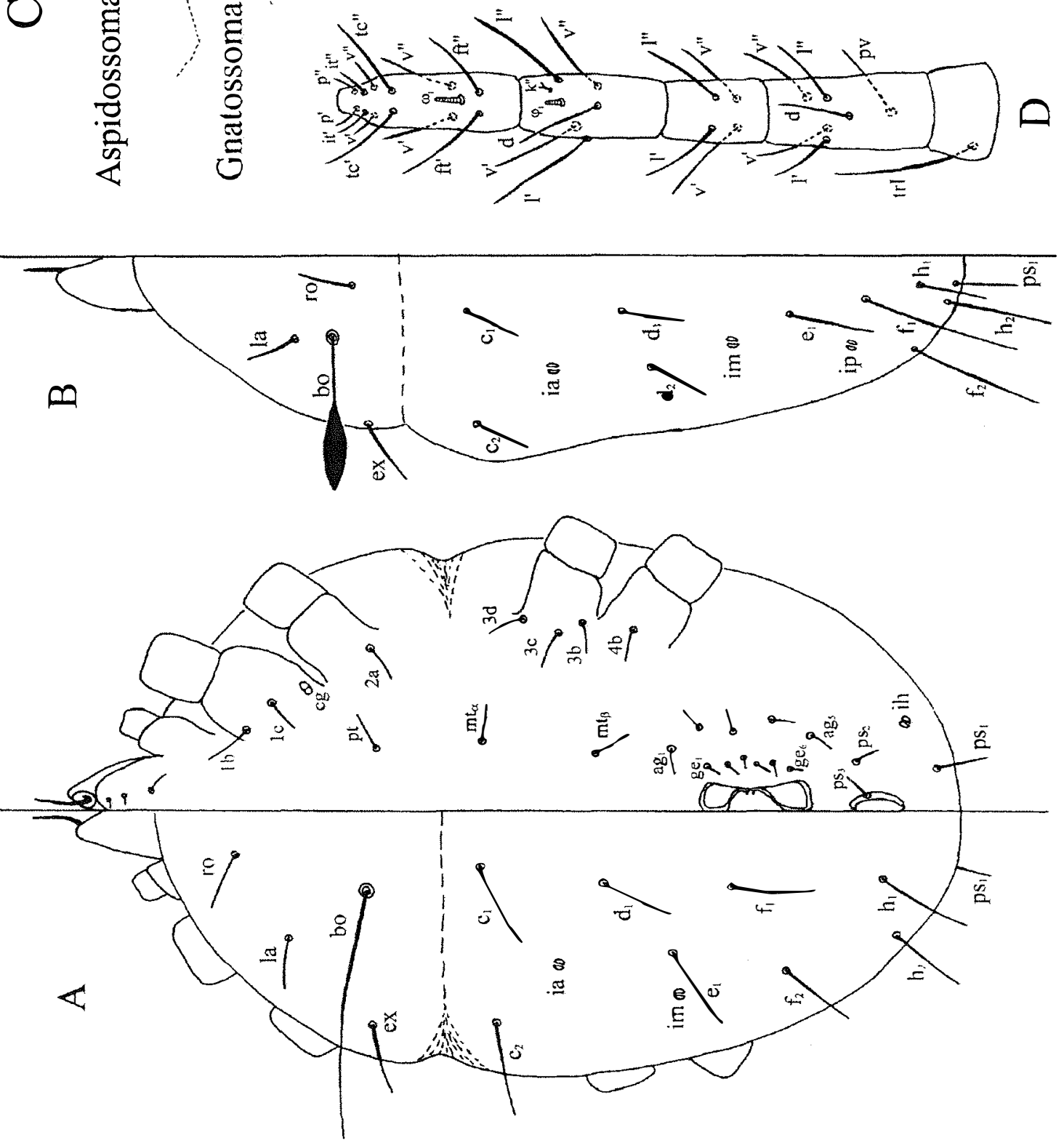